\title{
Impact of Stress-field Changes Induced by Hydraulic Fracturing on Subsurface Fault Stability
}

Qian Gao

West Virginia University

Follow this and additional works at: https://researchrepository.wvu.edu/etd

\section{Recommended Citation}

Gao, Qian, "Impact of Stress-field Changes Induced by Hydraulic Fracturing on Subsurface Fault Stability" (2012). Graduate Theses, Dissertations, and Problem Reports. 449.

https://researchrepository.wvu.edu/etd/449

This Thesis is protected by copyright and/or related rights. It has been brought to you by the The Research Repository @ WVU with permission from the rights-holder(s). You are free to use this Thesis in any way that is permitted by the copyright and related rights legislation that applies to your use. For other uses you must obtain permission from the rights-holder(s) directly, unless additional rights are indicated by a Creative Commons license in the record and/ or on the work itself. This Thesis has been accepted for inclusion in WVU Graduate Theses, Dissertations, and Problem Reports collection by an authorized administrator of The Research Repository @ WVU. For more information, please contact researchrepository@mail.wvu.edu. 
Impact of Stress-field Changes Induced by Hydraulic Fracturing on Subsurface Fault Stability

\title{
Qian Gao
}

Thesis submitted to the

College of Engineering and Mineral Resources

at West Virginia University

In partial fulfillment of the requirements

For the degree of

\author{
Master of Science \\ In \\ Petroleum and Natural Gas Engineering
}

Yueming Cheng, Ph. D., Chair

Samuel Ameri, M.S.

Khashayar Aminian, Ph. D.

Department of Petroleum and Natural Gas Engineering

Morgantown, West Virginia

2012

Keywords: Hydraulic Fracturing; Fault Stability; Finite Element Method

Copyright 2012 Qian Gao 


\title{
Abstract \\ Impact of Stress-field Changes Induced by Hydraulic Fracturing on Subsurface Fault Stability
}

\begin{abstract}
Qian Gao
Hydraulic fracturing is essential for economically producing hydrocarbons from shale reservoirs, and thus has been extensively used in completion of shale gas wells. However, fracturing formations can change in-situ stresses in the surrounding areas. There are concerns that hydraulic fracturing may potentially reactivate the subsurface faults nearby the treatment wells. The reactivated faults could cause many problems, such as early aborting/failure of fracturing treatment, fluid leakage along the fault and even seismicity events.
\end{abstract}

3D numerical models are developed based on finite element method. The comparison between analytical and numerical solutions indicates an excellent agreement has been achieved, which certificates the applicability of the numerical models to complex situations.

Stress redistribution around hydraulic fractures can occur due to the opening of hydraulic fractures and poroelastic effects. Only the opening of hydraulic fractures is considered in numerical models. The results indicate that the initial in-situ stress contrast in horizontal plane has a strong influence on the extent of stress-reveral region and reoriented-stress region. When the generated stress contrast is larger than the initial in-situ stress contrast, there will be stress-reversal region in the vicinity of fractures. As the distance from fractures increases, the generated stress contrasts become smaller. When the generated stress contrast is less than the initial in-situ stress contrast, the stress trajectories do not reverse. Usually the stress-reversal region is in the vicinity of fractures, the reorientedstress region is beyond the stress-reversal region and around fracture tips.

In this study, fault stability during hydraulic fracturing was investigated using 3D numerical models. Three typical faulting environments were considered. They are normal, strike-slip, and strike-slip/reverse faults. The orientation and relative magnitudes of insitu stress fields differ under different faulting environments, which in turn control the direction of fracture propagation. Three hydraulic fractures created simultaneously are considered in all case studies. It was found that the angle between fracture orientation and fault strike has a strong effect on the stability of a fault based on the change in the ratio of shear to effective normal stresses. Along the fault plane, the stability is strengthened in certain regions but weakened in other regions. The stress alteration patterns are different on the three types of fault. The normal faulting environment has the largest fluctuation in stresses and in the ratio of shear to effective normal stress. The reverse/strike-slip fault has the least perturbation on stresses and the ratio of shear to effective normal stress when hydraulic pressure is applied.

This study provides insight on the stress redistribution during hydraulic treatment and the impact of hydraulic fracturing on fault stability. The results indicate that it is feasible to manage the stability of faults by adjusting fracture design. 


\section{Acknowledgment}

I would like to express my sincere gratitude to my supervisor professor, Dr. Yueming Cheng, for her guidance and support, for providing the opportunity to conduct this research and for financial support throughout the course of this study. I am thankful for her interest, generosity, and encouragement.

I would like to thank my committee members, Prof. Sam Ameri and Dr. Kashy Aminian for their support, help, and patience. Their broad and profound knowledge has greatly improved my work and enriched my understanding about the Petroleum and Natural Gas Engineering. Additionally, I would like to thank Dr. Shahab Mohaghegh, Dr. Ilkin Bilgesu and Dr. Jingqin Bao for their help during my study at the West Virginia University.

I would like to thank Dr. Pramod Thakur for his kind suggestions about my study and life. I would like to express my gratitude to my family for their support. 


\section{Table of Contents}

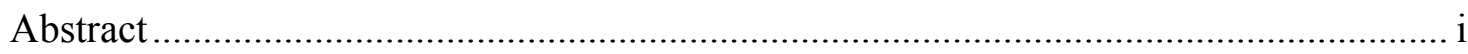

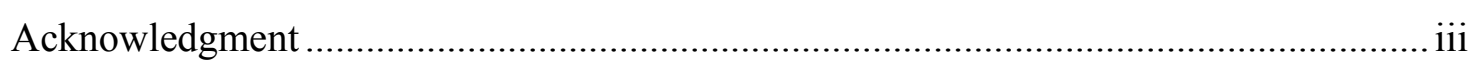

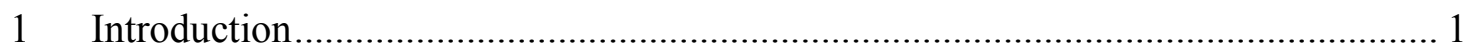

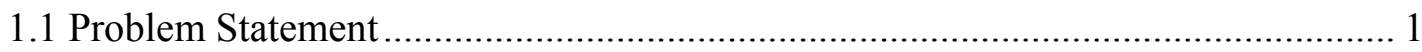

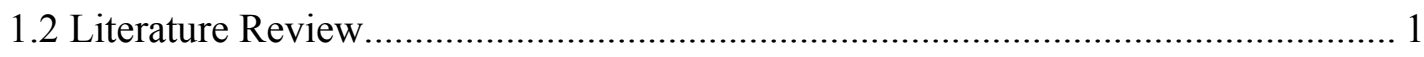

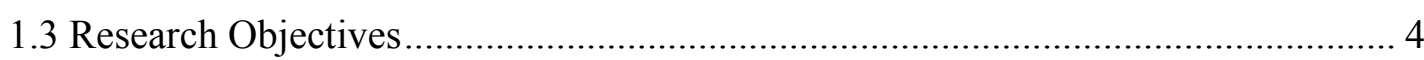

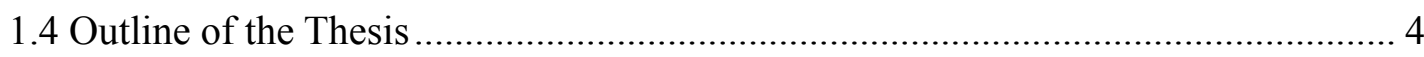

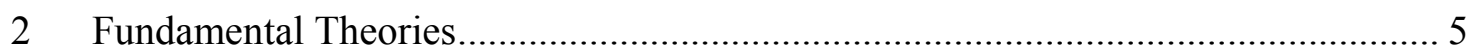

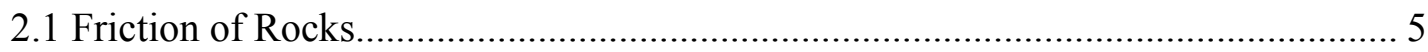

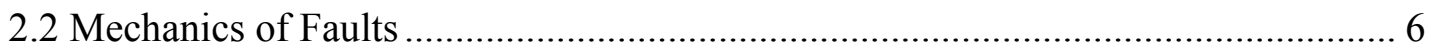

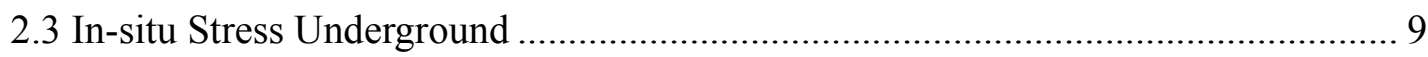

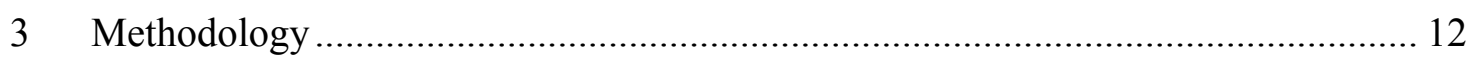

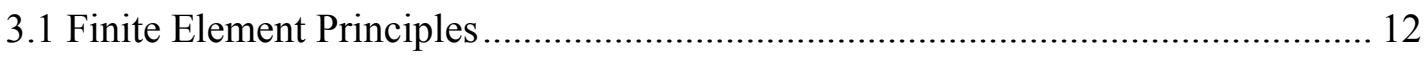

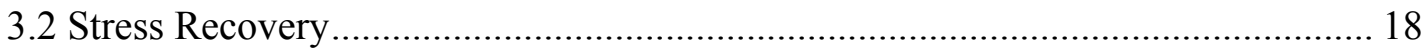

3.2.1 Calculation of Element Strains and Stresses.............................................. 18

3.2.2 Extrapolation of Integration Point Values to the Nodes................................. 19

3.3 Shear and Normal Stresses Calculation on Fault Plane ....................................... 20

3.3.1 Normal Stress for Nodal Points Located on Inclined Plane .......................... 21

3.3.2 Shear Stress for Nodal Points Located on Inclined Plane............................... 22

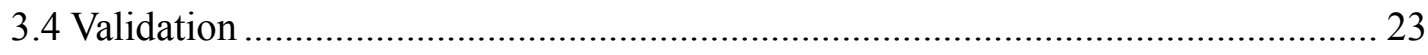

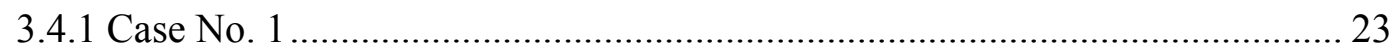

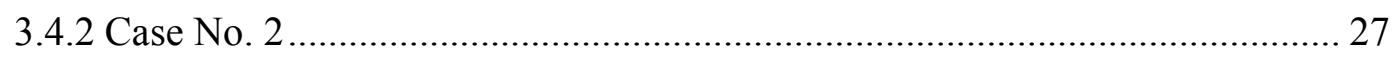

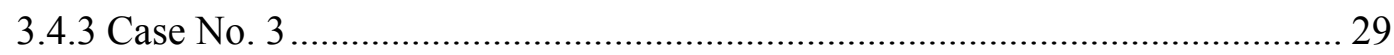

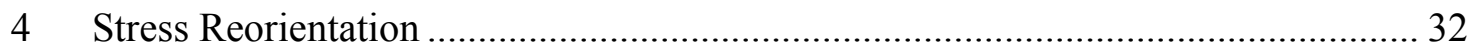




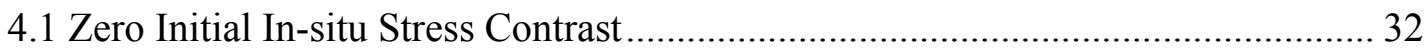

4.2 Nonzero Initial In-situ Stress Contrast.............................................................. 33

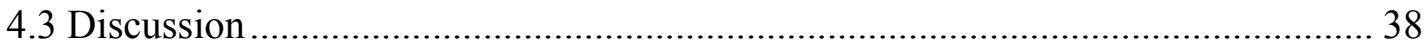

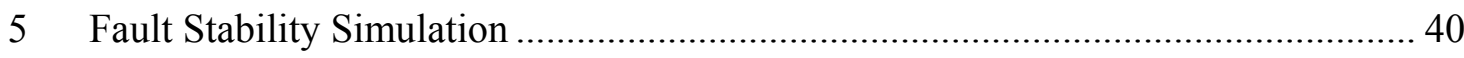

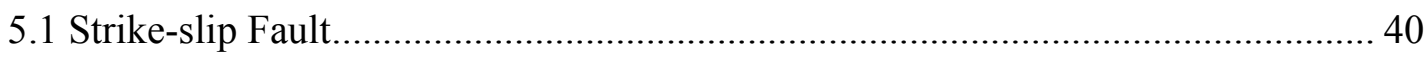

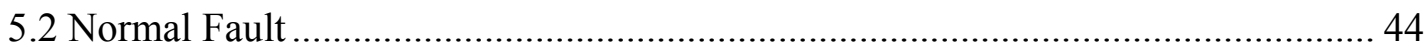

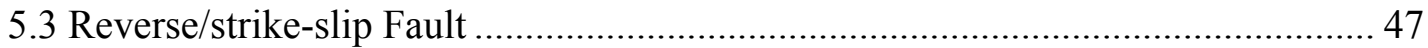

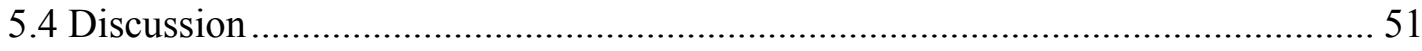

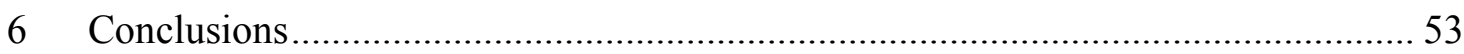

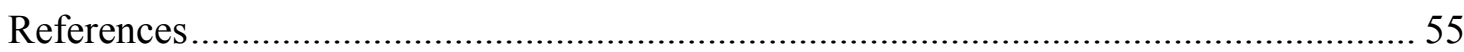




\section{List of Figures}

Figure 2.1 Common types of experimental configurations used in friction studies. 6

Figure 2.2 (a) Mohr diagram illustrating the Coulomb criterion; (b) Diagram showing the relationship between stress axes and shear angle. 7

Figure 2.3 Types of faulting system predicted by Anderson's theory. .................................................. 8

Figure 2.4 Effect of pore pressure increase on fault stability. 9

Figure 2.5 Differential stress required to initiate sliding on optimal oriented faults as a function of depth. 11

Figure 3.1 Six Stress Components in Three-Dimensional Coordinate. 18

Figure 3.2 Geometric model for Case No. One. 23

Figure 3.3 Shear and normal stresses on the inclined plane. 25

Figure 3.4 Discretized geometric model. 25

Figure 3.5 (a) Geometric model for case 2; (b) Discretized grid system.............................................. 28

Figure 3.6 Numerical results for Case No. Two................................................................................. 29

Figure 3.7 Illustration of the mathematical interpretation of the crack stress function............................. 30

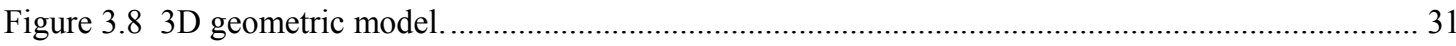

Figure 3.9 Comparisons of analytical and numerical solutions along the symmetric line normal to the semiinfinite fracture. 31

Figure 4.1 Stress trajectories on a horizontal plane through the center point of the model. 33

Figure 4.2 Stress trajectories on a horizontal plane through the center point of the model with 500 psi horizontal stress contrast..

Figure 4.3 Stress trajectories on a horizontal plane through the center point of the model with 600 psi horizontal stress contrast.. 36

Figure 4.4 Stress trajectories on a horizontal plane through the center point of the model with 700 psi horizontal stress contrast.. 37

Figure 4.5 Normalized stresses vs. distance normal to a fracture, fracture height used in the numerical model is $200 \mathrm{ft}$. 39

Figure 5.1 3D geometric model for strike-slip faulting environment. 41

Figure 5.2 Shear stress distribution on the strike-slip fault plane. 42 
Figure 5.3 Normal stress distribution on the strike-slip fault plane......

Figure 5.4 Ratio of shear to effective normal stress distributed on the strike-slip fault plane...

Figure 5.5 3D geometric model for normal faulting environment. 45

Figure 5.6 Shear stress distribution on the normal fault plane. 46

Figure 5.7 Normal stress distribution on the normal fault plane. 46

Figure 5.8 Ratio of shear to effective normal stress distributed on the normal fault plane. 47

Figure 5.9 3D geometric model for reverse/strike-slip faulting environment. 48

Figure 5.10 Shear stress distribution on the reverse/strike-slip fault plane. 49

Figure 5.11 Normal stress distribution on the reverse/strike-slip fault plane. 49

Figure 5.12 Ratio of shear to effective normal stress distributed on the reverse/strike-slip fault plane. ..... 50 


\section{List of Tables}

Table 3.1 Summary of numerical computation results using finite element method................................ 26

Table 3.2 State of Stress at Rangely, Colorado. ............................................................................. 28

Table 5.1 Summary of stress and ratio changes for different fault types.............................................. 51 


\section{Introduction}

\subsection{Problem Statement}

Hydraulic stimulation is an important technology for extracting hydrocarbons from both conventional and unconventional reservoirs. For ultralow-permeability shale reservoir now being regularly exploited, hydraulic treatment is absolutely essential to obtain economic levels of production (Sutton, Cox, \& Barree, 2010; N. Warpinski, Du, \& Zimmer, 2012). An important concern regarding the deployment of hydraulic fracturing is that it could reactivate pre-existing faults and triggers microseismicity, low magnitude seismic events that sometimes can be felt at the surface(Majer et al., 2007; McClure \& Horne, 2011). The potential impact on surface structures and shallow aquifers threatens public acceptance of it. Though induced seismicity associated with hydraulic fracturing is very small and generally not a problem (N. Warpinski et al., 2012), fault activations during hydraulic fracturing are reported (Downie, Kronenberger, \& Maxwell, 2010), which caused the failure of the treatment. A better understanding of fault mechanics and in-situ stress changes during hydraulic fracturing will increase our ability to better predict the likelihood and characteristic of stress field underground allowing for better optimizing hydraulic treatment design.

\subsection{Literature Review}

Once a fault has been formed its further motion is controlled by friction. Friction is a contact property rather than a bulk property (Scholz, 2002). Friction experiments were first carried out by Leonardo da Vinci. Leonardo's discoveries remained hidden and were rediscovered 200 years later by Amontons. Da Vinci found that frictional sliding will occur on a plane when the ratio of shear to normal stress reaches a material property of the material, $\mu$, the coefficient of friction (M. D. Zoback, 2010). A comprehensive summary of numerous laboratory experiments on friction on a wide variety of rock types indicates that at intermediate pressure and high pressure ( $\geq \sim 100 \mathrm{MPa})$, surface roughness, rock type, normal stress, etc. have little or no effect on friction. The coefficient of friction is found to be within a relatively small range: $0.6 \leq \mu \leq 1.0$. However, if the sliding surfaces are separated by large thickness of gouge composed of minerals such as montmorillonite 
and vermiculite the friction can be very low (Byerlee, 1978). For example, (Morrow, Shi, \& Byerlee, 1982) found that samples of fault gouge with clays from the San Andreas fault have coefficients of friction ranging from 0.15 to 0.55 . Fault gouges with a wide range of constituent minerals relevant to natural faults are found to have a strong influence on frictional stability, the friction of natural faults is strongly dependent on the composition of gouge (Ikari, Marone, \& Saffer, 2011).

Recent development of unconventional tight gas reservoir makes researchers investigate the mechanical properties of gas shale reservoir rocks (Sone \& Zoback, 2010; M. D. Zoback, Kohli, Das, \& Mcclure, 2012). Samples tested differ in their mineralogical composition, the degree of diagenesis, the total organic content and the degree of maturity of the organic material. It is suggested by laboratory data that Young's modulus correlates well with the amount of viscoplastic creep and frictional strength, coefficient of friction and amount of viscoplastic creep vary strongly with clay content. Based on rate and state friction experiments in the laboratory using shale samples with a large range of clay content, it is indicated that clay content determines the deformation mechanism of pre-existing fractures and faults (M. D. Zoback et al., 2012). When shales comprised of less than about $30 \%$ clay, slip on faults is expected to propagate unstably, thus conventional microseismic events are generated. For shales containing more than about $30 \%$ clay, fault slip is expected to propagate slowly, which does not generate high frequency seismic waves.

Depending upon the in-situ stress regime, faults underground may or may not be tectonically active. Generally active faults are in critical stress state, even a slight stress perturbations may trigger such faults to slip (Townend \& Zoback, 2000; M. D. Zoback, 2010). Fluid injection to subsurface reservoirs, such as hydraulic stimulation and geological sequestration of $\mathrm{CO}_{2}$, raises pore pressure and causes in-situ stress field changes, which would tend to influence the stability of underground faults. Researchers have done a lot of work on fault stability for $\mathrm{CO}_{2}$ sequestration (Bretan, Yielding, Mathiassen, \& Thorsnes, 2011; Chiaramonte, Zoback, Friedmann, \& Stamp, 2008; Rutqvist, Birkholzer, Cappa, \& Tsang, 2007; Streit \& Hillis, 2004). In order to prevent $\mathrm{CO}_{2}$ escape due to fault reactivation, the determination of fault orientations, ambient pore pressure and in-situ stresses in a potential storage site is required. Stress field changes 
induced by hydrocarbon production and associated pore pressure depletion are needed to be incorporated into fault stability analysis. Based on numerical and analytical methods, researchers estimated the maximum sustainable injection pressure during geological sequestration of $\mathrm{CO}_{2}$ (Rutqvist et al., 2007).

In addition to fluid injection in reservoir, reservoir depletion can also cause fault reactivation. According to the theory of poroelasticity, depleting a hydrocarbon reservoir alters the state of in-situ stresses, which can sufficiently reactivate and induce slip of nearby faults (Segall, 1989; Segall, 1992; Talwani, 1997; Yerkes \& Castle, 1976; M. D. Zoback \& Zinke, 2002).

Horizontal wells with multiple fractures are commonly used in unconventional gas reservoirs, such as the ultralow-permeability shales. It is absolutely essential to perform hydraulic stimulation in order to achieve commercial gas production rates (Sutton et al., 2010; N. Warpinski et al., 2012). During this kind of stimulation, the local earth stresses are changed, which effects the stability of underground faults. For hydraulic treatment, there are two common effects causing stress change during hydraulic fracturing (Economides, Nolte, \& Ahmed, 1989), thus effecting the stability of faults. The first one is the increase of minimum stress because of the poroelastic effect. During hydraulic treatment, fracturing fluid leaks into formations. Pore pressure increases around the hydraulic fractures due to the leakage, which results in dilation of the formation. The minimum stress thus increases in this stimulated region. When injection is stopped and the excess pore pressure spreads out into formation, this poroelastic effects disappear.

The second effect is the stress increase due to the opening of the fracture. If the induced fracture is held by proppant, this effect remains. These stresses can extend to significant distances into the formation due to the large area of fracture face (Palmer, 1993; N. Warpinski \& Branagan, 1989).

Because of the high pressures needed for fracture dilation and the large fracture surface area created, a hydraulic fracture can effectively alter the stress field. This could mean that the original fracture alters the in-situ stress, and a subsequent vertical fracture will initially propagate orthogonal to the original vertical fracture. 
When a fracture is reoriented, fracture width is expected to be reduced. The degree of reduction in the fracture width depends on the degree of orientation (Soliman, East, \& Adams, 2004). A narrow effective fracture width tends to cause high fracture pressure, and consequently high fracture-propagation pressure.

\subsection{Research Objectives}

Previous studies in the literature on fault stability focus on the geological sequestration of $\mathrm{CO}_{2}$, reservoir depletion and so on. A comprehensive analysis of how hydraulic stimulation influences the fault stability has not been fully investigated to date. Prediction of how pre-existing faults and fractures respond to hydraulic stimulation can help optimize field operations and improve recovery (M. D. Zoback et al., 2012).

The main purpose of the study is to investigate the in-situ stress change during hydraulic stimulation and evaluate its impact on the fault stability.

\subsection{Outline of the Thesis}

This thesis is presented in a series of manuscripts. This introductory chapter provides background information. Some basic knowledge involved in this study is provided in chapter 2. Chapter 3 presents the used methods, validation of the provided methods is performed through different examples. Chapter 4 investigates the stress distribution during hydraulic fracturing. Fault stability analysis is carried out in Chapter 5. The last chapter summarizes the study. 


\section{Fundamental Theories}

\subsection{Friction of Rocks}

Friction is the resistance to relative motion by which a tangential shearing force is required in order to displace two contacting surfaces (Jaeger, Cook, \& Zimmerman, 2007). At different stages of frictional sliding, there are three types of friction: initial friction, maximum friction and residual friction, respectively (Byerlee, 1978). The first two classical laws of friction, usually attributed to the Frenchman Guillaume Amontons, are:

1. The force of friction is directly proportional to the applied load.

2. The force of friction is independent of the apparent area of contact.

The coefficient of friction is defined as the ratio of shear to normal stress acting between the surfaces during sliding. Different physical mechanisms are involved in the sliding of rock at various pressures. At low pressure the surfaces can move with respect to one another by lifting over the interlocked irregularities, however, at very high pressure this effect is suppressed and the surfaces then slide by shearing through the irregularities.

Based on numerous laboratory experiments on a wide variety of rock types, Byerlee (1978) show that the frictional behavior of rocks could be fit by the following bilinear empirical expression:

$$
\begin{array}{cl}
\tau=0.85 \sigma & \text { for } \sigma<200 \mathrm{MPa} \\
\tau=50 \mathrm{MPa}+0.6 \sigma & \text { for } 200<\sigma<1700 \mathrm{MPa}
\end{array}
$$

Also, the friction can be very low if the sliding surfaces are separated by large thicknesses of gouge composed of minerals such as montmorillonite or vermiculite.

There are several different types of apparatus used to measure the friction of rocks. As shown in Figure 2.1, these are (a) triaxial compression, (b) direct shear, (c) biaxial loading, and (d) rotary. Each one has its own advantages and disadvantages. The triaxial test is best suitable for high-pressure and high-temperature studies. However, the amount of slip is limited and dynamic measurement during stick slip is doubtful due to the 
possibility of sample misalignment occurring during rapid slip. The other three types of tests are applicable to lower loads limited by the uniaxial failure strength of the rock.
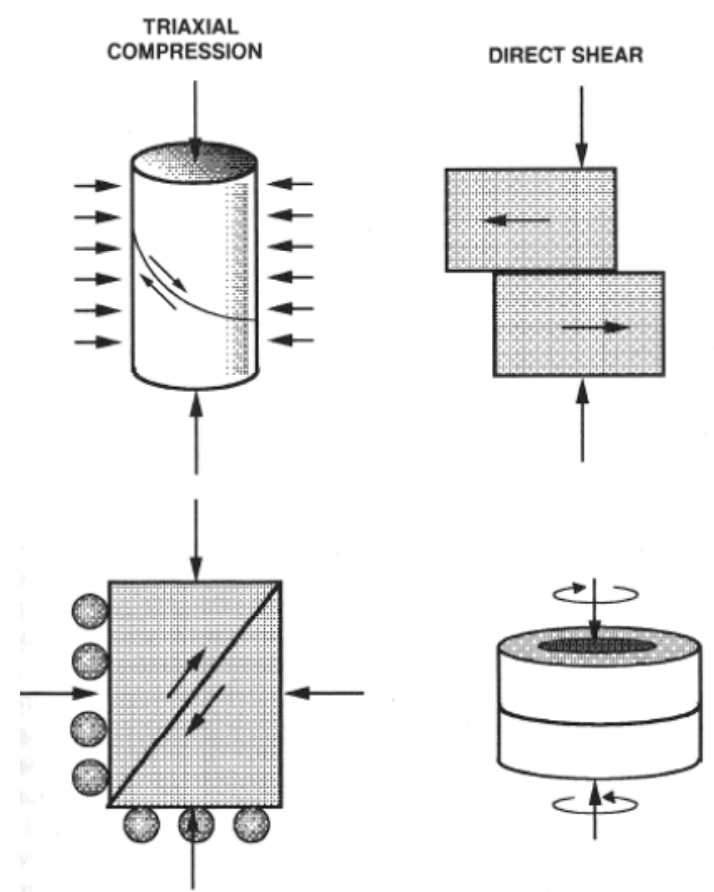

BIAXIAL

LOADING

ROTARY

Figure 2.1 Common types of experimental configurations used in friction studies.

\subsection{Mechanics of Faults}

Geological discontinuities such as faults are inherent in most petroleum formations. Frictional sliding can be expected to occur on a fault plane when the ratio of shear to effective normal stress along the fault plane equals the experimentally determined "frictional coefficient". This relationship is known as Amontons' law

$$
\frac{\tau}{\sigma_{\mathrm{n}}}=\mu
$$

where $\tau$ is the shear stress along the fault plane, $\sigma_{n}$ the effective normal stress, defined as $\left(S_{n}-P_{p}\right), \mu$ is a material property, called the coefficient of friction. $S_{n}$ is the normal stress on the plane, $P_{p}$ is the pore-pressure. Equation (2.2) is sometimes called the Coulomb criterion and is widely used in fault stability analysis (C. B. Raleigh, Healy, \& Bredehoeft, 1976; Sibson, 1974). 
When the ratio is less than $\mu$, a fault is stable and no slip should occur, because the shear stress is insufficient to overcome the frictional resistance to sliding, $\mu \sigma_{n}$. However, as the ratio equals $\mu$, frictional sliding will occur on a pre-existing fault plane since sufficient shear stress is available to overcome the frictional resistance to sliding. Confirmation of Equation (2.2) by in-situ measurements would mean that stress magnitudes at any given depth are limited by the frictional strength of underground discontinuities, such as faults, fractures.

E. M. Anderson developed the modern mechanical concepts of the origin of faults (Scholz, 2002). He applied the Coulomb criterion (Figure 2.2) to study faults, which is called Anderson's theory of faulting.
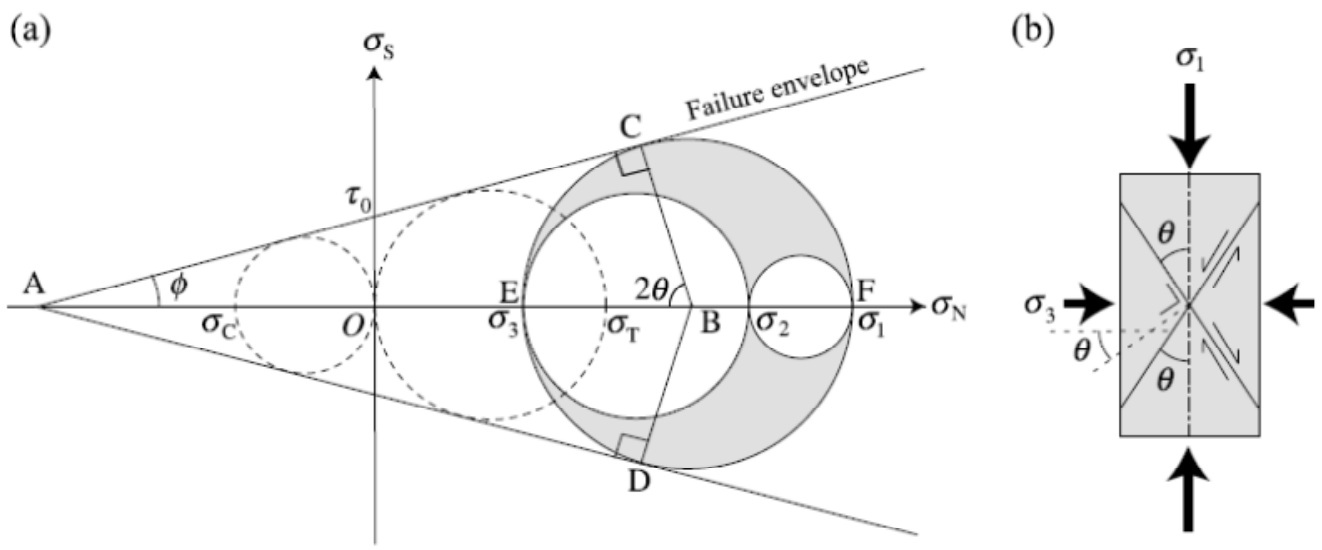

Figure 2.2 (a) Mohr diagram illustrating the Coulomb criterion; (b) Diagram showing the relationship between stress axes and shear angle. (Atsushi, 2007)

The basis of the theory is the assumption that the surface of the earth must be a principal plane of stress, the directions of other two principle stresses are parallel to the earth's surface. The third principal stress direction must be oriented normal to the earth's surface. Combining this with Coulomb criterion, an important relationship between the type of faulting and stress can be obtained.

The theory predicts that the direction of inter-mediate principal stress is parallel to fault planes. The fault plane has an angle $\frac{1}{2} \tan ^{-1}(1 / \mu)$ with the direction of maximum principal stress. Therefore, if the minimum principal stress is in vertical direction, the stress field gives rise to reverse faulting with dip angle of the faults less than $45^{\circ}$. If the 
maximum principal stress or inter-mediate principal stress is in the vertical direction, normal or strike-slip faults are formed. The dip angle of thrust faults should be $\sim 30^{\circ}$, the dip angle of normal faults should be $\sim 60^{\circ}$, and the dip angle of strike-slip faults should be about vertical (Figure 2.3).

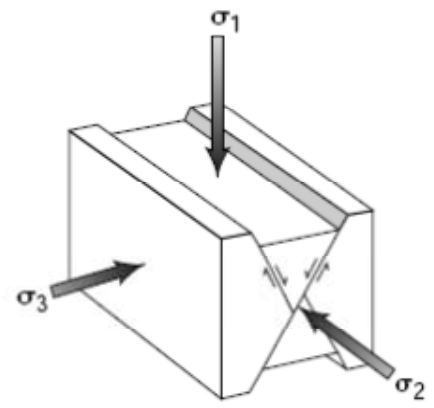

(a)

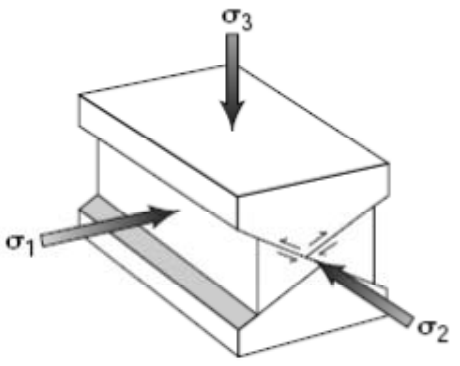

(b)

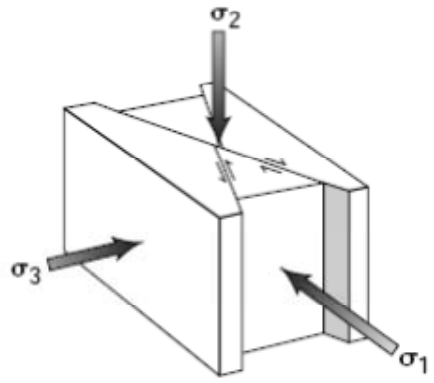

(c)

Figure 2.3 Types of faulting system predicted by Anderson's theory. (Van der Pluijm \& Marshak, 2004)

It should be remembered that Figure 2.3 illustrates the idealized relationship between potentially active faults and the stress state that caused them. In reality, after the faults were formed, the principal stresses in-situ may be changed in both magnitude and directions. Thus, preexisting faults may be reactivated even if the fault planes are not inclined at well-oriented degree $\left(\sim 30^{\circ}\right)$ to the direction of maximum principal stress. At the same time, the orientation of faults may change as the formation containing the faults undergoes progressive deformation.

As mentioned above, Equation (2.2) indicates that pore pressure takes a part of the absolute stress to lower the normal stress, thus raising pore pressure would tend to destabilize faults and make slip to occur by increasing the ratio of shear to effective normal stress. Figure 2.4 illustrates the effect of pore pressure increase on fault stability. Raising pore pressure shifts the Mohr circles leftward to traverse the failure envelope activating a pre-existing fault. 


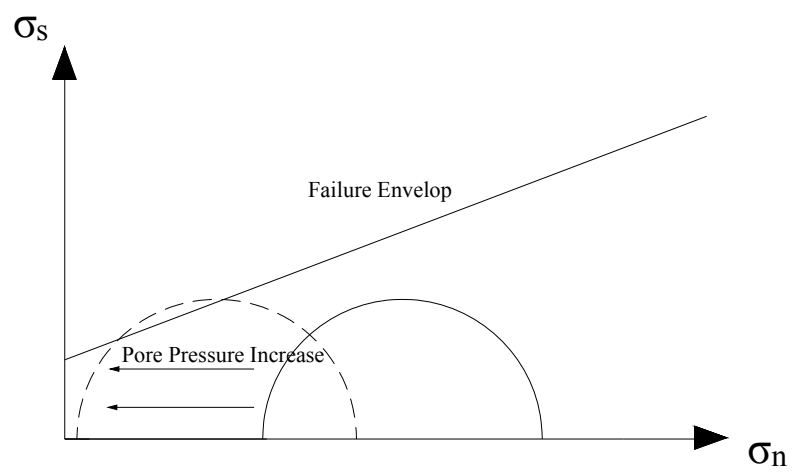

Figure 2.4 Effect of pore pressure increase on fault stability.

\subsection{In-situ Stress Underground}

In-situ stress acts as a load on the formation and is the dominant parameter that controls the propagation and geometry of hydraulic fractures (Economides et al., 1989). Fractures will always propagate along the path with the least resistance and create width in a direction that requires the least force. This means that a fracture will propagate parallel to the maximum principal stress and perpendicular to the minimum principal stress. Consequently, understanding of the direction of minimum principal stress allows prediction of the expected direction of hydraulic fracture propagating away from the wellbore. Also, it is generally accepted that the degree of fracture containment is determined primarily by the in-situ stress contrast between adjacent layers.

In practice, it is observed that the minimum principal stress is in the vertical direction at shallow depth, at which a hydraulic fracture is most likely to occur in a horizontal plane (Economides et al., 1989). In an extensional geologic environment, however, the minimum principal stress is generally in horizontal direction, even at shallow depths. In normally pressured sedimentary basins, the minimum principal stress is most probably in horizontal direction at depths greater than $3300 \mathrm{ft}$ (Plumb, 1994).

Underground discontinuities, such as faults and fractures, are widely distributed at different scales and orientations, it is thought that stress magnitudes at depth are limited by the frictional strength of these discontinuities (Sibson, 1974; Townend \& Zoback, 2000; M. D. Zoback, 2010). The in-situ stress measurements demonstrate that the stress 
states predicted using Coulomb frictional-failure theory with laboratory-derived frictional coefficients of 0.6-1.0 are consistent with the measured stresses.

Coulomb failure criterion, the simplest, and still most widely used failure criterion, states that failure will occur along a plane if the following condition is satisfied:

$$
\tau>\tau_{\mathrm{f}}=\mu \sigma_{\mathrm{n}}
$$

where $\tau$ is the applied shear stress, $\tau_{f}$ is the frictional shear resistance, $\mu$ is the static frictional coefficient, and $\sigma_{n}$ is the normal stress acting on the fault. It would be convenient to express the Coulomb failure criterion directly in terms of the principal stresses $\left\{\sigma_{1}, \sigma_{3}\right\}$, which is given by:

$$
\frac{\sigma_{1}}{\sigma_{3}}=\frac{S_{1}-P_{p}}{S_{3}-P_{p}} \geq\left[\left(1+\mu^{2}\right)^{1 / 2}+\mu\right]^{2}
$$

It has been shown that many geological faults fall into three classes termed normal, strikslip and reverse faults. When a fault first forms, it does so at an angle $\theta$ to $\sigma_{l}$ (Figure 2.2), where $\theta$ is the optimum angle for frictional sliding,

$$
\theta=\frac{1}{2} \tan ^{-1}\left(\frac{1}{\mu}\right)
$$

Using Anderson's faulting theory to determine which principal stress $\left(S_{H \max }, S_{h \min }\right.$, or $\left.S_{v}\right)$ corresponds to $S_{1}, S_{2}$ and $S_{3}$, respectively, Equation (2.6) can be used to estimate an upper bound of the ratio of the maximum to minimum effective stresses (M. D. Zoback, 2010), the following are the equations:

$$
\begin{gathered}
\text { Normal faulting } \frac{\sigma_{1}}{\sigma_{3}}=\frac{\mathrm{S}_{\mathrm{v}}-\mathrm{P}_{\mathrm{p}}}{\mathrm{S}_{\mathrm{hmin}}-\mathrm{P}_{\mathrm{p}}} \leq\left[\left(\mu^{2}+1\right)^{\frac{1}{2}}+\mu\right]^{2} \\
\text { Strik - slip faulting } \frac{\sigma_{1}}{\sigma_{3}}=\frac{\mathrm{S}_{\mathrm{Hmax}}-\mathrm{P}_{\mathrm{p}}}{\mathrm{S}_{\mathrm{hmin}}-\mathrm{P}_{\mathrm{p}}} \leq\left[\left(\mu^{2}+1\right)^{1 / 2}+\mu\right]^{2} \\
\text { Reverse faulting } \frac{\sigma_{1}}{\sigma_{3}}=\frac{S_{\mathrm{H} \max }-\mathrm{P}_{\mathrm{p}}}{\mathrm{S}_{\mathrm{v}}-\mathrm{P}_{\mathrm{p}}} \leq\left[\left(\mu^{2}+1\right)^{\frac{1}{2}}+\mu\right]^{2}
\end{gathered}
$$

The effective overburden pressure at a depth $z$ is given by

$$
\sigma_{\mathrm{v}}=\rho g z(1-\lambda)
$$


where $\rho$ is the formation density, $g$ is the gravity acceleration, and the pore pressure factor $\lambda=P_{p} / \rho g z, P_{p}$ being the pore pressure.

In a normal fault regime, where $\sigma_{v}=\sigma_{l}$, the limiting inequality for frictional sliding is

$$
\left(\sigma_{1}-\sigma_{3}\right) \geq\left[\frac{(\mathrm{R}-1)}{\mathrm{R}}\right] \rho \operatorname{\rho gz}(1-\lambda)
$$

where $\mathrm{R}=\left[\left(\mu^{2}+1\right)^{\frac{1}{2}}+\mu\right]^{2}$.

In a strik-slip fault regime, $\sigma_{v}=\sigma_{2}$, and $\sigma_{2}$ may be written in the form

$$
\sigma_{2}=\sigma_{3}+\mathrm{k}\left(\sigma_{1}-\sigma_{3}\right)
$$

where $0<k<1$. The limiting inequality for frictional sliding can be written as

$$
\left(\sigma_{1}-\sigma_{3}\right) \geq\left[\frac{(R-1)}{k(R-1)+1}\right] \rho g z(1-\lambda)
$$

In a reverse fault regime, $\sigma_{v}=\sigma_{3}$, the limiting inequality for frictional sliding is

$$
\left(\sigma_{1}-\sigma_{3}\right) \geq[(R-1)] \rho g z(1-\lambda)
$$

Based on the above relationships (Equations (2.8), (2.10) and (2.11)), limiting conditions for each of the three fault types are shown in Figure 2.5.

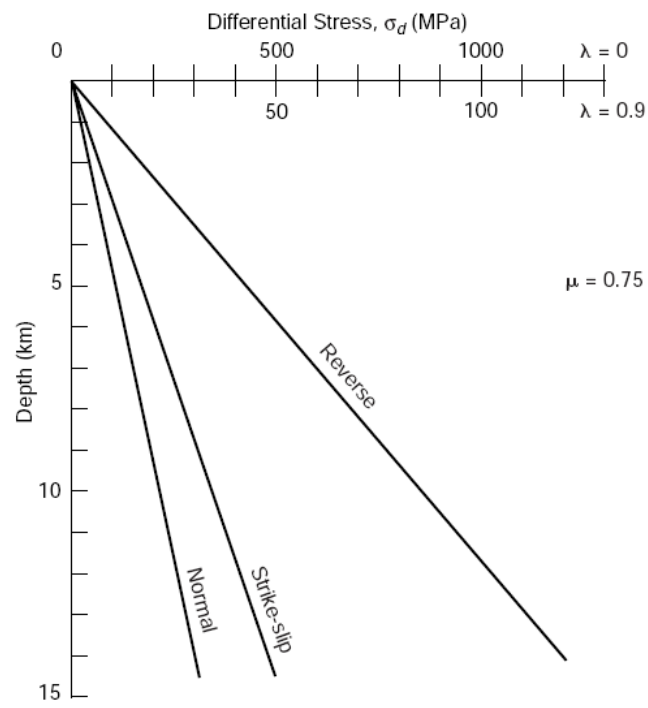

Figure 2.5 Differential stress required to initiate sliding on optimal oriented faults as a function of depth. $\left(\boldsymbol{\rho}=\mathbf{2 . 8} \times \mathbf{1 0 ^ { 3 }} \mathrm{kg} / \mathbf{m}^{3} ; \boldsymbol{g}=\mathbf{9 . 8} \mathrm{m} / \mathbf{s}^{2} ; \boldsymbol{\mu}=\mathbf{0 . 7 5} ; \boldsymbol{\theta}=\mathbf{2 7 ^ { \circ }}\right.$.) (Sibson, 1974; Van der Pluijm \& Marshak, 2004) 


\section{Methodology}

The 3D model developed in this study is based on finite element method (FEM). The finite element method is a widely used technique which is suitable for modeling geomechanical cases (Dhondt, 2004; Gudehus, 1978; Hughes, 2000; Lewis \& Schrefler, 1987; Smith \& Griffiths, 1998).

\subsection{Finite Element Principles}

In finite element method the continuum is divided into a series of elements which are connected at a finite number of points known as nodal points.

The governing equilibrium equations can be obtained by minimizing the total potential energy of a system. The total potential energy, $\pi$, can be expressed as

$$
\pi=\frac{1}{2} \int_{V}\{\boldsymbol{\sigma}\}^{T}\{\boldsymbol{\varepsilon}\} d V-\int_{V}\{\boldsymbol{\sigma}\}^{T}\{\mathbf{p}\} d V-\int_{S}\{\boldsymbol{\sigma}\}^{T}\{\mathbf{q}\} d S
$$

where $\sigma$ and $\varepsilon$ are the stress and strain vectors respectively, $\delta$ the displacements at any point, $\boldsymbol{p}$ the body forces per unit volume and $\boldsymbol{q}$ the applied surface tractions. Integrations are taken over the volume $V$ of the continuum and loaded surface area, $S$.

The first term on the right hand side of Equation (3.1) represents the internal strain energy and the second and third terms are respectively the work contributions of body forces and distributed surface loads (Hinton \& Owen, 1977).

In the finite element displacement method, the displacement is assumed to have unknown values only at the nodal points, so that the variation within any element is described in terms of the nodal values by means of interpolation functions. Thus

$$
\{\boldsymbol{\delta}\}=[\mathbf{N}]\left\{\boldsymbol{\delta}^{\mathbf{e}}\right\}
$$

where $\mathbf{N}$ is the set of interpolation functions termed the shape functions and $\boldsymbol{\delta}^{\mathbf{e}}$ is the vector of nodal displacements of the element. For different element types, the shape functions and vector of nodal displacements are different. The explicit formats of Equation (3.2) for 4-node rectangular element and 4-node tetrahedron element are given as examples, listed as following:

For 4-node rectangular element: 
$\left.\{\boldsymbol{\delta}\}=\left\{\begin{array}{l}\mathbf{u} \\ \mathbf{v}\end{array}\right\}=\left[\begin{array}{cccccccc}N_{1} & 0 & N_{2} & 0 & N_{3} & 0 & N_{4} & 0 \\ 0 & N_{1} & 0 & N_{2} & 0 & N_{3} & 0 & N_{4}\end{array}\right]\left\{\begin{array}{l}u_{1} \\ v_{1} \\ u_{2} \\ v_{2} \\ u_{3} \\ v_{3} \\ u_{4} \\ v_{4}\end{array}\right\}=[\mathbf{N}]\right]\left\{\mathbf{o}^{\mathbf{e}}\right\}$

where

$\mathbf{u}, \mathbf{v}$ are $x$ - and $y$-displacement at any position in the internal of a element.

$u_{i}, v_{i}$ are $x$-and $y$-displacement at nodes of element.

$N_{1}=\frac{1}{4}(1-\xi)(1-\eta)$

$N_{2}=\frac{1}{4}(1-\xi)(1+\eta)$

$N_{3}=\frac{1}{4}(1+\xi)(1+\eta)$

$N_{4}=\frac{1}{4}(1+\xi)(1-\eta)$

For 4-node tetrahedron element:

$$
\{\boldsymbol{\delta}\}=\left\{\begin{array}{l}
\mathbf{u} \\
\mathbf{v} \\
\mathbf{w}
\end{array}\right\}=\left[\begin{array}{cccccccccccc}
N_{1} & 0 & 0 & N_{2} & 0 & 0 & N_{3} & 0 & 0 & N_{4} & 0 & 0 \\
0 & N_{1} & 0 & 0 & N_{2} & 0 & 0 & N_{3} & 0 & 0 & N_{4} & 0 \\
0 & 0 & N_{1} & 0 & 0 & N_{2} & 0 & 0 & N_{3} & 0 & 0 & N_{4}
\end{array}\right]\left\{\begin{array}{l}
u_{1} \\
v_{1} \\
u_{2} \\
v_{2} \\
u_{3} \\
v_{3} \\
u_{4} \\
v_{4}
\end{array}\right\}=[\mathbf{N}]\left\{\boldsymbol{\delta}^{\mathbf{e}}\right\}
$$

where

$\mathbf{u}, \mathbf{v}, \mathbf{w}$ are $x-, y-$ and $z-$ displacements at any position in the internal of a element,

$u_{i}, v_{i}, w_{i}$ are $x-, y-$ and $z$-displacements at nodes of element.

$N_{1}=L_{1}$

$N_{2}=L_{2}$

$N_{3}=L_{3}$

$N_{4}=\left(1-L_{1}-L_{2}-L_{3}\right)$ 
The strains within the element can be expressed in terms of the element nodal displacements as

$$
\{\boldsymbol{\varepsilon}\}=[\mathbf{B}]\left\{\boldsymbol{\delta}^{\mathbf{e}}\right\}
$$

where $\mathbf{B}$ is the strain matrix generally composed of derivatives of the shape functions. The explicit form of Equation (3.3) for 4-node rectangular element and 4-node tetrahedron element are listed respectively as follows:

For 4-node rectangular element:

$$
\begin{aligned}
& \{\boldsymbol{\varepsilon}\}=\left\{\begin{array}{l}
\varepsilon_{x} \\
\varepsilon_{y} \\
\gamma_{x y}
\end{array}\right\}=\left[\begin{array}{cc}
\frac{\partial}{\partial x} & 0 \\
0 & \frac{\partial}{\partial y} \\
\frac{\partial}{\partial y} & \frac{\partial}{\partial x}
\end{array}\right]\left\{\begin{array}{l}
\mathbf{u} \\
\mathbf{v}
\end{array}\right\}=\left[\begin{array}{cc}
\frac{\partial}{\partial x} & 0 \\
0 & \frac{\partial}{\partial y} \\
\frac{\partial}{\partial y} & \frac{\partial}{\partial x}
\end{array}\right][\mathbf{N}]\left\{\boldsymbol{\delta}^{e}\right\} \\
& =\left[\begin{array}{cccccccc}
\frac{\partial N_{1}}{\partial x} & 0 & \frac{\partial N_{2}}{\partial x} & 0 & \frac{\partial N_{3}}{\partial x} & 0 & \frac{\partial N_{4}}{\partial x} & 0 \\
0 & \frac{\partial N_{1}}{\partial x} & 0 & \frac{\partial N_{2}}{\partial x} & 0 & \frac{\partial N_{3}}{\partial x} & 0 & \frac{\partial N_{4}}{\partial x} \\
\frac{\partial N_{1}}{\partial y} & \frac{\partial N_{1}}{\partial x} & \frac{\partial N_{2}}{\partial y} & \frac{\partial N_{2}}{\partial x} & \frac{\partial N_{3}}{\partial y} & \frac{\partial N_{3}}{\partial x} \frac{\partial N_{4}}{\partial y} & \frac{\partial N_{4}}{\partial x}
\end{array}\right]\left\{\boldsymbol{\delta}^{e}\right\}=[\mathbf{B}]\left\{\boldsymbol{\delta}^{\mathbf{e}}\right\} \\
& \text { where } \\
& {\left[\begin{array}{cccc}
\frac{\partial N_{1}}{\partial x} & \frac{\partial N_{2}}{\partial x} & \frac{\partial N_{3}}{\partial x} & \frac{\partial N_{4}}{\partial x} \\
\frac{\partial N_{1}}{\partial y} & \frac{\partial N_{2}}{\partial y} & \frac{\partial N_{3}}{\partial y} & \frac{\partial N_{4}}{\partial y}
\end{array}\right]=\left[\begin{array}{cc}
\frac{\partial x}{\partial \xi} & \frac{\partial y}{\partial \xi} \\
\frac{\partial x}{\partial \eta} & \frac{\partial y}{\partial \eta}
\end{array}\right]^{-1}\left[\begin{array}{cccc}
\frac{\partial N_{1}}{\partial \xi} & \frac{\partial N_{2}}{\partial \xi} & \frac{\partial N_{3}}{\partial \xi} & \frac{\partial N_{4}}{\partial \xi} \\
\frac{\partial N_{1}}{\partial \eta} & \frac{\partial N_{2}}{\partial \eta} & \frac{\partial N_{3}}{\partial \eta} & \frac{\partial N_{4}}{\partial \eta}
\end{array}\right]} \\
& x=N_{1} x_{1}+N_{2} x_{2}+N_{3} x_{3}+N_{4} x_{4} \\
& y=N_{1} y_{1}+N_{2} y_{2}+N_{3} y_{3}+N_{4} y_{4}
\end{aligned}
$$


For 4-node tetrahedron element:

$$
\{\boldsymbol{\varepsilon}\}=\left\{\begin{array}{l}
\varepsilon_{x} \\
\varepsilon_{y} \\
\varepsilon_{z} \\
\gamma_{x y} \\
\gamma_{y z} \\
\gamma_{y z}
\end{array}\right\}=\left[\begin{array}{ccc}
\frac{\partial}{\partial x} & 0 & 0 \\
0 & \frac{\partial}{\partial y} & 0 \\
0 & 0 & \frac{\partial}{\partial z} \\
\frac{\partial}{\partial y} & \frac{\partial}{\partial x} & 0 \\
0 & \frac{\partial}{\partial z} & \frac{\partial}{\partial y} \\
\frac{\partial}{\partial z} & 0 & \frac{\partial}{\partial x}
\end{array}\right]\left\{\begin{array}{l}
\mathbf{u} \\
\mathbf{v}
\end{array}\right\}=\left[\begin{array}{ccc}
\frac{\partial}{\partial x} & 0 & 0 \\
0 & \frac{\partial}{\partial y} & 0 \\
0 & 0 & \frac{\partial}{\partial z} \\
\frac{\partial}{\partial y} & \frac{\partial}{\partial x} & 0 \\
0 & \frac{\partial}{\partial z} & \frac{\partial}{\partial y} \\
\frac{\partial}{\partial z} & 0 & \frac{\partial}{\partial x}
\end{array}\right][\mathbf{N}]\left\{\boldsymbol{\delta}^{e}\right\}
$$$$
=\left[\begin{array}{cccccccccccc}
\frac{\partial N_{1}}{\partial x} & 0 & 0 & \frac{\partial N_{2}}{\partial x} & 0 & 0 & \frac{\partial N_{3}}{\partial x} & 0 & 0 & \frac{\partial N_{4}}{\partial x} & 0 & 0 \\
0 & \frac{\partial N_{1}}{\partial y} & 0 & 0 & \frac{\partial N_{2}}{\partial y} & 0 & 0 & \frac{\partial N_{3}}{\partial y} & 0 & 0 & \frac{\partial N_{4}}{\partial y} & 0 \\
0 & 0 & \frac{\partial N_{1}}{\partial z} & 0 & 0 & \frac{\partial N_{2}}{\partial z} & 0 & 0 & \frac{\partial N_{3}}{\partial z} & 0 & 0 & \frac{\partial N_{4}}{\partial z} \\
\frac{\partial N_{1}}{\partial y} & \frac{\partial N_{1}}{\partial x} & 0 & \frac{\partial N_{2}}{\partial y} & \frac{\partial N_{2}}{\partial x} & 0 & \frac{\partial N_{3}}{\partial y} & \frac{\partial N_{3}}{\partial x} & 0 & \frac{\partial N_{4}}{\partial y} & \frac{\partial N_{4}}{\partial x} & 0 \\
0 & \frac{\partial N_{1}}{\partial z} & \frac{\partial N_{1}}{\partial y} & 0 & \frac{\partial N_{2}}{\partial z} & \frac{\partial N_{2}}{\partial y} & 0 & \frac{\partial N_{3}}{\partial z} & \frac{\partial N_{3}}{\partial y} & 0 & \frac{\partial N_{4}}{\partial z} & \frac{\partial N_{4}}{\partial y} \\
\frac{\partial N_{1}}{\partial z} & 0 & \frac{\partial N_{1}}{\partial x} & \frac{\partial N_{2}}{\partial z} & 0 & \frac{\partial N_{2}}{\partial x} & \frac{\partial N_{3}}{\partial z} & 0 & \frac{\partial N_{3}}{\partial x} & \frac{\partial N_{4}}{\partial z} & 0 & \frac{\partial N_{4}}{\partial x}
\end{array}\right]\left\{\boldsymbol{\delta}^{e}\right\}
$$

$=[\mathbf{B}]\left\{\boldsymbol{\delta}^{\mathrm{e}}\right\}$

where

$$
\begin{aligned}
& {\left[\begin{array}{llll}
\frac{\partial N_{1}}{\partial x} & \frac{\partial N_{2}}{\partial x} & \frac{\partial N_{3}}{\partial x} & \frac{\partial N_{4}}{\partial x} \\
\frac{\partial N_{1}}{\partial y} & \frac{\partial N_{2}}{\partial y} & \frac{\partial N_{3}}{\partial y} & \frac{\partial N_{4}}{\partial y} \\
\frac{\partial N_{1}}{\partial z} & \frac{\partial N_{2}}{\partial z} & \frac{\partial N_{3}}{\partial z} & \frac{\partial N_{4}}{\partial z}
\end{array}\right]=\left[\begin{array}{lll}
\frac{\partial x}{\partial L_{1}} & \frac{\partial y}{\partial L_{2}} & \frac{\partial z}{\partial L_{3}} \\
\frac{\partial x}{\partial L_{1}} & \frac{\partial y}{\partial L_{2}} & \frac{\partial z}{\partial L_{3}} \\
\frac{\partial x}{\partial L_{1}} & \frac{\partial y}{\partial L_{2}} & \frac{\partial z}{\partial L_{3}}
\end{array}\right]^{-1}\left[\begin{array}{llll}
\frac{\partial N_{1}}{\partial L_{1}} & \frac{\partial N_{2}}{\partial L_{2}} & \frac{\partial N_{3}}{\partial L_{3}} & \frac{\partial N_{4}}{\partial L_{4}} \\
\frac{\partial N_{1}}{\partial L_{1}} & \frac{\partial N_{2}}{\partial L_{2}} & \frac{\partial N_{3}}{\partial L_{3}} & \frac{\partial N_{4}}{\partial L_{4}} \\
\frac{\partial N_{1}}{\partial L_{1}} & \frac{\partial N_{2}}{\partial L_{2}} & \frac{\partial N_{3}}{\partial L_{3}} & \frac{\partial N_{4}}{\partial L_{4}}
\end{array}\right]} \\
& x=N_{1} x_{1}+N_{2} x_{2}+N_{3} x_{3}+N_{4} x_{4} \\
& y=N_{1} y_{1}+N_{2} y_{2}+N_{3} y_{3}+N_{4} y_{4} \\
& z=N_{1} z_{1}+N_{2} z_{2}+N_{3} z_{3}+N_{4} z_{4}
\end{aligned}
$$


Finally the stresses are related to the strains by use of an elasticity matrix $\mathbf{D}$, as follows

$$
\{\boldsymbol{\sigma}\}=[\mathbf{D}]\{\boldsymbol{\varepsilon}\}
$$

The explicit form of Equation (3.4) for for 4-node rectangular element and 4-node tetrahedron element are listed respectively in the following:

For 4-node rectangular element:

$$
\{\boldsymbol{\sigma}\}=\left\{\begin{array}{l}
\sigma_{x} \\
\sigma_{y} \\
\tau_{x y}
\end{array}\right\}=\frac{E}{1-v^{2}}\left[\begin{array}{ccc}
1 & v & 0 \\
v & 1 & 0 \\
0 & 0 & \frac{1-v}{2}
\end{array}\right]\left\{\begin{array}{l}
\varepsilon_{x} \\
\varepsilon_{y} \\
\gamma_{x y}
\end{array}\right\}=[\mathbf{D}]\{\boldsymbol{\varepsilon}\} \text { (plane stress) }
$$

For 4-node tetrahedron element:

$$
\{\boldsymbol{\sigma}\}=\left\{\begin{array}{l}
\sigma_{x} \\
\sigma_{y} \\
\sigma_{z} \\
\tau_{x y} \\
\tau_{y z} \\
\tau_{z x}
\end{array}\right\}=\frac{E(1-v)}{(1+v)(1-2 v)}\left[\begin{array}{cccccc}
1 & \frac{v}{1-v} & \frac{v}{1-v} & 0 & 0 & 0 \\
\frac{v}{1-v} & 1 & \frac{v}{1-v} & 0 & 0 & 0 \\
\frac{v}{1-v} & \frac{v}{1-v} & 1 & 0 & 0 & 0 \\
0 & 0 & 0 & \frac{1-2 v}{2(1-v)} & 0 & 0 \\
0 & 0 & 0 & 0 & \frac{1-2 v}{2(1-v)} & 0 \\
0 & 0 & 0 & 0 & 0 & \frac{1-2 v}{2(1-v)}
\end{array}\right]\left\{\begin{array}{l}
\varepsilon_{x} \\
\varepsilon_{y} \\
\gamma_{x y} \\
\gamma_{y z} \\
\gamma_{z x}
\end{array}\right\}=[\mathbf{D}]\{\boldsymbol{\varepsilon}\}
$$

The total potential energy of the continuum is the sum of the energy contributions of the individual elements. Thus

$$
\pi=\sum_{e} \pi_{e}
$$

where $\pi_{e}$ represents the total potential energy of element $e$ which, on use of Equation (3.1), can be written 


$$
\pi_{e}=\frac{1}{2} \int_{V_{e}}\left\{\boldsymbol{\delta}^{e}\right\}^{\mathbf{T}}[\mathbf{B}]^{\mathbf{T}}[\mathbf{D}][\mathbf{B}]\left\{\boldsymbol{\delta}^{e}\right\} d V-\int_{V_{e}}\left\{\boldsymbol{\delta}^{e}\right\}^{\mathbf{T}}[\mathbf{N}]^{\mathbf{T}}\{\mathbf{p}\} d V-\int_{S_{e}}\left\{\boldsymbol{\delta}^{e}\right\}^{\mathbf{T}}[\mathbf{N}]^{\mathbf{T}}\{\mathbf{q}\} d S
$$

where $V_{e}$ is the element volume and $S_{e}$ the loaded element surface area. Performance of the minimization for element $e$ with respect to the nodal displacement $\boldsymbol{\delta}^{\mathrm{e}}$ for the element results in

$$
\frac{\pi_{e}}{\boldsymbol{\delta}^{\mathbf{e}}}=\int_{V_{e}}\left([\mathbf{B}]^{\mathrm{T}} \mathbf{D B}\right) \boldsymbol{\delta}^{e} d V-\int_{V_{e}}[\mathbf{N}]^{\mathrm{T}} \mathbf{p} d V-\int_{S_{e}}[\mathbf{N}]^{\mathrm{T}} \mathbf{q} d S=\mathbf{K}^{e} \boldsymbol{\delta}^{e}-\mathbf{F}^{e}
$$

where

$$
\mathbf{F}^{e}=\int_{V_{e}}[\mathbf{N}]^{\mathrm{T}} \mathbf{p} d V+\int_{S_{e}}[\mathbf{N}]^{\mathrm{T}} \mathbf{q} d S
$$

are the equivalent nodal forces for the element, and

$$
\mathbf{K}^{e}=\int_{V_{e}}\left([\mathbf{B}]^{\mathbf{T}} \mathbf{D B}\right) d V
$$

is termed the element stiffness matrix. The summation of the terms in Equation (3.7) over all the elements, when equated to zero, results in a system of equilibrium equations for the complete continuum. These equations are then solved to yield the nodal displacements.

In a finite element model, the fracture surface applied hydraulic pressure could be treated as interior boundary condition. When hydraulic pressure is applied, the pressure is transferred into node forces, and the forces are applied along the surface of the hydraulic fractures. The remaining model should experience stress redistribution so that the surface of the region applied hydraulic pressure is indeed an 'interior boundary'.

All element stiffness matrixes are assembled by a sparse matrix assembly procedure in this study. Iterative solution technique is adopted to solve the assembled global linear algebraic equations. For static equilibrium problems, the assembled system matrix is symmetric positive definite matrix (Smith \& Griffiths, 1998; Zienkiewicz, Taylor, \& Zhu, 2005). The Symmetric Successive Overrelaxation method, or SSOR, is then used, which is highly efficient to solve sparse symmetrical equations (Axelsson, 1972; Barrett et al., 1987; Chen \& Yung, 2001). 
The stresses within each element can then be calculated from the displacement using Equations (3.3) and (3.4).

\subsection{Stress Recovery}

In finite element method, the final results of stress and strain are presented in a Global Coordinate System. Each element (or cell) in a three dimension model has six components of stress, namely, the three normal stresses, $\sigma_{x}, \sigma_{y}, \sigma_{z}$, and the three shearing stresses $\tau_{x y}=\tau_{y x}, \tau_{x z}=\tau_{z x}, \tau_{y z}=\tau_{z y}$ (Figure 3.1).

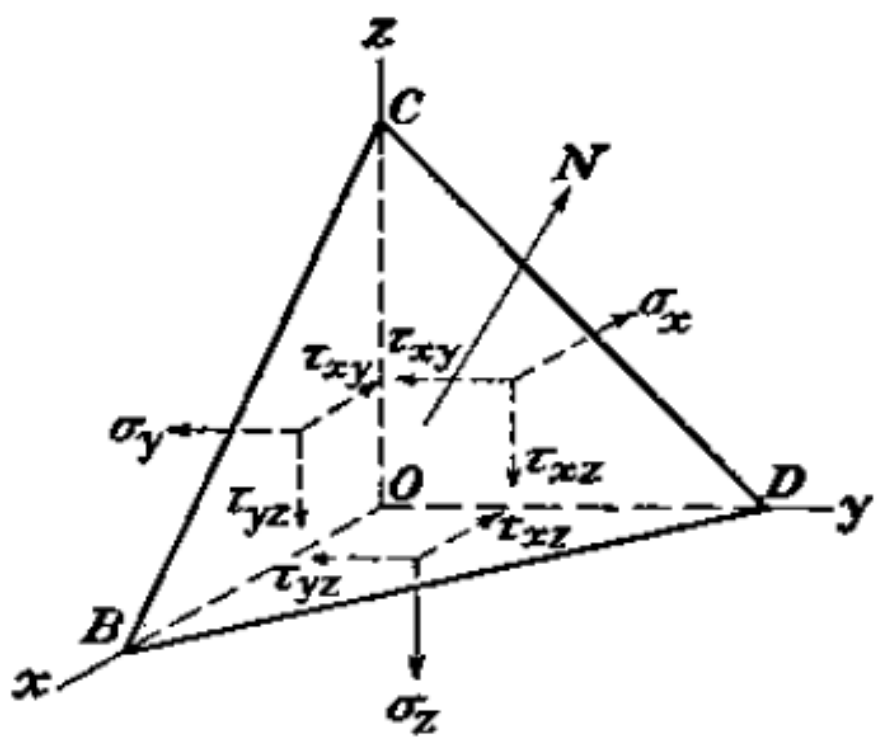

Figure 3.1 Six Stress Components in Three-Dimensional Coordinate.

Due to numerical integration adopted in finite element calculation, the strains and stresses are more accurate at integration points than anywhere else (Dhondt, 2004). The field variables (stresses and strains) are usually evaluated at the integration points, and can be extrapolated to element nodes.

In fault stability analysis, it is required to calculate shear and normal stresses at nodes located on an inclined plane (fault plane), so the six stress components at element nodes should be determined first, based on which shear and normal stresses could be calculated.

\subsubsection{Calculation of Element Strains and Stresses}

Suppose that we have solved the master stiffness equations 


$$
[\mathbf{K}]\{\boldsymbol{\delta}\}=\{\mathbf{f}\}
$$

for the node displacements $\boldsymbol{\delta}$, where $\mathbf{K}$ is the stiffness matrix.

Let $\boldsymbol{\delta}^{\mathbf{e}}$ the vector of computed node displacements for one element, the strains at any point in the element may be related to these displacements as

$$
\{\boldsymbol{\varepsilon}\}=[\mathbf{B}]\left\{\boldsymbol{\delta}^{\mathbf{e}}\right\}
$$

A loop is performed over all defined elements, where $\mathbf{B}$ is the strain-displacement matrix. The corresponding stresses for each element are given by

$$
\{\boldsymbol{\sigma}\}=[\mathbf{D}]\{\boldsymbol{\varepsilon}\}=[\mathbf{D}][\mathbf{B}]\left\{\boldsymbol{\delta}^{\mathbf{e}}\right\}
$$

where $\mathbf{D}$ is the stress-strain matrix.

\subsubsection{Extrapolation of Integration Point Values to the Nodes}

Usually two approaches are used in practice to compute element nodal stresses:

(1). Calculate $\sigma$ at element node locations by substituting natural coordinates of the nodal points as arguments to shape function modules.

(2). Calculate $\sigma$ at Gauss integration points used in the element stiffness integration rule and then extrapolate to the element node points.

For quadrilateral elements whose geometry departs substantially from the rectangular shape, empirical evidence indicates that the second approach generally delivers better stress values. In this report, the second approach is adopted.

The extrapolation is done on an element basis. Each node will obtain as many values as the number of elements it belongs to. The stresses computed at the same node from adjacent elements will not generally be the same, since stresses are not required to be continuous in displacement-assumed finite elements. Stress averaging should be used to improve the stress accuracy. This is done by calculating the mean value over all elements the node belongs to. The results from this averaging procedure are called nodal point stresses. 
Assume that the shape functions that are used in Equation (3.2) for displacements are also used for stresses, strains and any other dependent fields and the field variables, such as stresses, are known at nodes. Then, the values at integration point could be obtained by

$$
\{\boldsymbol{\sigma}\}_{\text {integration points }}=[\mathbf{N}]\{\boldsymbol{\sigma}\}_{\text {nodes }}
$$

where $\mathbf{N}$ is matrix for shape function.

Consequently, the values at nodes could be calculated by inverting the above equation

$$
\{\sigma\}_{\text {nodes }}=[\mathrm{N}]^{-1}\{\sigma\}_{\text {integration points }}
$$

For tetrahedron elements with 4 integration points:

$$
[N]^{-1}=\left[\begin{array}{c}
+1.92705-0.30902-0.30902-0.30902 \\
-0.30902+1.92705-0.30902-0.30902 \\
-0.30902-0.30902+1.92705-0.30902 \\
-0.30902-0.30902-0.30902+1.92705
\end{array}\right]
$$

For hexahedron elements with 8 integration points:

$$
[N]^{-1}=\left[\begin{array}{l}
+2.549-0.683-0.683+0.183-0.683+0.183+0.183-0.049 \\
-0.683+2.549+0.183-0.683+0.183-0.683-0.049+0.183 \\
+0.183-0.683-0.683+2.549-0.049+0.183+0.183-0.683 \\
-0.683+0.183+2.549-0.683+0.183-0.049-0.683+0.183 \\
-0.683+0.183+0.183-0.049+2.549-0.683-0.683+0.183 \\
+0.183-0.683-0.049+0.183-0.683+2.549+0.183-0.683 \\
-0.049+0.183+0.183-0.683+0.183-0.683-0.683+2.549 \\
+0.183-0.049-0.683+0.183-0.683+0.183+2.549-0.683
\end{array}\right]
$$

The values in the middle nodes are found by taking the mean of the neighboring vertex nodal point values.

\subsection{Shear and Normal Stresses Calculation on Fault Plane}

If stress components at element nodes located on fault plane are known, the stress acting on the inclined plane through this point can be calculated from equations of statics.

Let $O$ be a node on an inclined plane, and suppose the six stress components are known for the coordinate plane $x y, x z, y z$ (Figure 3.1). To obtain shear and normal stresses for an 
inclined plane through $O$, a plane $B C D$ parallel to the inclined plane at a small distance from $O$ is used. Plane $B C D$ together with the coordinate planes cuts out a very small tetrahedron $B C D O$. The stresses acting on the plane $B C D$ will approach the stresses on the parallel plane through $O$ as the small tetrahedron $B C D O$ is made infinitesimal.

If $N$ is the normal to the plane $B C D$ in Figure 3.1, and it could be wrote that

$$
\begin{aligned}
& \cos (N, x)=l \\
& \cos (N, y)=m \\
& \cos (N, z)=n
\end{aligned}
$$

If the three components of stress are denoted by $X, Y, Z$, parallel to the Global Coordinate Axes, acting on the inclined face $B C D$, then the equations of equilibrium of the tetrahedron $B C D O$ can be written

$$
\begin{aligned}
& X=\sigma_{x} l+\tau_{x y} m+\tau_{x z} n \\
& Y=\tau_{x y} l+\sigma_{y} m+\tau_{z y} n \\
& Z=\tau_{x z} l+\tau_{y z} m+\sigma_{z} n
\end{aligned}
$$

Provided the six components of stress $\sigma_{x}, \sigma_{y}, \sigma_{z}, \tau_{x y}, \tau_{y x}, \tau_{x z}$ at point $O$ are known, the components of stress on any plane, defined by the direction cosines $l, m, n$, can be calculated according to Equation (3.16).

\subsubsection{Normal Stress for Nodal Points Located on Inclined Plane}

Any plane in 3-dimensional rectangular coordinate system is determined by the following geometric equation:

$$
A x+B y+C z+D=0
$$

By substituting four nodes on a plane, the constants $A, B, C$ and $D$ can be determined. The normal direction cosines for the plane $(l, m, n$,$) can be calculated through following$ equations: 


$$
\begin{aligned}
& l=\frac{A}{\sqrt{A^{2}+B^{2}+C^{2}}} \\
& m=\frac{B}{\sqrt{A^{2}+B^{2}+C^{2}}} \\
& n=\frac{C}{\sqrt{A^{2}+B^{2}+C^{2}}}
\end{aligned}
$$

Projecting the three components of stress $(X, Y, Z)$ determined by Equation (3.16) to the normal direction of the plane, the normal stress $\left(\sigma_{v}\right)$ on this particular plane can be calculated as

$$
\sigma_{n}=X l+Y m+Z n
$$

Substituting the values of $X, Y, Z$ from Equation (3.16), then

$$
\sigma_{n}=\sigma_{x} l^{2}+\sigma_{y} m^{2}+\sigma_{z} n^{2}+2 \tau_{y z} m n+2 \tau_{x z} l n+2 \tau_{x y} l m
$$

\subsubsection{Shear Stress for Nodal Points Located on Inclined Plane}

The magnitude of the total stress $\sigma_{(v)}$ on an inclined plane through nodal points is

$$
\sigma_{(v)}=\sqrt{X^{2}+Y^{2}+Z^{2}}
$$

In 3-dimensional coordinate system, the total stress could be represented by a vector, which has an ordered set of three components representing its projections on the coordinate axes. In this case, the total stress is written as

$$
\underline{\sigma_{(v)}}=X \underline{i}+Y \underline{j}+Z \underline{k}
$$

where $i, j, k$ are unit vectors in the 3 -dimensional coordinate system.

The normal stress on the inclined plane could also be written in the form of vector, listed as following:

$$
\underline{\sigma_{n}}=\left(X l^{2}\right) \underline{i}+\left(Y m^{2}\right) \underline{j}+\left(Z n^{2}\right) \underline{k}
$$

According to vector operation, the shear stress $\tau$ on the inclined plane could be derived as

$$
\underline{\tau}=\underline{\sigma_{(v)}}-\underline{\sigma_{n}}=\left(X-X l^{2}\right) \underline{i}+\left(Y-Y m^{2}\right) \underline{j}+\left(Z-Z n^{2}\right) \underline{k}
$$


For each nodes located on the inclined plane (fault plane), a loop is performed to carry out all the above procedures to calculate shear and normal stresses at these points.

\subsection{Validation}

Three different cases are used to validate the above mentioned methods. The case No. 1 and 2 are utilized to validate the shear and normal stresses calculation. In the case No. 3, the stress distribution of a 3D numerical model is compared to analytical solutions when a constant hydraulic pressure is acting on the surfaces of a fracture.

For case No. 1, the shear and normal stresses on an inclined plane could be calculated through analytical method. Numerical calculation using finite element method is also carried out. The results obtained from numerical calculation are compared to those computed through analytical method.

A field case is used in case No. 2, the results obtained from numerical simulation is compared with those calculated by analytical method.

\subsubsection{Case No. 1}

In this case, a square column is fixed at the bottom, the lateral boundaries are free (without restraint). A constant pressure is applied on the top of the column. There is an inclined plane in the column, dipped at an angle of $60^{\circ}$. The geometric model is illustrated in Figure 3.2.

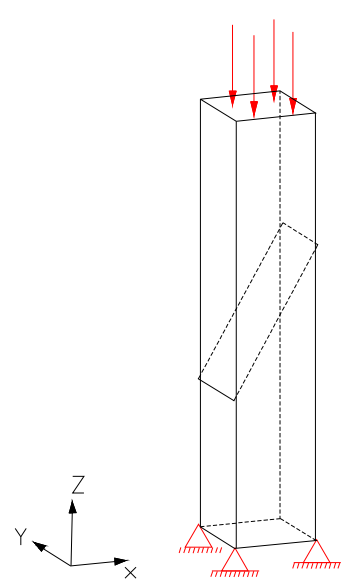

Figure 3.2 Geometric model for Case No. One.

The boundary conditions are listed as following: 
- Top surface: uniform distributed pressure in vertical downward direction, value of which is 6.94 psi.

- Four lateral surfaces: free (without restraint).

- Bottom: fixed in vertical direction.

Young's modulus and Poisson's ratio are $1.12 \times 10^{6}$ psi and 0.28 , respectively.

\subsubsection{Analytical Results}

For the given geometric configuration and boundary conditions, the total force acting on the top surface should be equal to the one acting on the inclined plane. In other words, the following equilibrium equation should be satisfied:

Force Acting on Top Surface = Force Acting on the Inclined Inner Plane

or

Vertical Downward Pressure on Top Surface $\times$ Area of Top Surface $=$ Vertical DownWard Pressure on Inclined Plane $\times$ Area of Inclined Plane $\sigma_{(v)}=$ Vertical DownWard Pressure on Inclined Plane

$\sigma_{(v)}=$ Vertical Downward Pressure on Top Surface $\times \frac{\text { Area of Top Surface }}{\text { Area of Inclined Plane }}$ $\sigma_{(v)}=6.94 \times \cos 60^{\circ}=3.47 p s i$

Derived from force equilibrium equations, the total stress acting on the lower part below the inclined plane is in the downward vertical direction, with a magnitude of 3.47 psi.

The shear and normal stresses on the inclined plane could be calculated as following:

$$
\begin{aligned}
\sigma_{n} & =\sigma_{(v)} \times \cos 60^{\circ}=3.47 \times 0.5=1.735 p s i \\
\tau & =\sigma_{(v)} \times \cos 30^{\circ}=3.47 \times 0.866=3.005 p s i
\end{aligned}
$$

The ratio of shear to normal stress is $\tan 60^{\circ}=1.732$. The directions of shear and normal stresses are illustrated in Figure 3.3. 


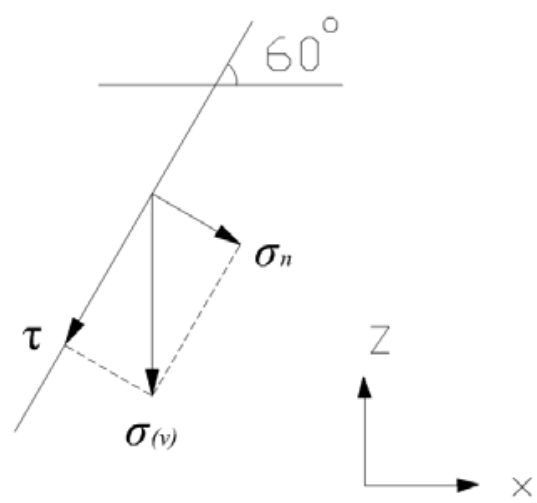

Figure 3.3 Shear and normal stresses on the inclined plane.

\subsubsection{Numerical Results}

The discretized model is shown in Figure 3.4. There are 105 nodes located on the inclined inner plane. Using the method discussed before, the shear and normal stresses on the inclined plane are calculated at those nodes. The results are summarized in Table 3.1.

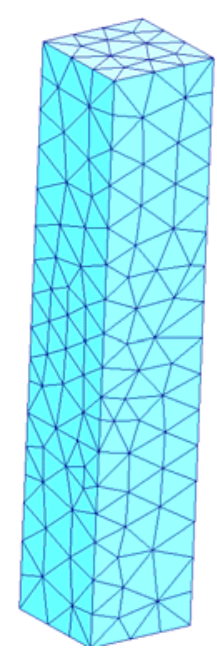

Figure 3.4 Discretized geometric model.

For Case No. 1, as can be seen from Table 3.1, the shear and normal stresses are almost the same as that calculated using analytical method. The maximum differences for shear and normal stresses between the analytical results and the numerical ones are $0.00273 \mathrm{psi}$ and 0.00162 psi, respectively. For the ratio of shear to normal stress, the maximum difference is 0.000108 . 
It is thought that these differences between analytical and numerical results are acceptable for engineering application and the proposed methods for calculating shear and normal stresses are reliable.

Table 3.1 Summary of numerical computation results using finite element method.

\begin{tabular}{|c|c|c|c|c|c|c|c|c|c|}
\hline \multirow[b]{2}{*}{ Node No. } & \multirow{2}{*}{\begin{tabular}{|c} 
Shear Stress \\
(psi)
\end{tabular}} & \multicolumn{3}{|c|}{ Shear Stress Direction } & \multirow{2}{*}{$\begin{array}{c}\text { Normal Stress } \\
\text { (psi) }\end{array}$} & \multicolumn{3}{|c|}{ Normal Stress Direction } & \multirow[b]{2}{*}{$R^{*}$} \\
\hline & & $x$-direction & $y$-direction & z-direction & & $x$-direction & $y$-direction & $z$-direction & \\
\hline 5 & 3.00784 & -0.50001 & 0.00005 & -0.86602 & -1.73662 & -0.86602 & 0.00000 & 0.50001 & -1.73201 \\
\hline 6 & 3.00768 & -0.50001 & -0.00003 & -0.86602 & -1.73651 & -0.86602 & 0.00000 & 0.50001 & -1.73203 \\
\hline 7 & 3.00709 & -0.50001 & 0.00000 & -0.86602 & -1.73620 & -0.86602 & 0.00000 & 0.50001 & -1.73200 \\
\hline 8 & 3.00709 & -0.50001 & 0.00000 & -0.86602 & -1.73619 & -0.86602 & 0.00000 & 0.50001 & -1.73200 \\
\hline 29 & 3.00749 & -0.50001 & 0.00002 & -0.86602 & -1.73634 & -0.86602 & 0.00000 & 0.50001 & -1.73208 \\
\hline 30 & 3.00708 & -0.50001 & 0.00000 & -0.86602 & -1.73619 & -0.86602 & 0.00000 & 0.50001 & -1.73200 \\
\hline 31 & 3.00727 & -0.50001 & 0.00001 & -0.86602 & -1.73624 & -0.86602 & 0.00000 & 0.50001 & -1.73206 \\
\hline 32 & 3.00735 & -0.50001 & -0.00002 & -0.86602 & -1.73638 & -0.86602 & 0.00000 & 0.50001 & -1.73197 \\
\hline 33 & 3.00753 & -0.50001 & -0.00003 & -0.86602 & -1.73643 & -0.86602 & 0.00000 & 0.50001 & -1.73202 \\
\hline 34 & 3.00753 & -0.50001 & 0.00002 & -0.86602 & -1.73639 & -0.86602 & 0.00000 & 0.50001 & -1.73206 \\
\hline 35 & 3.00723 & -0.50001 & 0.00001 & -0.86602 & -1.73625 & -0.86602 & 0.00000 & 0.50001 & -1.73203 \\
\hline 36 & 3.00713 & -0.50001 & 0.00001 & -0.86602 & -1.73622 & -0.86602 & 0.00000 & 0.50001 & -1.73200 \\
\hline 37 & 3.00707 & -0.50001 & 0.00001 & -0.86602 & -1.73621 & -0.86602 & 0.00000 & 0.50001 & -1.73197 \\
\hline 38 & 3.00704 & -0.50001 & 0.00001 & -0.86602 & -1.73620 & -0.86602 & 0.00000 & 0.50001 & -1.73197 \\
\hline 39 & 3.00703 & -0.50001 & 0.00000 & -0.86602 & -1.73621 & -0.86602 & 0.00000 & 0.50001 & -1.73195 \\
\hline 40 & 3.00705 & -0.50001 & 0.00000 & -0.86602 & -1.73622 & -0.86602 & 0.00000 & 0.50001 & -1.73196 \\
\hline 41 & 3.00708 & -0.50001 & 0.00000 & -0.86602 & -1.73622 & -0.86602 & 0.00000 & 0.50001 & -1.73197 \\
\hline 42 & 3.00709 & -0.50001 & 0.00000 & -0.86602 & -1.73621 & -0.86602 & 0.00000 & 0.50001 & -1.73198 \\
\hline 43 & 3.00710 & -0.50001 & 0.00000 & -0.86602 & -1.73620 & -0.86602 & 0.00000 & 0.50001 & -1.73200 \\
\hline 44 & 3.00710 & -0.50001 & 0.00000 & -0.86602 & -1.73620 & -0.86602 & 0.00000 & 0.50001 & -1.73200 \\
\hline 45 & 3.00709 & -0.50001 & 0.00000 & -0.86602 & -1.73619 & -0.86602 & 0.00000 & 0.50001 & -1.73200 \\
\hline 46 & 3.00709 & -0.50001 & 0.00000 & -0.86602 & -1.73619 & -0.86602 & 0.00000 & 0.50001 & -1.73200 \\
\hline 47 & 3.00709 & -0.50001 & 0.00000 & -0.86602 & -1.73620 & -0.86602 & 0.00000 & 0.50001 & -1.73200 \\
\hline 48 & 3.00709 & -0.50001 & 0.00000 & -0.86602 & -1.73620 & -0.86602 & 0.00000 & 0.50001 & -1.73200 \\
\hline 49 & 3.00709 & -0.50001 & 0.00000 & -0.86602 & -1.73620 & -0.86602 & 0.00000 & 0.50001 & -1.73200 \\
\hline 50 & 3.00709 & -0.50001 & 0.00000 & -0.86602 & -1.73620 & -0.86602 & 0.00000 & 0.50001 & -1.73200 \\
\hline 51 & 3.00709 & -0.50001 & 0.00000 & -0.86602 & -1.73620 & -0.86602 & 0.00000 & 0.50001 & -1.73200 \\
\hline 52 & 3.00745 & -0.50001 & -0.00001 & -0.86602 & -1.73631 & -0.86602 & 0.00000 & 0.50001 & -1.73209 \\
\hline 53 & 3.00719 & -0.50001 & -0.00001 & -0.86602 & -1.73625 & -0.86602 & 0.00000 & 0.50001 & -1.73200 \\
\hline 54 & 3.00712 & -0.50001 & -0.00001 & -0.86602 & -1.73623 & -0.86602 & 0.00000 & 0.50001 & -1.73199 \\
\hline 55 & 3.00705 & -0.50001 & 0.00000 & -0.86602 & -1.73621 & -0.86602 & 0.00000 & 0.50001 & -1.73197 \\
\hline 56 & 3.00703 & -0.50001 & 0.00000 & -0.86602 & -1.73620 & -0.86602 & 0.00000 & 0.50001 & -1.73196 \\
\hline 57 & 3.00704 & -0.50001 & 0.00000 & -0.86602 & -1.73622 & -0.86602 & 0.00000 & 0.50001 & -1.73195 \\
\hline 58 & 3.00706 & -0.50001 & 0.00000 & -0.86602 & -1.73622 & -0.86602 & 0.00000 & 0.50001 & -1.73196 \\
\hline 59 & 3.00708 & -0.50001 & 0.00000 & -0.86602 & -1.73622 & -0.86602 & 0.00000 & 0.50001 & -1.73197 \\
\hline 60 & 3.00709 & -0.50001 & 0.00000 & -0.86602 & -1.73621 & -0.86602 & 0.00000 & 0.50001 & -1.73199 \\
\hline 61 & 3.00709 & -0.50001 & 0.00000 & -0.86602 & -1.73620 & -0.86602 & 0.00000 & 0.50001 & -1.73200 \\
\hline 62 & 3.00709 & -0.50001 & 0.00000 & -0.86602 & -1.73620 & -0.86602 & 0.00000 & 0.50001 & -1.73200 \\
\hline 63 & 3.00709 & -0.50001 & 0.00000 & -0.86602 & -1.73619 & -0.86602 & 0.00000 & 0.50001 & -1.73200 \\
\hline 64 & 3.00709 & -0.50001 & 0.00000 & -0.86602 & -1.73619 & -0.86602 & 0.00000 & 0.50001 & -1.73200 \\
\hline 125 & 3.00709 & -0.50001 & 0.00000 & -0.86602 & -1.73620 & -0.86602 & 0.00000 & 0.50001 & -1.73200 \\
\hline 126 & 3.00709 & -0.50001 & 0.00000 & -0.86602 & -1.73620 & -0.86602 & 0.00000 & 0.50001 & -1.73200 \\
\hline 127 & 3.00698 & -0.50001 & 0.00000 & -0.86602 & -1.73616 & -0.86602 & 0.00000 & 0.50001 & -1.73197 \\
\hline 128 & 3.00696 & -0.50001 & 0.00002 & -0.86602 & -1.73607 & -0.86602 & 0.00000 & 0.50001 & -1.73205 \\
\hline 129 & 3.00699 & -0.50001 & -0.00004 & -0.86602 & -1.73614 & -0.86602 & 0.00000 & 0.50001 & -1.73200 \\
\hline 130 & 3.00694 & -0.50001 & -0.00003 & -0.86602 & -1.73608 & -0.86602 & 0.00000 & 0.50001 & -1.73203 \\
\hline 131 & 3.00710 & -0.50001 & -0.00003 & -0.86602 & -1.73617 & -0.86602 & 0.00000 & 0.50001 & -1.73203 \\
\hline 132 & 3.00725 & -0.50001 & -0.00003 & -0.86602 & -1.73616 & -0.86602 & 0.00000 & 0.50001 & -1.73213 \\
\hline 133 & 3.00736 & -0.50001 & -0.00004 & -0.86602 & -1.73626 & -0.86602 & 0.00000 & 0.50001 & -1.73208 \\
\hline 134 & 3.00702 & -0.50001 & 0.00004 & -0.86602 & -1.73609 & -0.86602 & 0.00000 & 0.50001 & -1.73206 \\
\hline 135 & 3.00710 & -0.50001 & 0.00001 & -0.86602 & -1.73623 & -0.86602 & 0.00000 & 0.50001 & -1.73198 \\
\hline 136 & 3.00717 & -0.50001 & 0.00003 & -0.86602 & -1.73618 & -0.86602 & 0.00000 & 0.50001 & -1.73206 \\
\hline 137 & 3.00742 & -0.50001 & 0.00005 & -0.86602 & -1.73632 & -0.86602 & 0.00000 & 0.50001 & -1.73206 \\
\hline 138 & 3.00692 & -0.50001 & 0.00000 & -0.86602 & -1.73609 & -0.86602 & 0.00000 & 0.50001 & -1.73201 \\
\hline 139 & 3.00695 & -0.50001 & -0.00001 & -0.86602 & -1.73613 & -0.86602 & 0.00000 & 0.50001 & -1.73199 \\
\hline 140 & 3.00704 & -0.50001 & 0.00000 & -0.86602 & -1.73621 & -0.86602 & 0.00000 & 0.50001 & -1.73196 \\
\hline 141 & 3.00708 & -0.50001 & 0.00000 & -0.86602 & -1.73621 & -0.86602 & 0.00000 & 0.50001 & -1.73197 \\
\hline
\end{tabular}


Table 3.1 Summary of numerical computation results using finite element method. (continued)

\begin{tabular}{|c|c|c|c|c|c|c|c|c|c|}
\hline 142 & 3.00709 & -0.50001 & 0.00000 & -0.86602 & -1.73621 & -0.86602 & 0.00000 & 0.50001 & -1.73199 \\
\hline 143 & 3.00709 & -0.50001 & 0.00000 & -0.86602 & -1.73620 & -0.86602 & 0.00000 & 0.50001 & -1.73200 \\
\hline 144 & 3.00695 & -0.50001 & 0.00002 & -0.86602 & -1.73605 & -0.86602 & 0.00000 & 0.50001 & -1.73206 \\
\hline 145 & 3.00696 & -0.50001 & 0.00002 & -0.86602 & -1.73612 & -0.86602 & 0.00000 & 0.50001 & -1.73200 \\
\hline 146 & 3.00702 & -0.50001 & 0.00001 & -0.86602 & -1.73619 & -0.86602 & 0.00000 & 0.50001 & -1.73197 \\
\hline 147 & 3.00708 & -0.50001 & 0.00000 & -0.86602 & -1.73622 & -0.86602 & 0.00000 & 0.50001 & -1.73197 \\
\hline 148 & 3.00709 & -0.50001 & 0.00000 & -0.86602 & -1.73620 & -0.86602 & 0.00000 & 0.50001 & -1.73200 \\
\hline 149 & 3.00709 & -0.50001 & 0.00000 & -0.86602 & -1.73620 & -0.86602 & 0.00000 & 0.50001 & -1.73200 \\
\hline 150 & 3.00709 & -0.50001 & 0.00000 & -0.86602 & -1.73619 & -0.86602 & 0.00000 & 0.50001 & -1.73200 \\
\hline 151 & 3.00693 & -0.50001 & -0.00002 & -0.86602 & -1.73608 & -0.86602 & 0.00000 & 0.50001 & -1.73202 \\
\hline 152 & 3.00699 & -0.50001 & -0.00002 & -0.86602 & -1.73615 & -0.86602 & 0.00000 & 0.50001 & -1.73199 \\
\hline 153 & 3.00707 & -0.50001 & 0.00000 & -0.86602 & -1.73621 & -0.86602 & 0.00000 & 0.50001 & -1.73197 \\
\hline 154 & 3.00709 & -0.50001 & 0.00000 & -0.86602 & -1.73620 & -0.86602 & 0.00000 & 0.50001 & -1.73200 \\
\hline 155 & 3.00706 & -0.50001 & 0.00002 & -0.86602 & -1.73617 & -0.86602 & 0.00000 & 0.50001 & -1.73201 \\
\hline 156 & 3.00712 & -0.50001 & -0.00001 & -0.86602 & -1.73612 & -0.86602 & 0.00000 & 0.50001 & -1.73210 \\
\hline 157 & 3.00706 & -0.50001 & 0.00002 & -0.86602 & -1.73617 & -0.86602 & 0.00000 & 0.50001 & -1.73201 \\
\hline 158 & 3.00713 & -0.50001 & 0.00003 & -0.86602 & -1.73616 & -0.86602 & 0.00000 & 0.50001 & -1.73206 \\
\hline 159 & 3.00701 & -0.50001 & 0.00001 & -0.86602 & -1.73618 & -0.86602 & 0.00000 & 0.50001 & -1.73196 \\
\hline 160 & 3.00700 & -0.50001 & 0.00002 & -0.86602 & -1.73614 & -0.86602 & 0.00000 & 0.50001 & -1.73200 \\
\hline 161 & 3.00707 & -0.50001 & 0.00000 & -0.86602 & -1.73622 & -0.86602 & 0.00000 & 0.50001 & -1.73196 \\
\hline 162 & 3.00705 & -0.50001 & 0.00000 & -0.86602 & -1.73622 & -0.86602 & 0.00000 & 0.50001 & -1.73196 \\
\hline 163 & 3.00709 & -0.50001 & 0.00000 & -0.86602 & -1.73620 & -0.86602 & 0.00000 & 0.50001 & -1.73199 \\
\hline 164 & 3.00709 & -0.50001 & 0.00000 & -0.86602 & -1.73621 & -0.86602 & 0.00000 & 0.50001 & -1.73198 \\
\hline 165 & 3.00709 & -0.50001 & 0.00000 & -0.86602 & -1.73619 & -0.86602 & 0.00000 & 0.50001 & -1.73200 \\
\hline 166 & 3.00709 & -0.50001 & 0.00000 & -0.86602 & -1.73620 & -0.86602 & 0.00000 & 0.50001 & -1.73200 \\
\hline 167 & 3.00709 & -0.50001 & 0.00000 & -0.86602 & -1.73620 & -0.86602 & 0.00000 & 0.50001 & -1.73200 \\
\hline 168 & 3.00709 & -0.50001 & 0.00000 & -0.86602 & -1.73619 & -0.86602 & 0.00000 & 0.50001 & -1.73200 \\
\hline 169 & 3.00708 & -0.50001 & -0.00002 & -0.86602 & -1.73618 & -0.86602 & 0.00000 & 0.50001 & -1.73201 \\
\hline 170 & 3.00701 & -0.50001 & -0.00002 & -0.86602 & -1.73616 & -0.86602 & 0.00000 & 0.50001 & -1.73200 \\
\hline 171 & 3.00702 & -0.50001 & -0.00002 & -0.86602 & -1.73618 & -0.86602 & 0.00000 & 0.50001 & -1.73198 \\
\hline 172 & 3.00704 & -0.50001 & -0.00001 & -0.86602 & -1.73622 & -0.86602 & 0.00000 & 0.50001 & -1.73194 \\
\hline 173 & 3.00706 & -0.50001 & 0.00000 & -0.86602 & -1.73622 & -0.86602 & 0.00000 & 0.50001 & -1.73196 \\
\hline 174 & 3.00708 & -0.50001 & 0.00000 & -0.86602 & -1.73621 & -0.86602 & 0.00000 & 0.50001 & -1.73198 \\
\hline 175 & 3.00709 & -0.50001 & 0.00000 & -0.86602 & -1.73620 & -0.86602 & 0.00000 & 0.50001 & -1.73199 \\
\hline 176 & 3.00709 & -0.50001 & 0.00000 & -0.86602 & -1.73620 & -0.86602 & 0.00000 & 0.50001 & -1.73200 \\
\hline 177 & 3.00709 & -0.50001 & 0.00000 & -0.86602 & -1.73620 & -0.86602 & 0.00000 & 0.50001 & -1.73200 \\
\hline 178 & 3.00709 & -0.50001 & 0.00000 & -0.86602 & -1.73620 & -0.86602 & 0.00000 & 0.50001 & -1.73200 \\
\hline 179 & 3.00709 & -0.50001 & 0.00000 & -0.86602 & -1.73621 & -0.86602 & 0.00000 & 0.50001 & -1.73199 \\
\hline 180 & 3.00703 & -0.50001 & -0.00001 & -0.86602 & -1.73621 & -0.86602 & 0.00000 & 0.50001 & -1.73196 \\
\hline 181 & 3.00697 & -0.50001 & -0.00003 & -0.86602 & -1.73612 & -0.86602 & 0.00000 & 0.50001 & -1.73200 \\
\hline 182 & 3.00709 & -0.50001 & 0.00000 & -0.86602 & -1.73620 & -0.86602 & 0.00000 & 0.50001 & -1.73200 \\
\hline 183 & 3.00709 & -0.50001 & 0.00000 & -0.86602 & -1.73621 & -0.86602 & 0.00000 & 0.50001 & -1.73199 \\
\hline 184 & 3.00706 & -0.50001 & 0.00000 & -0.86602 & -1.73622 & -0.86602 & 0.00000 & 0.50001 & -1.73196 \\
\hline 185 & 3.00695 & -0.50001 & 0.00001 & -0.86602 & -1.73613 & -0.86602 & 0.00000 & 0.50001 & -1.73198 \\
\hline 186 & 3.00701 & -0.50001 & 0.00004 & -0.86602 & -1.73610 & -0.86602 & 0.00000 & 0.50001 & -1.73205 \\
\hline 187 & 3.00689 & -0.50001 & 0.00000 & -0.86602 & -1.73603 & -0.86602 & 0.00000 & 0.50001 & -1.73206 \\
\hline 188 & 3.00706 & -0.50001 & 0.00005 & -0.86602 & -1.73614 & -0.86602 & 0.00000 & 0.50001 & -1.73204 \\
\hline 189 & 3.00702 & -0.50001 & -0.00005 & -0.86602 & -1.73613 & -0.86602 & 0.00000 & 0.50001 & -1.73203 \\
\hline \multicolumn{4}{|c|}{ * : Ratio of Shear Stress and Normal Stress. } & & & & & & \\
\hline
\end{tabular}

\subsubsection{Case No. 2}

The second case is a famous experiment of fluid injection induced earthquakes at Rangely oil field in Colorado (Haimson, 1972; C. Raleigh, Healy, \& Bredehoeft, 1972; C. Raleigh, Healy, \& Bredehoeft, 1976; M. D. Zoback \& Healy, 1984). It thoroughly analyzed the mechanics of crustal earthquakes in terms of the magnitude of in-situ stresses and the frictional strength of faults. The researchers attempted to demonstrate 
that raising pore pressure would tend to induce strike-slip faulting by increasing the ratio of shear to effective normal stress on a pre-existing fault.

Table 3.2 illustrates the orientation and magnitude of three principal stresses. The preexisting fault plane strikes $\mathrm{N} 50^{\circ} \mathrm{E}$ and dips $80^{\circ} \mathrm{NW}$. Using tensor transformation (C. Raleigh et al., 1976; M. L. Zoback \& Zoback, 1980), the shear and normal stresses resolved into the slip direction and normal to the fault plane are $1943.51 \mathrm{psi}$ and 6874.79 psi, respectively.

Table 3.2 State of Stress at Rangely, Colorado. (C. Raleigh et al., 1976; M. D. Zoback \& Healy, 1984)

\begin{tabular}{|c|c|c|c|c|c|c|}
\hline \multicolumn{3}{|c|}{ Principal Stresses } & \multicolumn{2}{|c|}{ Stress on Fault } & \multirow{2}{*}{$\begin{array}{c}\text { Pore } \\
\text { Pressure } \\
\text { (psi) }\end{array}$} & \multirow{2}{*}{$\begin{array}{l}\text { Coefficient } \\
\text { of Fiction }\end{array}$} \\
\hline $\mathrm{S}_{\mathrm{Hmax}}(\mathrm{psi})$ & $\mathrm{S}_{\mathrm{hmax}}(\mathrm{psi})$ & $\mathrm{S}_{\mathrm{v}}($ & $\begin{array}{c}\text { Shear Stress } \\
\text { (psi) }\end{array}$ & $\begin{array}{c}\text { Normal Stress } \\
\text { (psi) }\end{array}$ & & \\
\hline $\begin{array}{c}8557.23 \\
\left(\mathrm{~N} 80^{\circ} \mathrm{W}\right)\end{array}$ & $\begin{array}{l}4554.18 \\
\left(\mathrm{~N} 10^{\circ} \mathrm{E}\right) \\
\end{array}$ & $\begin{array}{c}6193.11 \\
\text { (Vertical) }\end{array}$ & 1943.51 & 6874.79 & 3988.54 & 0.67 \\
\hline
\end{tabular}

Numerical analysis is also performed using the finite element method. Figure 3.5 shows the geometric model and the corresponding discretized grid system. Stress boundary conditions are used. $S_{H \max }$ is applied in $y$ direction, $S_{h \max }$ in $x$ direction, $S_{v}$ in $z$ direction. The bottom has been restrained (zero displacement) in vertical direction.

Young's modulus and Poisson's ratio are $4.02 \times 10^{6} \mathrm{psi}$ and 0.209 , respectively.

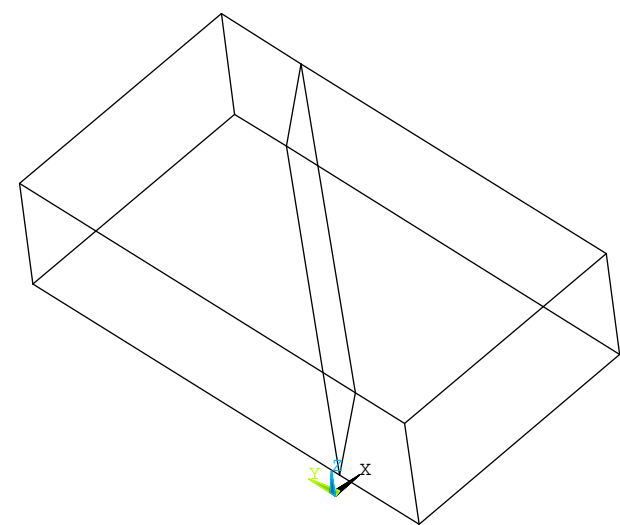

(a)

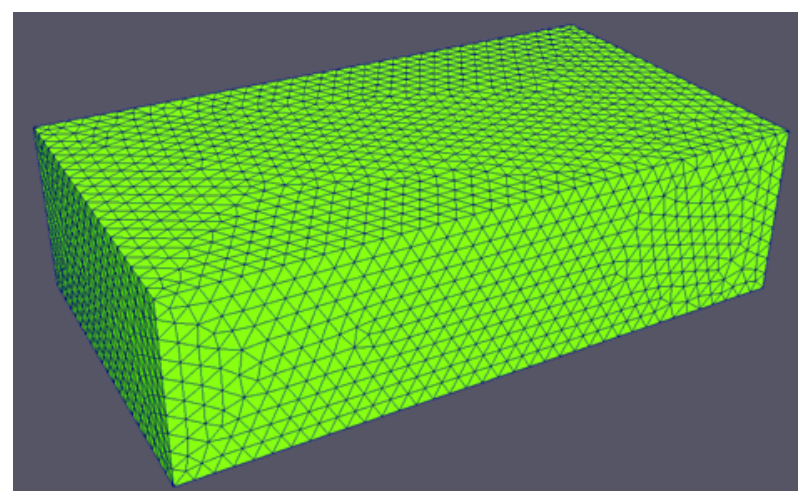

(b)

Figure 3.5 (a) Geometric model for case 2; (b) Discretized grid system. 
Numerical model was built to simulate the in-situ stress field, the normal and shear stresses distributed on the fault plane were then calculated according to the above mentioned method. As can be seen in Figure 3.6, the numerical results are almost the same as that calculated by tensor transformation.

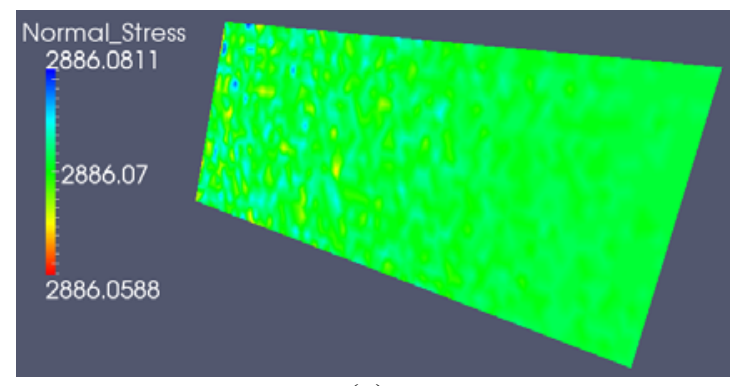

(a)

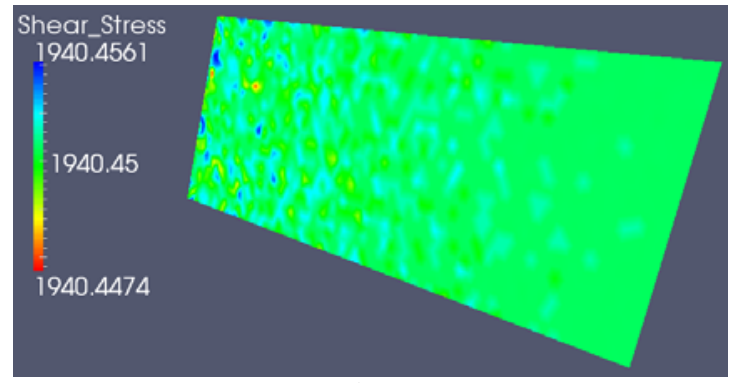

(b)

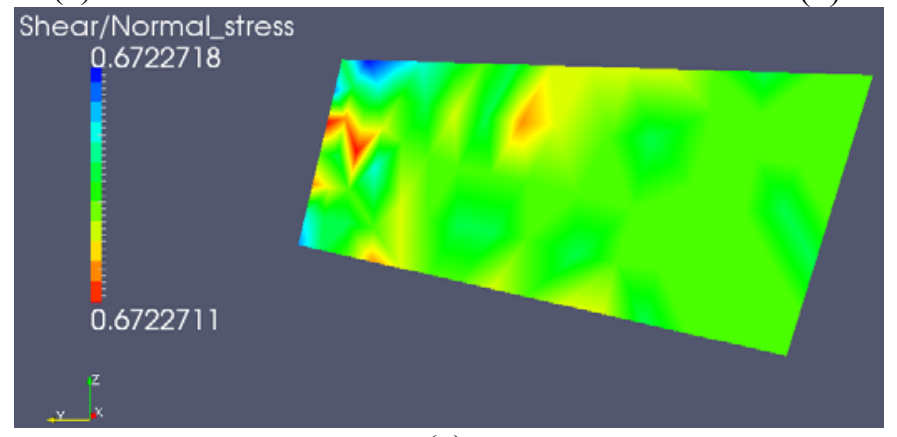

(c)

Figure 3.6 Numerical results for Case No. Two. (a) Effective normal stress distribution on the fault plane, unit: psi. (b) Shear stress distribution on the fault plane, unit: psi. (c) Ratio of shear stress and effective normal stress.

\subsubsection{Case No. 3}

Sneddon and Elliott (1946) (Sneddon \& Elliot, 1946) derived the analytical solutions for the stress distribution in the vicinity of a semi-infinite crack in an elastic medium. They assumed the fracture is rectangular, with limited height and infinite length, in order to simplify the problem. The fracture is open under uniform internal pressure. The final solution for semi-infinite crack given by Sneddon and Elliot (1946) is listed as following: 


$$
\begin{gathered}
\frac{1}{2}\left(\sigma_{\mathrm{y}}+\sigma_{\mathrm{x}}\right)=\mathrm{p}_{0}\left\{\frac{\mathrm{r}}{\sqrt{\mathrm{r}_{1} \mathrm{r}_{2}}} \cos \left(\theta-0.5 \theta_{1}-0.5 \theta_{2}\right)-1\right\} \\
\frac{1}{2}\left(\sigma_{\mathrm{y}}-\sigma_{\mathrm{x}}\right)=\mathrm{p}_{0} \frac{2 \mathrm{r} \sin \theta}{\mathrm{H}}\left(\frac{\mathrm{H}^{2}}{4 \mathrm{r}_{1} \mathrm{r}_{2}}\right)^{\frac{3}{2}} \sin \left(\frac{3}{2}\left(\theta_{1}+\theta_{2}\right)\right) \\
\tau_{\mathrm{xy}}=-\mathrm{p}_{0} \frac{2 \mathrm{r} \sin \theta}{\mathrm{H}}\left(\frac{\mathrm{H}^{2}}{4 \mathrm{r}_{1} \mathrm{r}_{2}}\right)^{\frac{3}{2}} \sin \left(\frac{3}{2}\left(\theta_{1}+\theta_{2}\right)\right) \\
\sigma_{\mathrm{z}}=v\left(\sigma_{\mathrm{y}}+\sigma_{\mathrm{x}}\right)
\end{gathered}
$$

Figure 3.7 illustrates the mathematical interpretation of the crack stress function. The 3D geometric model is given in Figure 3.8. The results of the 3D numerical model were compared to analytical solutions by plotting normalized additional stresses as a function of the ratio of distance $(L)$ to fracture height $(H)$ along the line of symmetry (x-axis in Figure 3.7). The line of symmetry is horizontal and perpendicular to the fracture. As can been see in Figure 3.9, there is an excellent unanimity between the analytical and the numerical solutions.

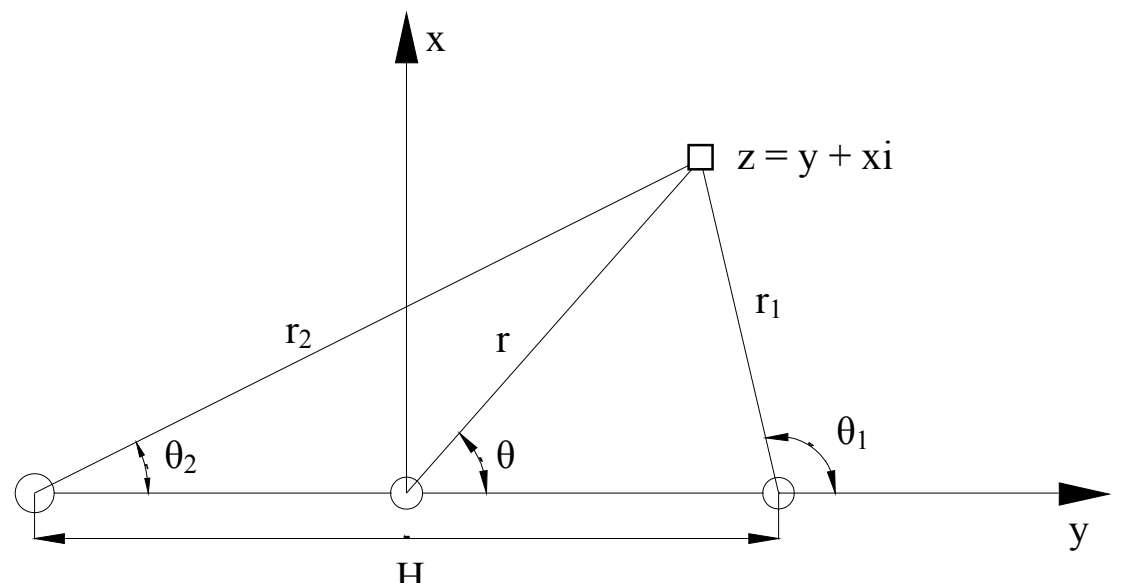

Figure 3.7 Illustration of the mathematical interpretation of the crack stress function. 


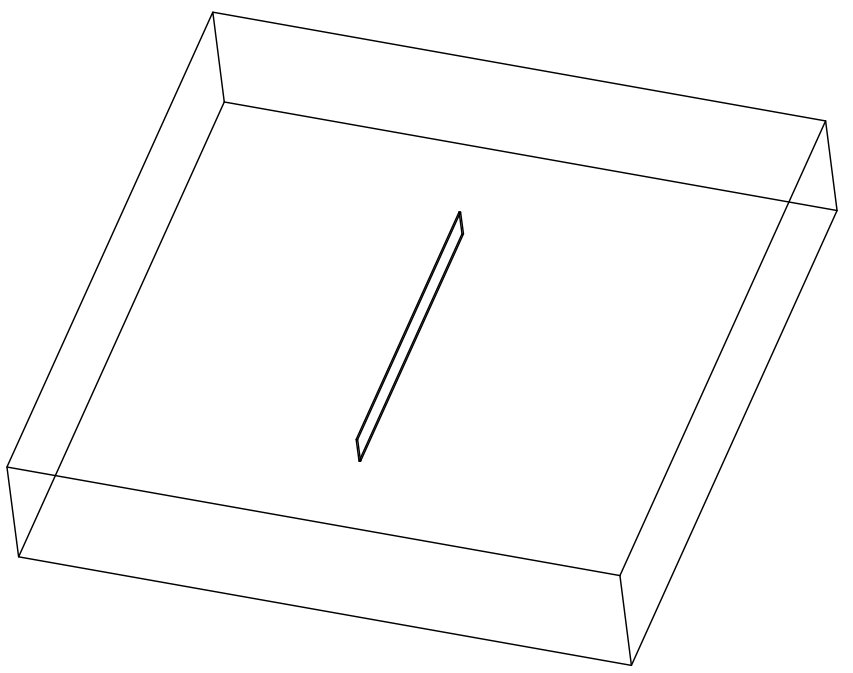

Figure 3.8 3D geometric model.

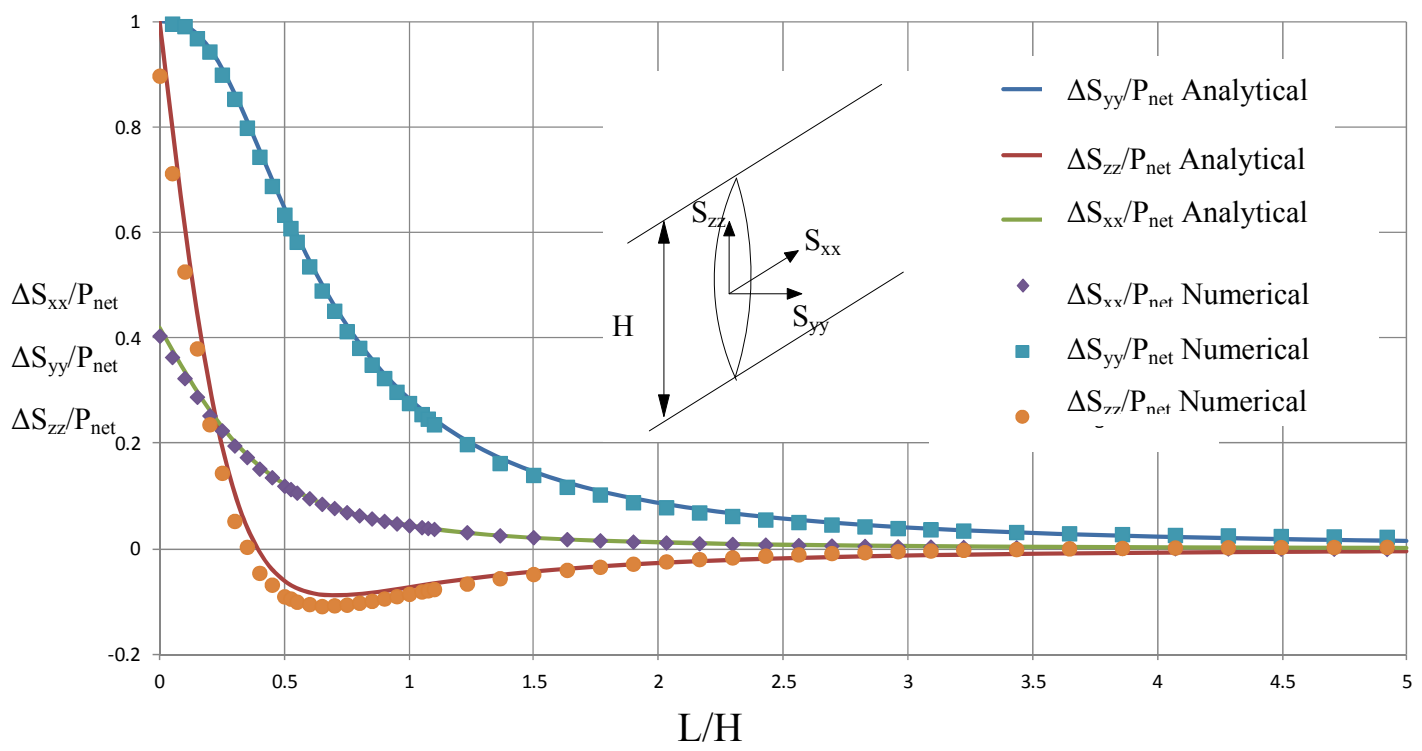

Figure 3.9 Comparisons of analytical and numerical solutions along the symmetric line normal to the semi-infinite fracture. 


\section{Stress Reorientation}

In-situ stress underground can be altered due to the opening of propped hydraulic fractures and poroelastic effects (Olson, 2008; Roussel \& Sharma, 2010; Siebrits et al., 1998; Singh, Roussel, \& Sharma, 2008; Soliman et al., 2004). When the production or injection of fluids is minimal, poroelastic effects can be neglected during hydraulic operations (Cheng, 2009; Roussel \& Sharma, 2010; N. Warpinski \& Wright, 2001). In this study, in-situ stress field alteration induced by the opening of propped fractures is considered. The extent of stress reversal and reorientation has been investigated for two different cases: (a) in-situ stress contrast equals to zero $\left(S_{H \max }-S_{\text {hmin }}=0\right)$, and (b) in-situ stress contrast does not equal to zero $\left(S_{H \max }-S_{h \min } \neq 0\right)$.

The 3D geometric model is illustrated in Figure 3.8. One hydraulic fracture is created at the center of the model. A constant stress, equal to the minimum in-situ horizontal stress $S_{\text {hmin }}$ plus net pressure $p_{\text {net }}$ is imposed on the faces of the fracture.

\subsection{Zero Initial In-situ Stress Contrast}

In-situ stresses are initialized before imposing hydraulic pressure, the values of which are $S_{\text {Hmax }}=S_{\text {hmin }}=4055$ psi, $S_{v}=6373$ psi. After applying hydraulic pressure ( $p_{\text {net }}=1000 \mathrm{psi}$ ), stress trajectory patterns on a horizontal plane through the center point of the model are found, as illustrated in Figure 4.1. The trajectories of minimum horizontal principal stress encircle the hydraulic fracture, converging near the fracture ends. The maximum horizontal principal stress is perpendicular to the fracture face along the fracture wall. 


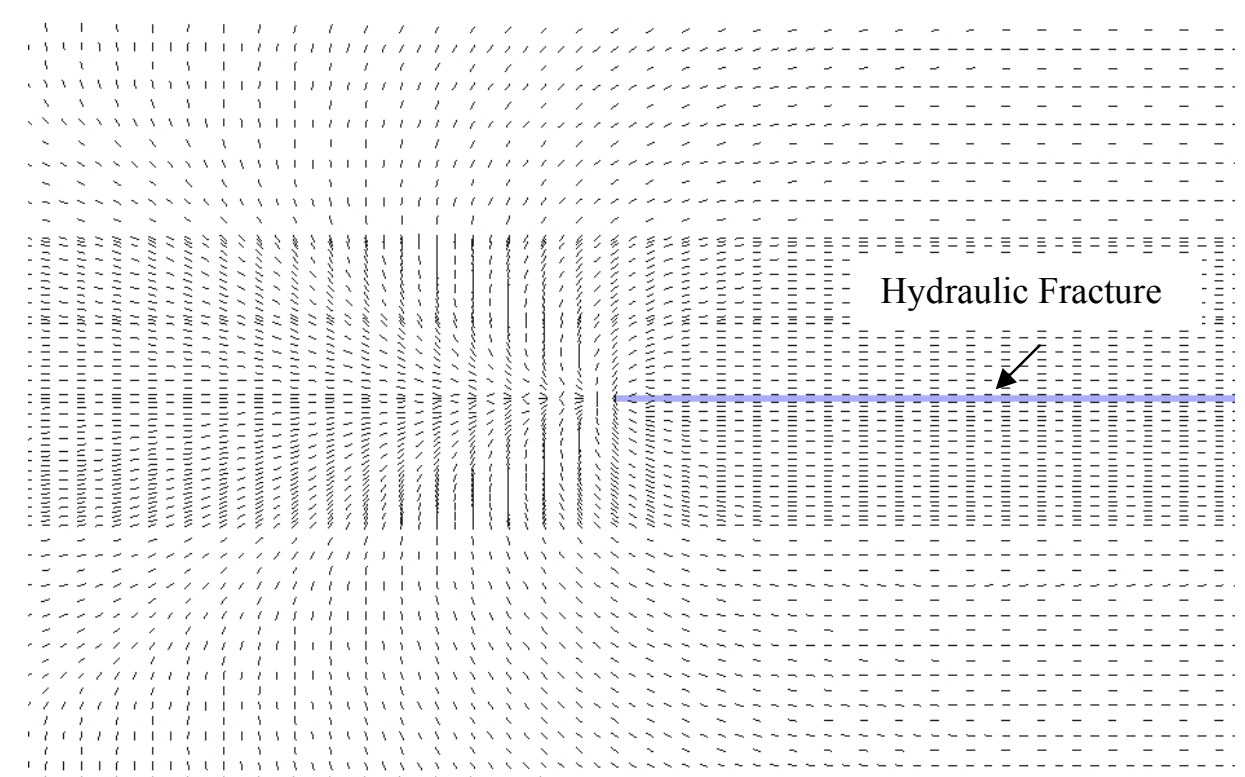

(a)

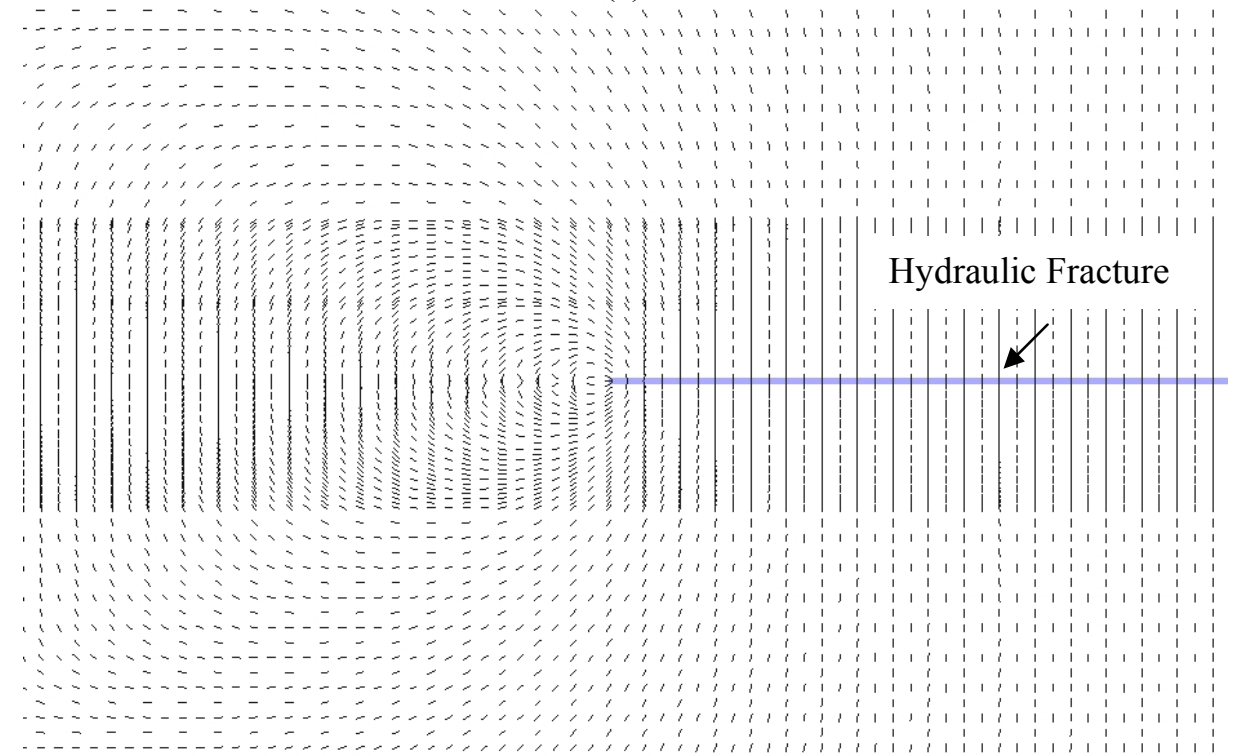

(b)

Figure 4.1 Stress trajectories on a horizontal plane through the center point of the model. (a) Minimum horizontal principal stress trajectories. (b) Maximum horizontal principal stress trajectories.

\subsection{Nonzero Initial In-situ Stress Contrast}

Three different stress contrasts are created when initiating the in-situ stresses before applying hydraulic pressure. They are (1) $S_{H \max }=4555 \mathrm{psi}, S_{\text {hmin }}=4055 \mathrm{psi}, S_{v}=6373 \mathrm{psi}$; (2) $S_{\text {Hmax }}=4655 \mathrm{psi}, S_{\text {hmin }}=4055 \mathrm{psi}, S_{v}=6373 \mathrm{psi}$; and (3) $S_{\text {Hmax }}=4755 \mathrm{psi}, S_{\text {hmin }}=4055$ 
psi, $S_{v}=6373$ psi. After applying hydraulic pressure $\left(p_{n e t}=1000\right.$ psi), the stress trajectories for the three scenarios are presented on a horizontal plane through the center point of the model, they are presented in Figure 4.2, Figure 4.3, and Figure 4.4, respectively. The stress trajectory patterns of the three scenarios are different from that obtained with zero initial in-situ stress contrast.

For the scenario with 500 psi horizontal stress contrast (Figure 4.2), the minimum and maximum horizontal principal stresses are rotated $90^{\circ}$ from their initial in-situ directions in the vicinity of the fracture. The extent of the stress-reversal region is $100 \mathrm{ft}$ in this scenario. Outside the stress-reversal region, there are reoriented-stress regions which are around the fracture tips and confined to the vicinity of the fracture.

When the initial horizontal stress contrast is 600 psi (Figure 4.3), the minimum and maximum horizontal principal stresses are rotated $90^{\circ}$ from their initial in-situ directions in the vicinity of the fracture. The extent of the stress-reversal region is $80 \mathrm{ft}$ in this scenario. There is a very interested phenomenon that is the stress trajectories are oriented as initially on the face of the fracture.

For the scenario with 700 psi horizontal stress contrast (Figure 4.4), there is no stressreversal region in the vicinity of the fracture. The reoriented-stress region is around the fracture tips. 


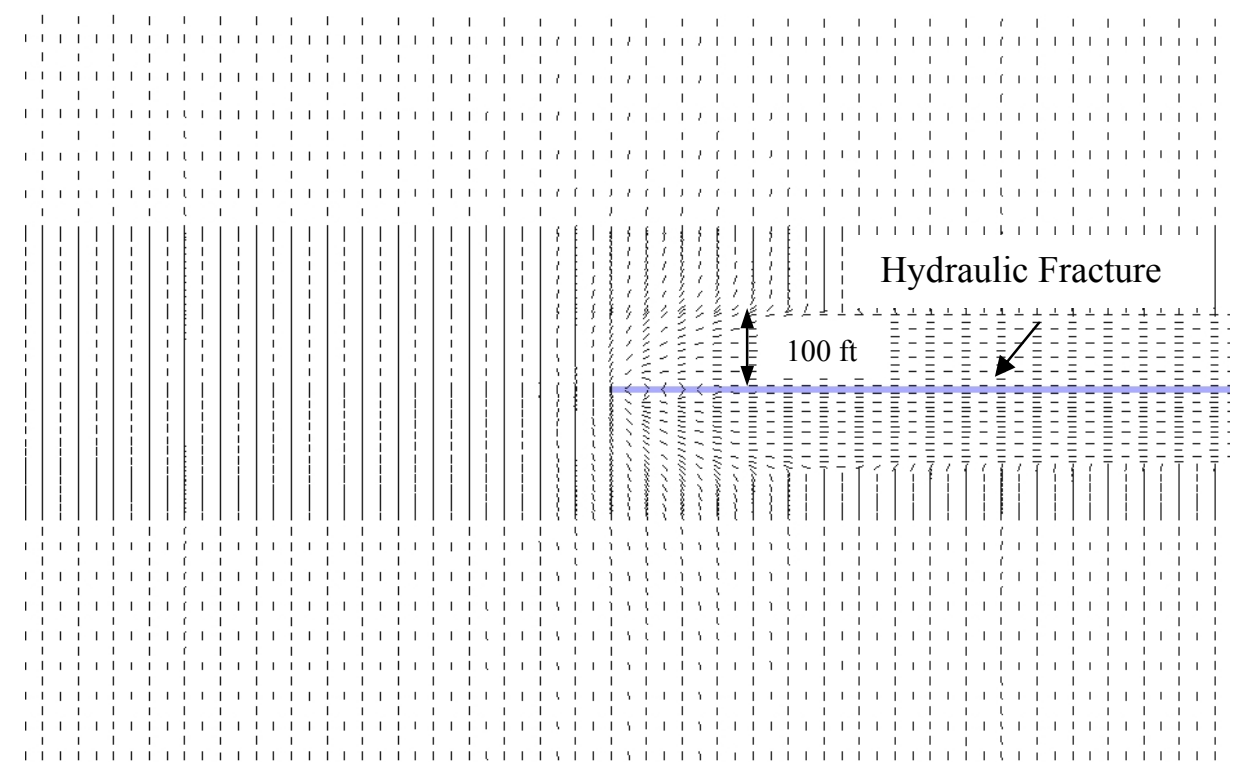

(a)

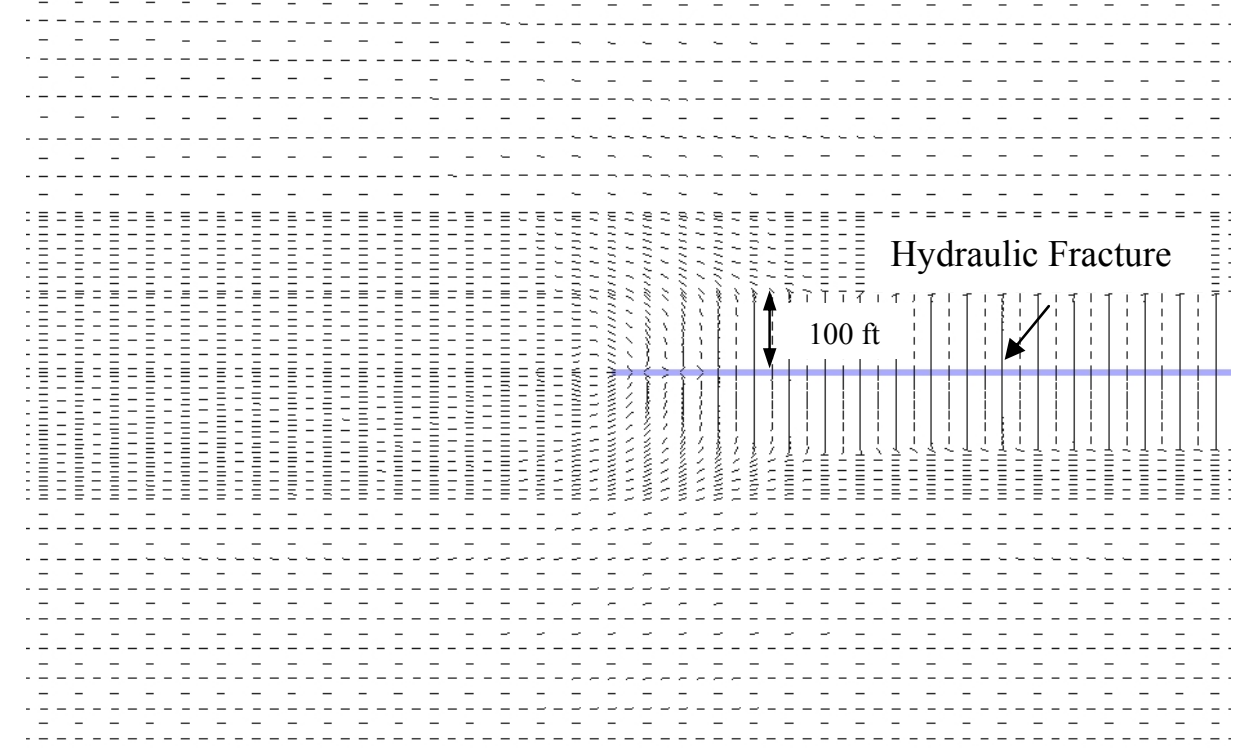

(b)

Figure 4.2 Stress trajectories on a horizontal plane through the center point of the model with 500 psi horizontal stress contrast. (a) Minimum horizontal principal stress trajectories. (b) Maximum horizontal principal stress trajectories. 


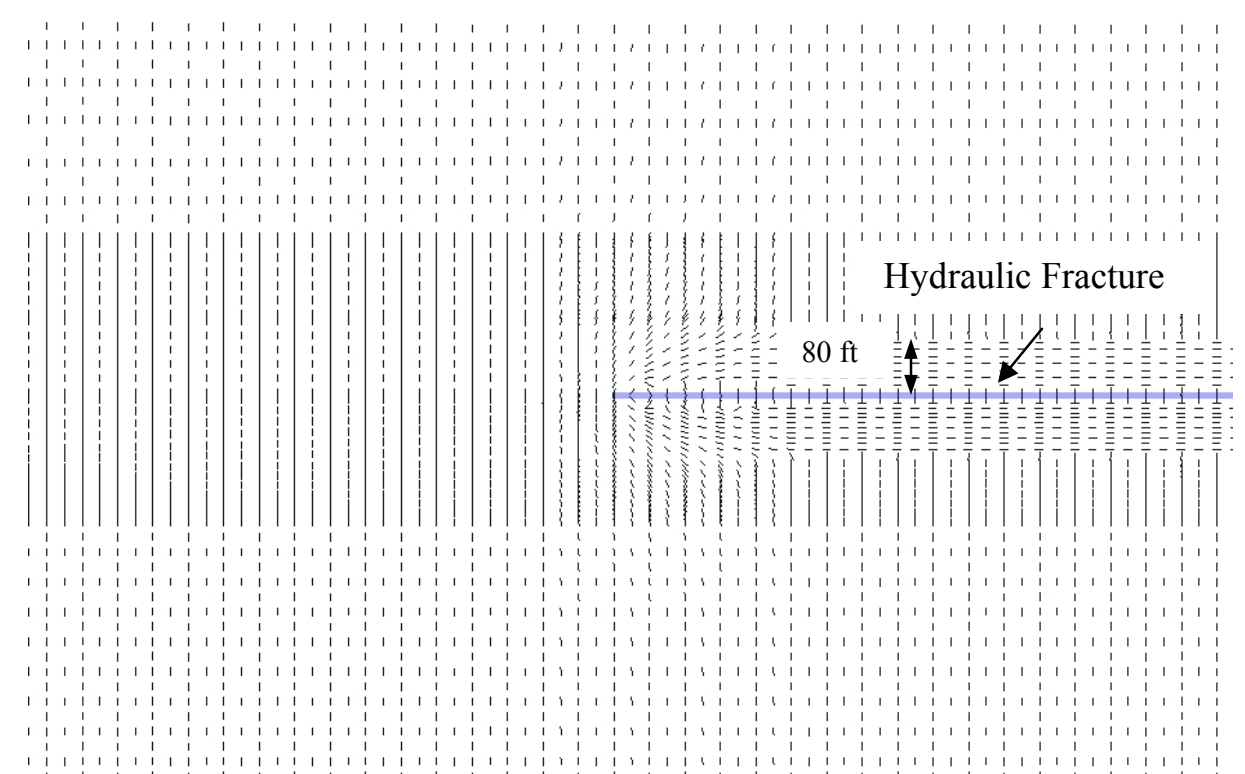

(a)

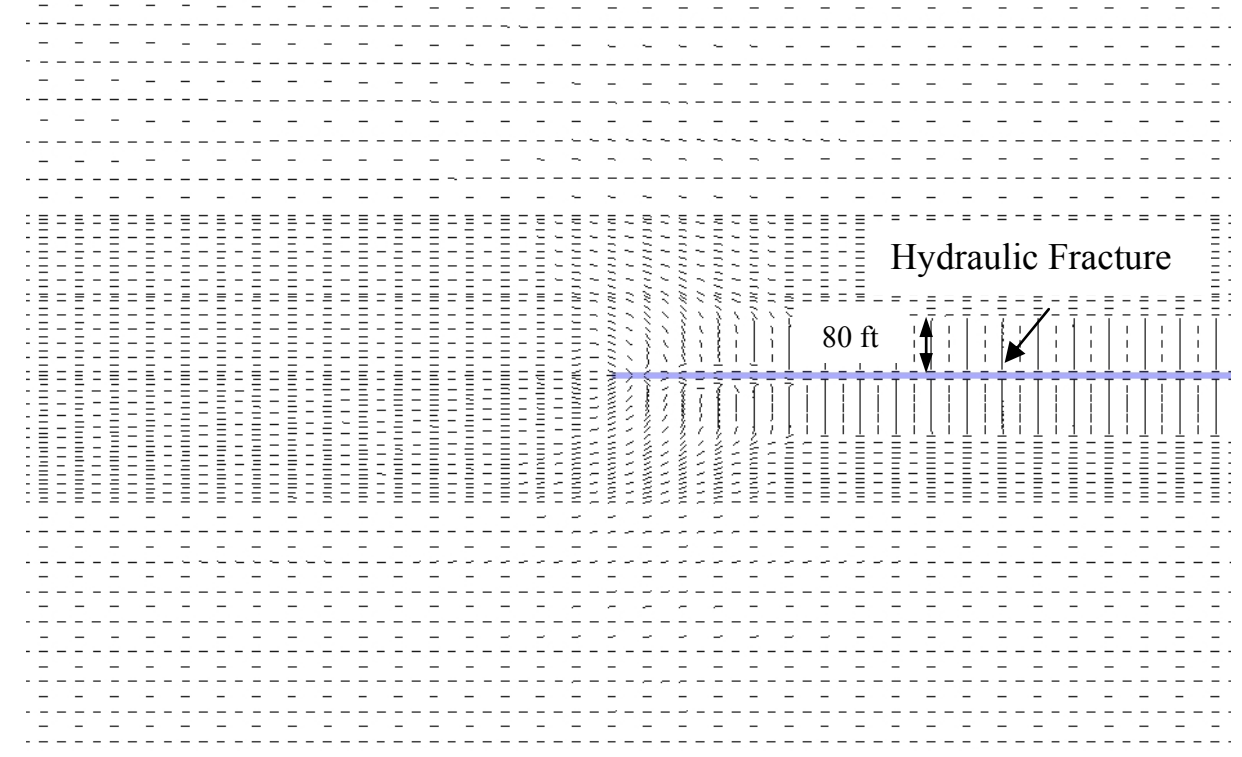

(b)

Figure 4.3 Stress trajectories on a horizontal plane through the center point of the model with 600 psi horizontal stress contrast. (a) Minimum horizontal principal stress trajectories. (b) Maximum horizontal principal stress trajectories. 


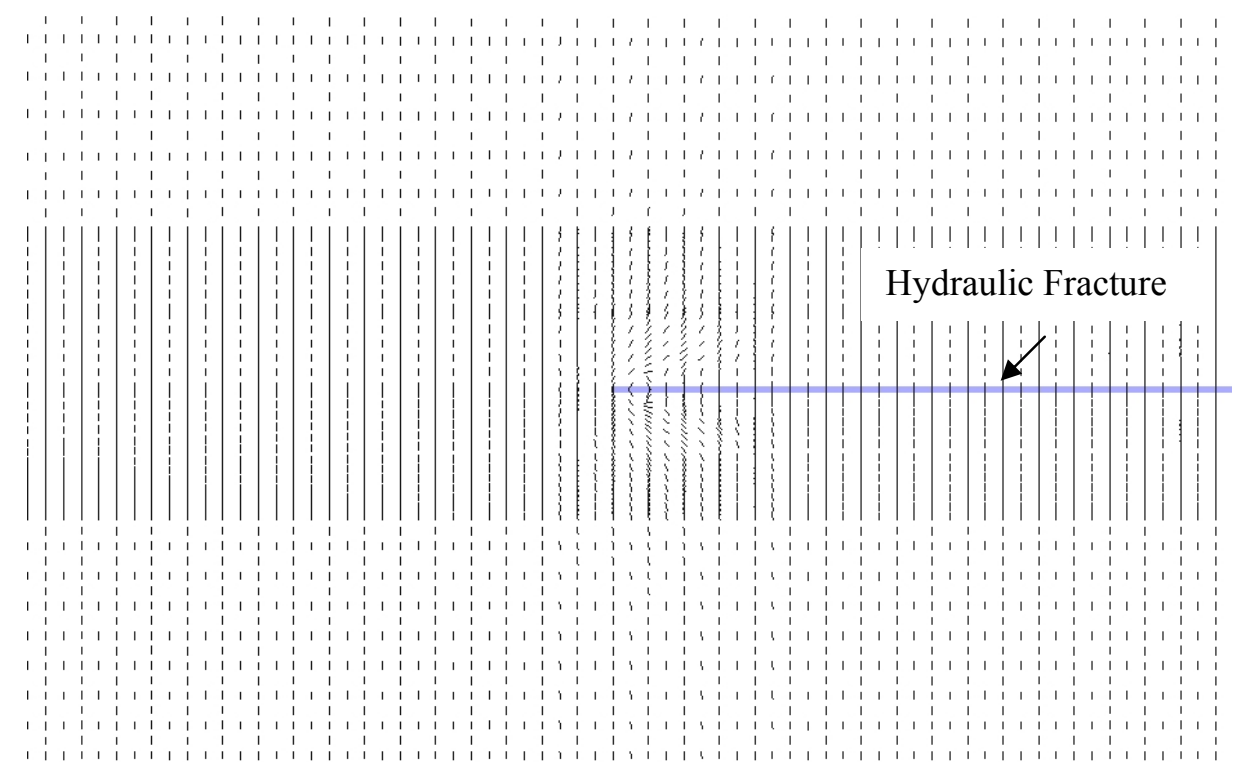

(a)

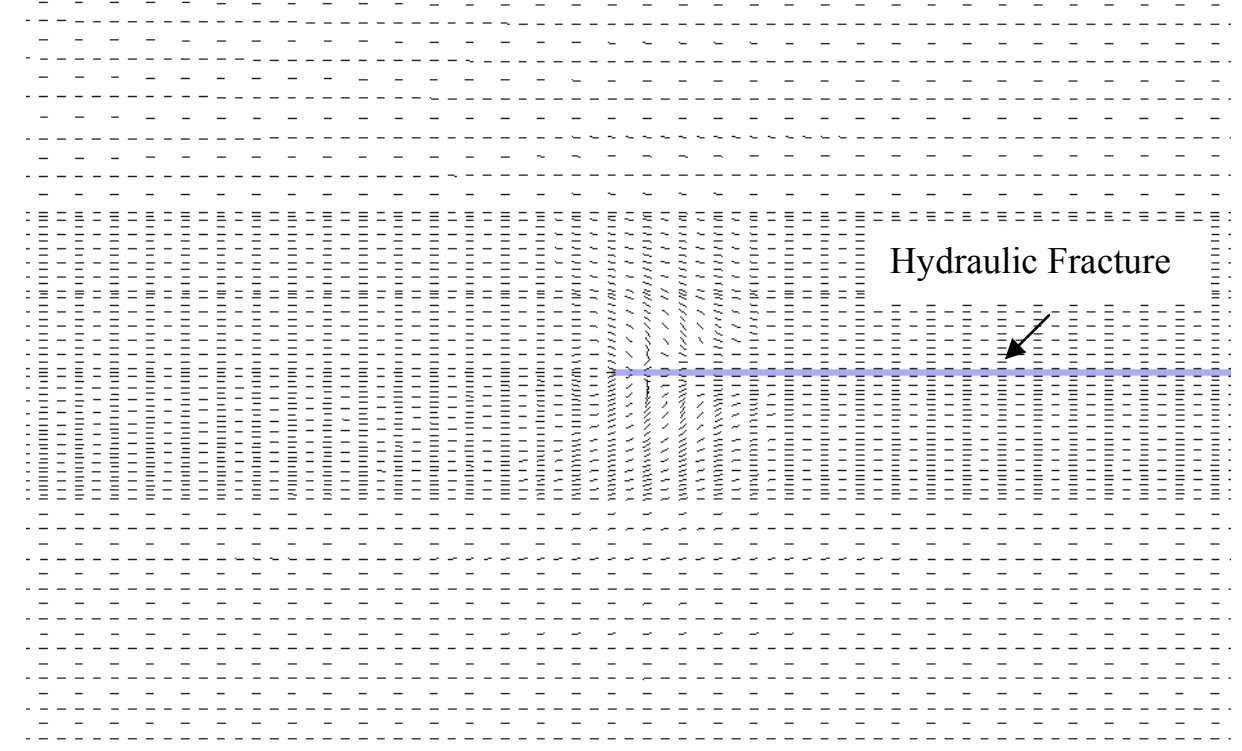

(b)

Figure 4.4 Stress trajectories on a horizontal plane through the center point of the model with 700 psi horizontal stress contrast. (a) Minimum horizontal principal stress trajectories. (b) Maximum horizontal principal stress trajectories. 


\subsection{Discussion}

Based on the 3D numerical model (Figure 3.8), the generated stress contrast $\left(\Delta S_{y y}-\Delta S_{x x}\right)$ normalized by the net pressure ( $p_{n e t}=1000 \mathrm{psi}$ ) is plotted along a symmetric line normal to the fracture face (Figure 4.5). As can been seen, the generated stress contrast $\left(\triangle S_{y y}-\right.$ $\left.\Delta S_{x x}\right)$ is less than 700 psi when the net pressure is 1000 psi. There is no stress-reversal region if the initial in-situ stress contrast $\left(S_{y y}-S_{x x}\right)$ is $700 \mathrm{psi}$ (Figure 4.4).

When the initial in-situ stress contrast is $600 \mathrm{psi}$, the extent of the stress-reversal region is $80 \mathrm{ft}$ (Figure 4.3). The generated stress contrast on the surface of the fracture is $600 \mathrm{psi}$, which is equal to the initial in-situ stress contrast. In this situation, relatively small stress perturbations are sufficient to change the stress trajectories on the fracture surface (Figure 4.3).

When the initial in-situ stress contrast is $500 \mathrm{psi}$, the extent of the stress-reversal region is $100 \mathrm{ft}$ (Figure 4.2). If the initial in-situ stress contrast is zero, the extent of the stressreversal region could be infinite (Figure 4.1). The stress distribution in Figure 4.5 confirms the phenomena shown from Figure 4.1 to Figure 4.4.

Generally, the operation of hydraulic fracturing alters the in-situ stress field. The extent of the stress-reversal region and the reoriented-stress region largely depends on the initial in-situ stress contrast. As revealed in this study, when the horizontal stress contrast is zero, the stress trajectories are totally determined by the created hydraulic fracture. When the horizontal stress contrast is not zero, the generated stress contrast $\left(\Delta S_{y y}-\Delta S_{x x}\right)$, difference between the stress change in the direction perpendicular to and in the direction parallel to the fracture (Figure 3.7), may cause the horizontal stress trajectories to rotate $90^{\circ}$ in the vicinity of the fracture. As the distance from the fracture increases, the generated stress contrast $\left(\Delta S_{y y}-\Delta S_{x x}\right)$ becomes smaller than the initial in-situ stress contrast $\left(S_{y y}-S_{x x}\right)$, the stress trajectories are oriented in initial directions. When the initial in-situ stress contrast $\left(S_{y y}-S_{x x}\right)$ is larger than the generated stress contrast $\left(\Delta S_{y y}-\Delta S_{x x}\right)$, there will be no stressreversal region in the vicinity of the fracture, however, reoriented-stress region still exits around the fracture tips. 
The relationship between the generated stress contrast $\left(\Delta S_{y y}-\Delta S_{x x}\right)$ and the initial in-situ stress contrast $\left(S_{y y}-S_{x x}\right)$ determines the stress redistribution during hydraulic fracture. $\left(\Delta S_{y y}-\Delta S_{x x}\right)$ is a function of net pressure and fracturing spacing, this indicates we can control the extent of stress-reversal region and reoriented-stress region by adjusting net pressure and fracturing spacing.

Further work is needed to investigate the relationships between net pressure, initial stress contrast and the extent of stress-reversal/reoriented-stress region.

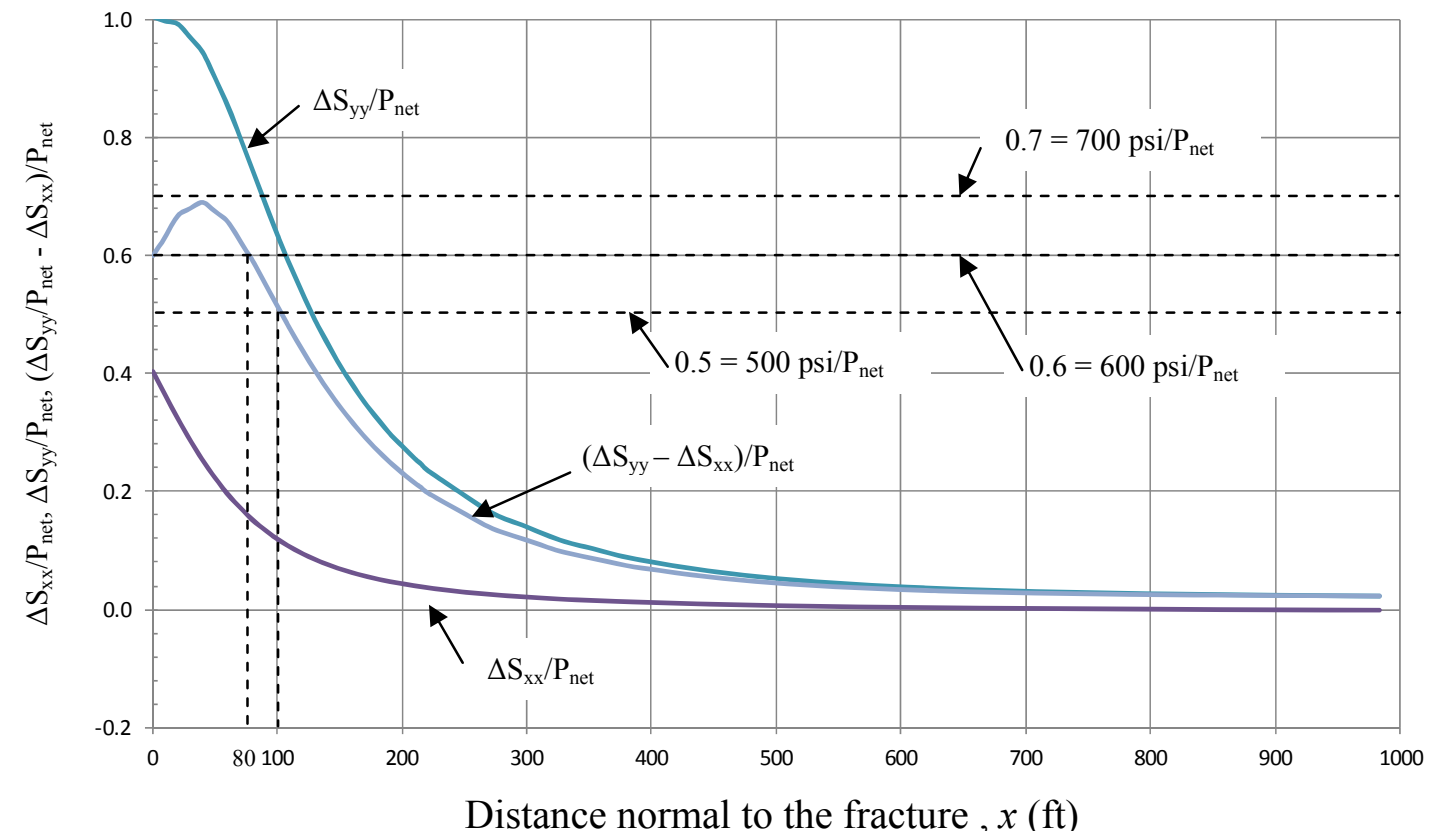

Figure 4.5 Normalized stresses vs. distance normal to a fracture, fracture height used in the numerical model is $200 \mathrm{ft}$. 


\section{Fault Stability Simulation}

In order to evaluate fault stability during hydraulic fracturing, 3D numerical models based on the finite element method were developed to simulate the stress distributions in reservoirs intersected by geological faults during hydraulic fracturing. The potential of reactivation of fault was evaluated based on the changes of stress state around the fault resulting from creation of multiple hydraulic fractures. Three basic types of faults (normal, strike-slip, and reverse/strike-slip) are considered and characterized with their typical corresponding configuration of in-situ stresses. The orientation and relative magnitudes of in-situ stress fields differ under different faulting environments, which in turn control the direction of fracture propagation.

Three hydraulic fractures created simultaneously are considered in all case studies. The closest distance between the hydraulic fracture and a fault is varied for each fault type so that effects of this factor on fault stability can be quantified. The closest distances used are $50 \mathrm{ft}, 100 \mathrm{ft}$ and $150 \mathrm{ft}$.

Poroelastic effects due to the leakoff of the fracturing fluid into reservoirs are neglected in this study because of the ultralow-permeability of shale gas reservoirs. Constant net pressure is assumed along the hydraulic fractures (uniform proppant distribution).

\subsection{Strike-slip Fault}

The case used to simulate strike-slip faulting environment is modified from the famous fluid injection experiment carried out at Rangely, Colorado (Haimson, 1972; C. Raleigh et al., 1976; M. D. Zoback \& Healy, 1984) . Hydrostatic pore pressure is used in the current case, which is different with the one used in validation analysis. The configuration of hydraulic fractures and a strike-slip fault plane is illustrated in Figure 5.1. The three fractures are perpendicular to the direction of horizontal minimum principal stress $\left(S_{h \min }\right)$. 


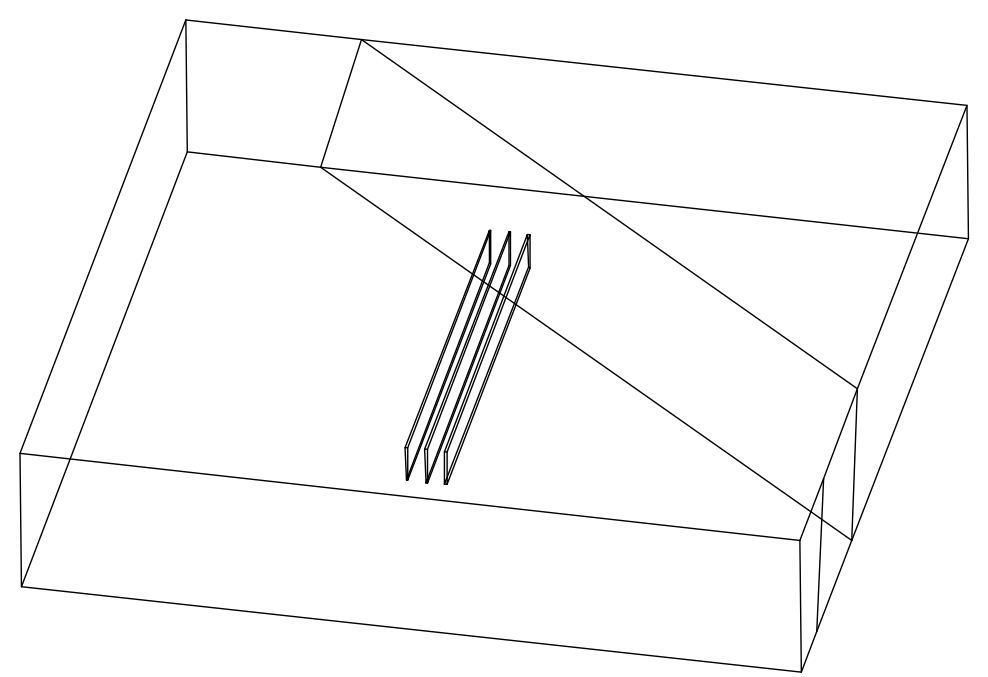

Figure 5.1 3D geometric model for strike-slip faulting environment.

The basic reservoir and fracture properties are listed in the following:

\section{Reservoir Properties}

Geometry

Depth of reservoir top

Young's modulus

Bulk density of reservoir

Reservoir pore pressure

Maximum Horizontal Stress

Minimum Horizontal Stress

Fracture Parameters

$\begin{array}{llll}\text { Geometry (length/height) } & 2000 \times 200 \mathrm{ft}^{2} & \text { Number of fractures } & 3 \\ \text { Fracture spacing } & 100 \mathrm{ft} & \text { Net pressure } & 1000 \mathrm{psi}\end{array}$

$4,000 \times 4,000 \times 800 \mathrm{ft}^{3}$ (length/width/height)

$5794.15 \mathrm{ft} \quad$ Fault dip angle $\quad 80^{\circ}$

$4.02 \times 10^{6} \mathrm{psi} \quad$ Poisson's Ratio 0.209

$156 \mathrm{lb} / \mathrm{ft}^{3} \quad$ Vertical Stress $\quad 6277 \mathrm{psi}$

$0.433 \mathrm{psi} / \mathrm{ft}$

8673 psi (x-direction in the model)

4616 psi (y-direction in the model)

Figure 5.2 and Figure 5.3 illustrate the distribution of shear and normal stresses on the strike-slip fault plane. Before applying hydraulic pressure, the shear stress ranges from 1967 to 1974 psi. It changes when applying hydraulic pressure, it ranges from 1850 to 2000 psi for the scenario with the closest distance of $50 \mathrm{ft}$ between hydraulic fractures and the fault plane. The change behavior on the fault plane is very similar to each other for the three different scenarios. The maximum change on the fault plane occurs at the 
point that has the closest distance from hydraulic fractures. As shown in Figure 5.2, the shear stress increases on one side of the line AB. However, on the opposite side of the line $\mathrm{AB}$, the shear stress decreases. The shear stress has a wider range of stress change than the normal stress.

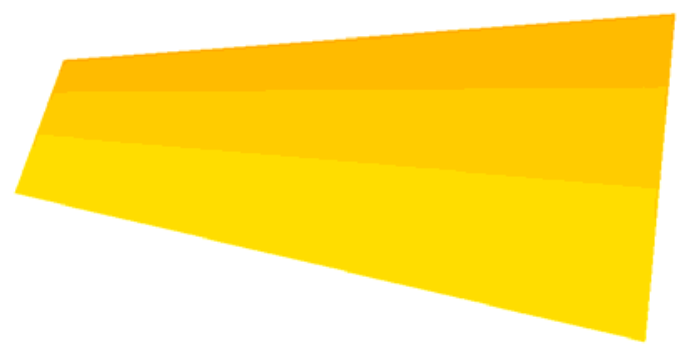

(a)

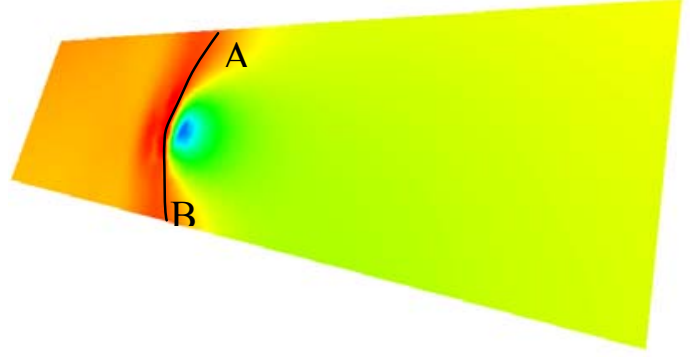

(c)

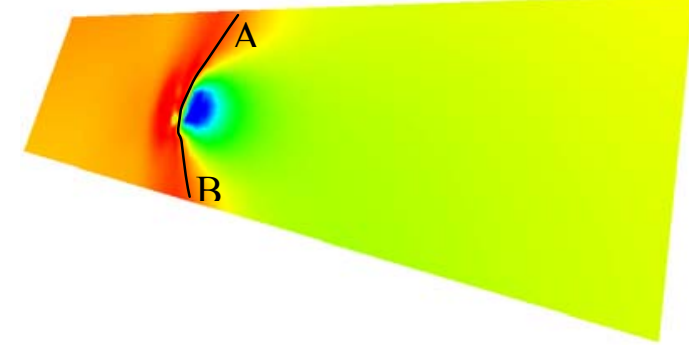

(b)

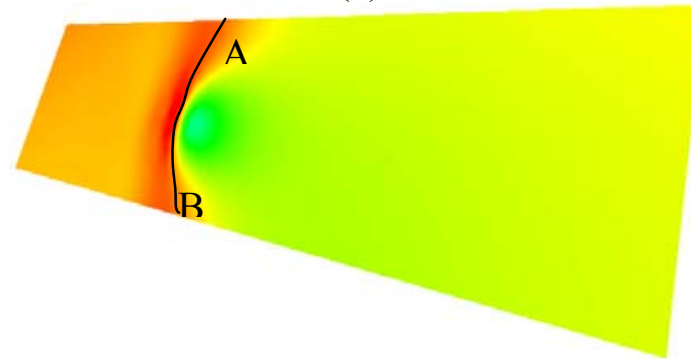

(d)

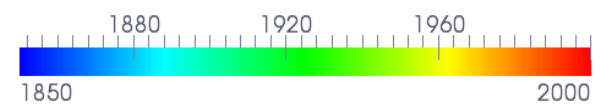

Figure 5.2 Shear stress distribution on the strike-slip fault plane. (a) initial stress state; (b) after applying hydraulic pressure (50 ft); (c) after applying hydraulic pressure (100 ft); (d) after applying hydraulic pressure $(100 \mathrm{ft})$. The number $(50,100,150)$ indicates the closest distance between the hydraulic fractures and the fault plane.

Before applying hydraulic pressure, the normal stress ranges between 6850 and 7100 psi. This range changes when applying hydraulic pressure. The maximum value increases to $7340 \mathrm{psi}$, the minimum value decreases to $6820 \mathrm{psi}$. The normal stress deceases on the left side of the line CD in Figure 5.3, where the shear stress increases in Figure 5.2. On the right side of line $\mathrm{CD}$, the normal stress increases and the shear stress decreases. This pattern is confirmed in Fig. 4.5 by the ratio of shear to normal stress. 


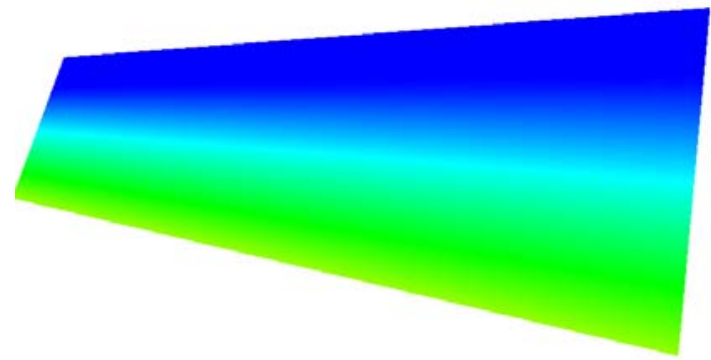

(a)

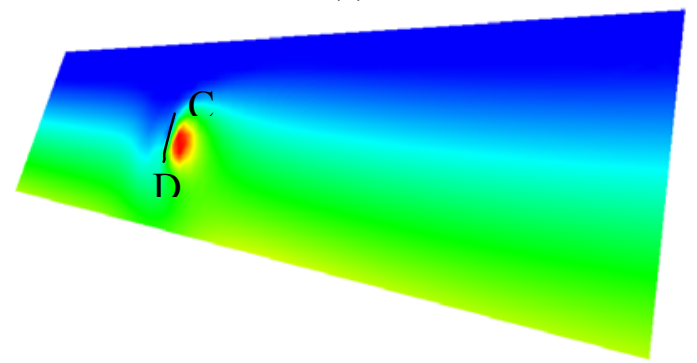

(c)

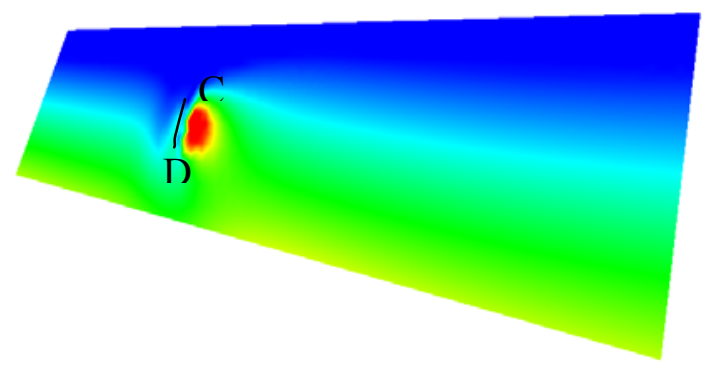

(b)

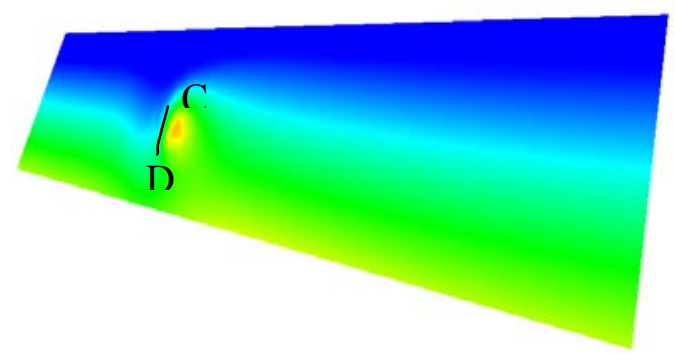

(d)

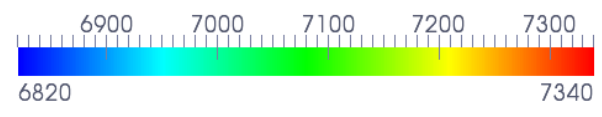

Figure 5.3 Normal stress distribution on the strike-slip fault plane. (a) initial stress state; (b) after applying hydraulic pressure (50 ft); (c) after applying hydraulic pressure (100 ft); (d) after applying hydraulic pressure $(100 \mathrm{ft})$. The number $(50,100,150)$ indicates the closest distance between the hydraulic fractures and the fault plane.

Figure 5.4 gives the ratio of shear to effective normal stress distributed on the strike-slip fault plane. Before applying hydraulic pressure, the ratio ranges between 0.45 and 0.46 . When applying hydraulic pressure, the ratio on the left side of the line EF increases (Figure 5.4), which means fault plane tends to become unstable; on the contrary, the ratio on the right side of the line EF decreases, which indicates the fault plane becomes more stable. 
(a)

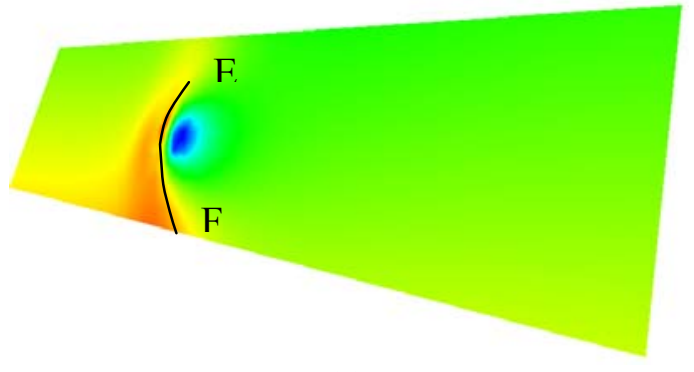

(c)

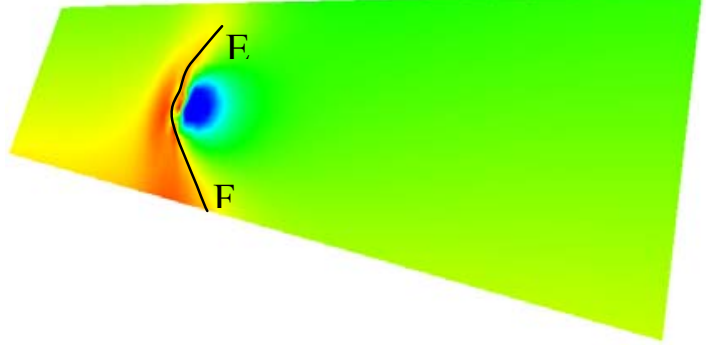

(b)

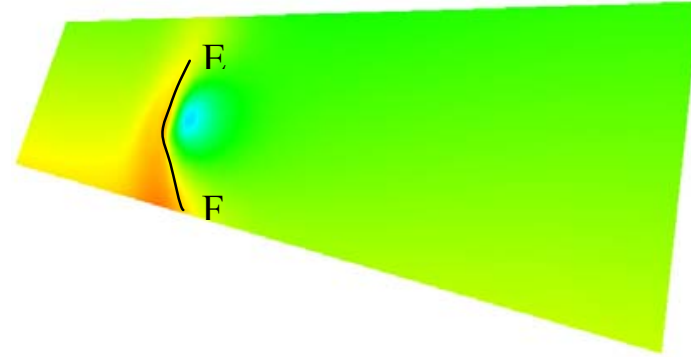

(d)

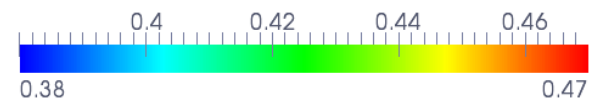

Figure 5.4 Ratio of shear to effective normal stress distributed on the strike-slip fault plane. (a) initial state; (b) after applying hydraulic pressure (50 ft); (c) after applying hydraulic pressure (100 ft); (d) after applying hydraulic pressure (100 ft). The number $(50,100,150)$ indicates the closest distance between the hydraulic fractures and the fault plane.

\subsection{Normal Fault}

Stress regime for normal faulting environment is assumed based on the Anderson's theory. Figure 5.5 shows the geometric model. The basic reservoir and fracture properties are listed in the following:

\section{Reservoir properties}

Geometry

Depth of reservoir top

Young's modulus

Bulk density of reservoir

Reservoir pore pressure

Maximum Horizontal Stress

Minimum Horizontal Stress
$4,000 \times 4,000 \times 800 \mathrm{ft}^{3}$ (length/width/height)

$$
5794.15 \mathrm{ft}
$$

$4.02 \times 10^{6} \mathrm{psi}$ Fault dip angle $60^{\circ}$

$156 \mathrm{lb} / \mathrm{ft}^{3}$

Poisson's Ratio

$0.433 \mathrm{psi} / \mathrm{ft}$

$0.8 \mathrm{psi} / \mathrm{ft}$

$0.7 \mathrm{psi} / \mathrm{ft}$ 


\section{Fracture Parameters}

$\begin{array}{llll}\text { Geometry (length/height) } & 2000 \times 200 \mathrm{ft}^{2} & \text { Number of fractures } & 3 \\ \text { Fracture spacing } & 100 \mathrm{ft} & \text { Net pressure } & 1000 \mathrm{psi}\end{array}$

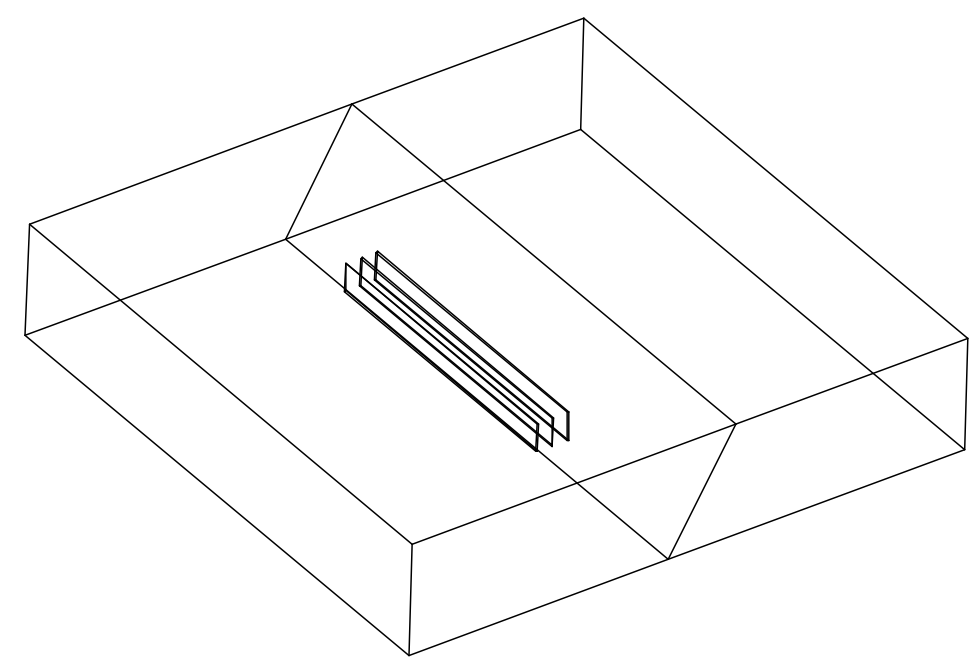

Figure 5.5 3D geometric model for normal faulting environment.

The distribution of shear and normal stresses on fault plane is shown in Figure 5.6 and Figure 5.7, respectively. The shear stress ranges from 860 to 1140 psi before applying hydraulic pressure. After applying hydraulic pressure, the shear stress decreases by a maximum value of $195 \mathrm{psi}$ above the line $\mathrm{AB}$ as shown in Figure 5.6. Points on the line $\mathrm{AB}$ have the closest distance from hydraulic fractures to the fault plane. On the contrary, the region below the line $\mathrm{AB}$ has increased shear stress by a maximum value of $260 \mathrm{psi}$.

Before applying hydraulic pressure, the original normal stress on the normal fault plane ranges from 4430 to 4830 psi. The normal stress increases in the region around the line $\mathrm{AB}$ after applying hydraulic pressure. The maximum increased magnitude is $470 \mathrm{psi}$ for the scenario with the closest distance between the hydraulic fractures and the fault plane being $50 \mathrm{ft}$. There is no region with decreased normal stress in the normal faulting environment. 


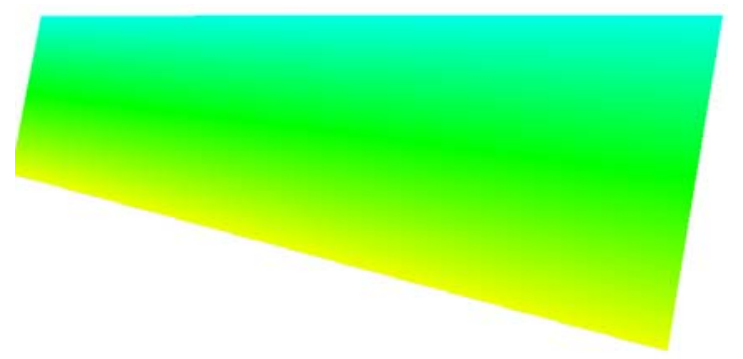

(a)

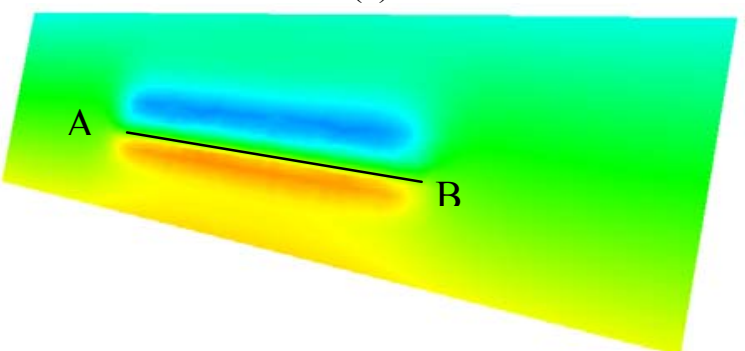

(c)

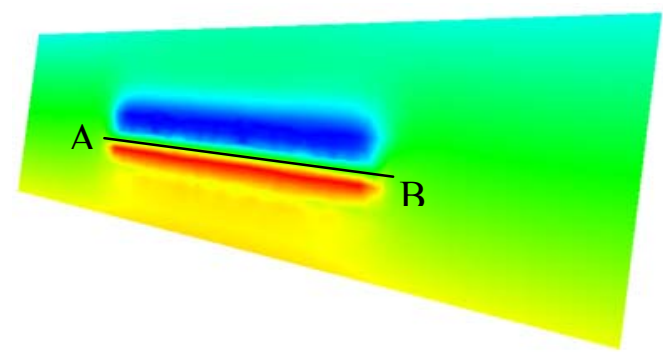

(b)

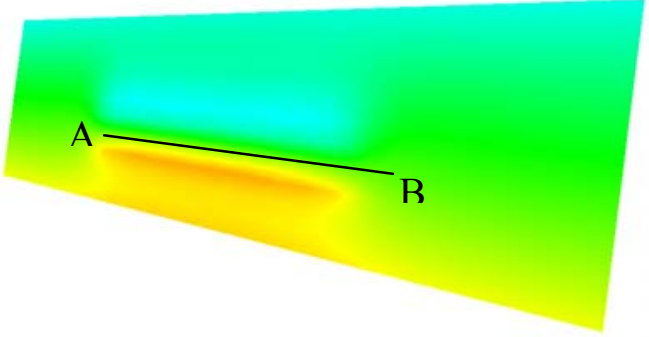

(d)

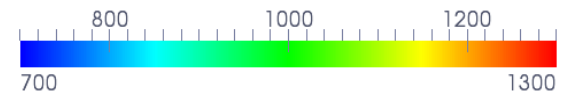

Figure 5.6 Shear stress distribution on the normal fault plane. (a) initial stress state; (b) after applying hydraulic pressure (50 ft); (c) after applying hydraulic pressure (100 ft); (d) after applying hydraulic pressure $(100 \mathrm{ft})$. The number $(50,100,150)$ indicates the closest distance between the hydraulic fractures and the fault plane.

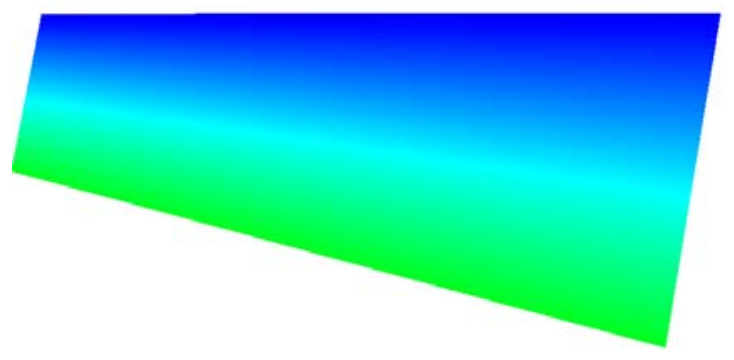

(a)

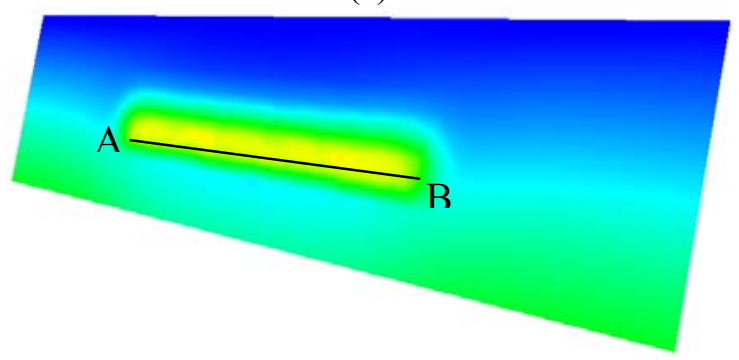

(c)

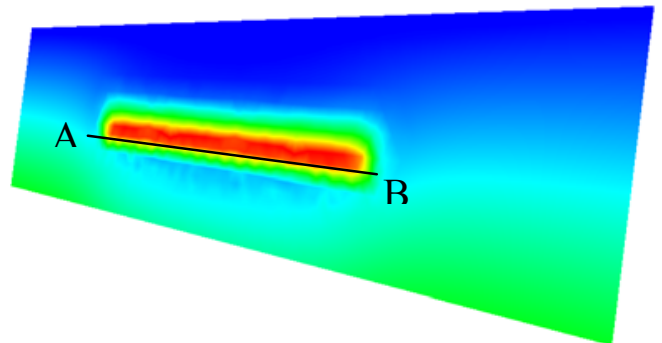

(b)

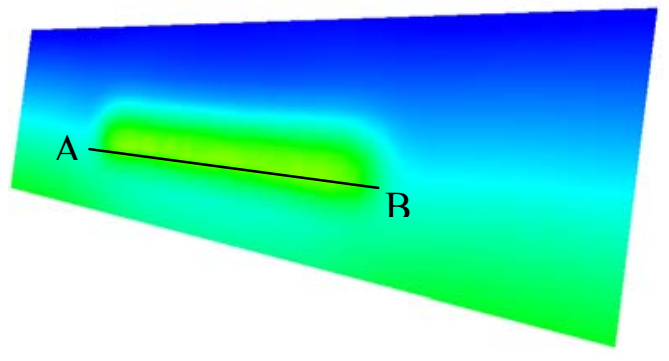

(d)

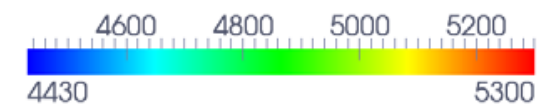

Figure 5.7 Normal stress distribution on the normal fault plane. (a) initial stress state; (b) after applying hydraulic pressure (50 ft); (c) after applying hydraulic pressure (100 ft); (d) after applying hydraulic pressure $(100 \mathrm{ft})$. The number $(50,100,150)$ indicates the closest distance between the hydraulic fractures and the fault plane. 
The ratio of shear to effective normal stress distributed on the normal fault plane is illustrated in Figure 5.8. It ranges from 0.41 to 0.53 before applying hydraulic pressure. The ratio decreases with a maximum value of 0.14 above the line $\mathrm{AB}$ after applying hydraulic pressure. Below the line $\mathrm{AB}$, the ratio increases with a maximum value of 0.08 . Changes of the ratio conform to the alteration of shear and normal stresses.

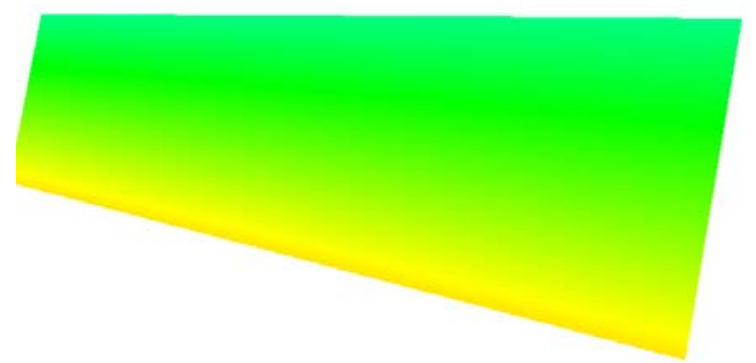

(a)

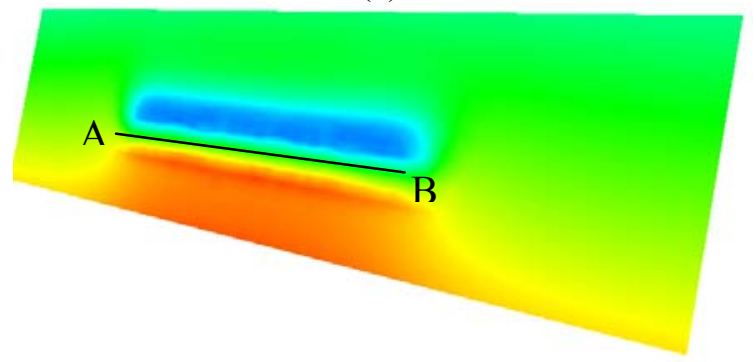

(c)

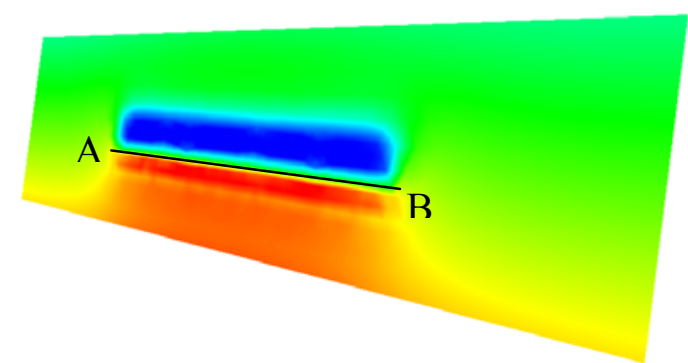

(b)

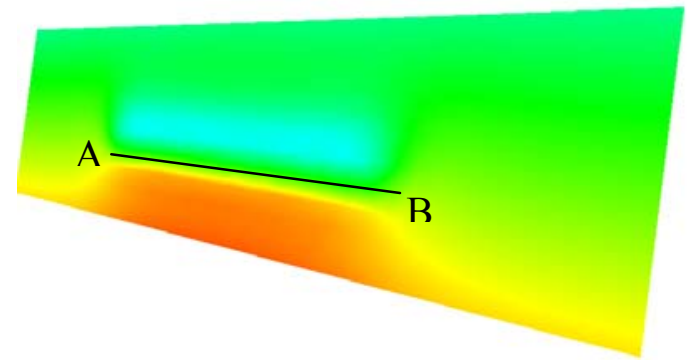

(d)

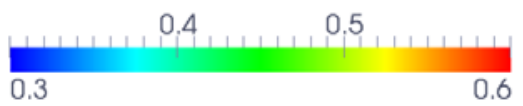

Figure 5.8 Ratio of shear to effective normal stress distributed on the normal fault plane. (a) initial state; (b) after applying hydraulic pressure (50 ft); (c) after applying hydraulic pressure $(100 \mathrm{ft})$; (d) after applying hydraulic pressure $(100 \mathrm{ft})$. The number $(50,100,150)$ indicates the closest distance between the hydraulic fractures and the fault plane.

\subsection{Reverse/strike-slip Fault}

A fault which has a component of dip-slip and a component of strike-slip is termed an oblique-slip fault. Reverse/strike-slip fault means the hanging wall moves in both upward and horizontal directions.

The geometric model for reverse/strike-slip fault is shown in Figure 5.9. Based on the Anderson's theory, stress regime for reverse/strike-slip fault is assumed. The basic reservoir and fracture properties are listed in the following: 


\section{Reservoir properties}

Geometry

$4,000 \times 4,000 \times 800 \mathrm{ft}^{3}$ (length/width/height)

Depth of reservoir top $5794.15 \mathrm{ft}$

Fault dip angle $30^{\circ}$

Young's modulus

$4.02 \times 10^{6} \mathrm{psi}$

Poisson's Ratio

0.209

Bulk density of reservoir

$156 \mathrm{lb} / \mathrm{ft}^{3}$

Vertical Stress

$1.05 \mathrm{psi} / \mathrm{ft}$

Reservoir pore pressure

$0.433 \mathrm{psi} / \mathrm{ft}$

Maximum Horizontal Stress $1.25 \mathrm{psi} / \mathrm{ft}$

Minimum Horizontal Stress 0.98 psi/ft

\section{Fracture Parameters}

Geometry (length/height) $2000 \times 200 \mathrm{ft}^{2}$ Number of fractures 3

Fracture spacing $100 \mathrm{ft}$

Net pressure 1000 psi

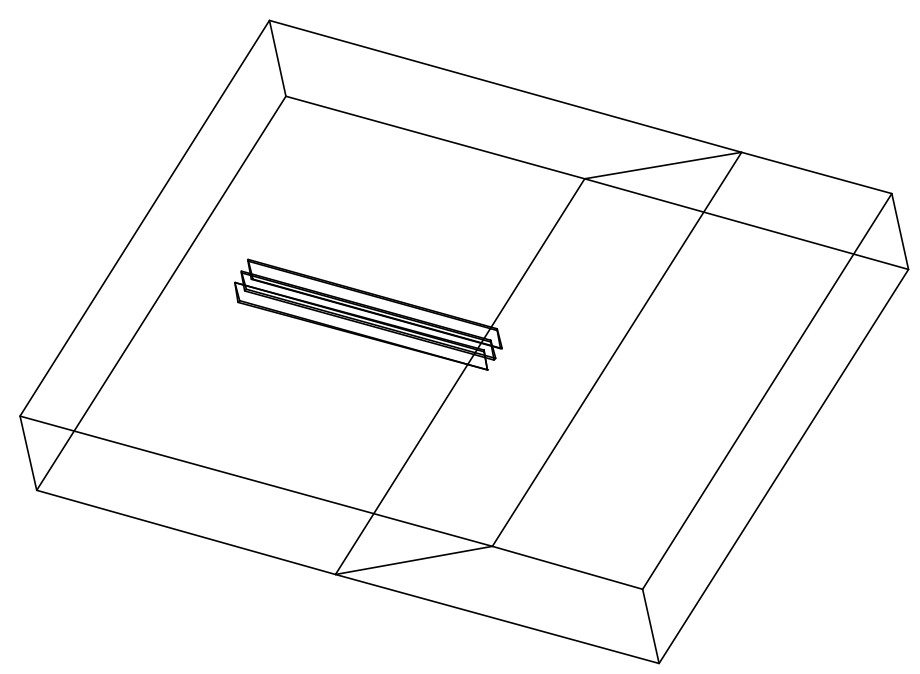

Figure 5.9 3D geometric model for reverse/strike-slip faulting environment.

Figure 5.10 illustrates the shear stress distribution on the reverse/strike-slip fault plane. The shear stress ranges from 363 to 640 psi before applying hydraulic pressure. After applying hydraulic pressure, the shear stress ranges from 342 to 640 psi, the lower bound of it decreases by a value of 21 psi. 


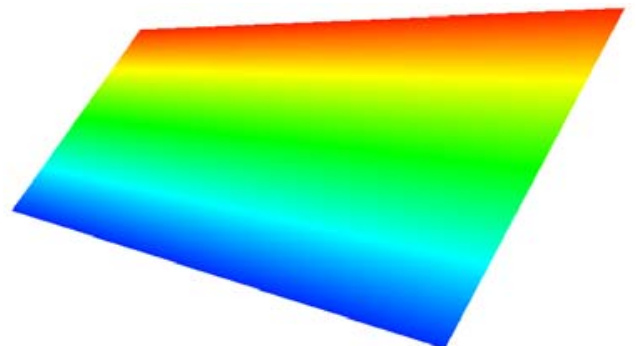

(a)

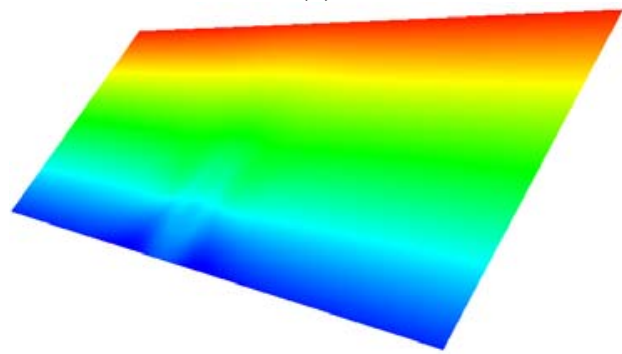

(c)

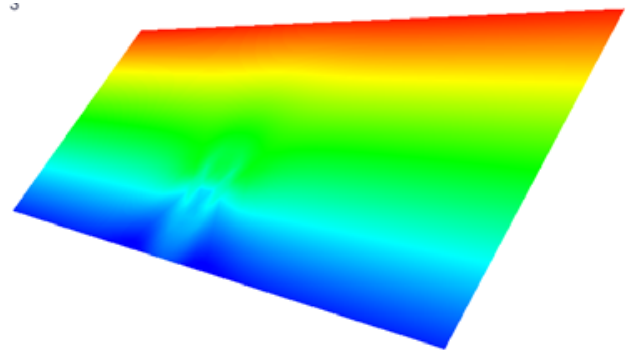

(b)

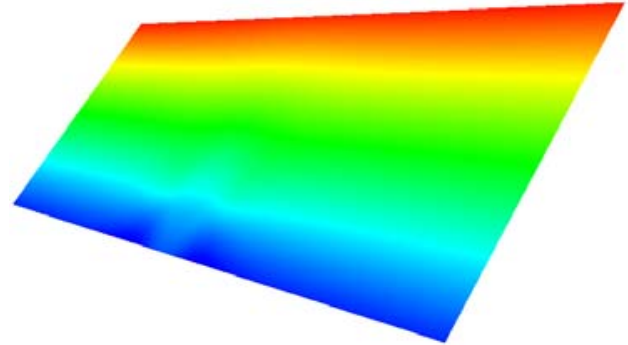

(d)

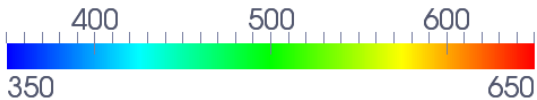

650

Figure 5.10 Shear stress distribution on the reverse/strike-slip fault plane. (a) initial stress state; (b) after applying hydraulic pressure (50 ft); (c) after applying hydraulic pressure (100 ft); (d) after applying hydraulic pressure $(100 \mathrm{ft})$. The number $(50,100,150)$ indicates the closest distance between the hydraulic fractures and the fault plane.

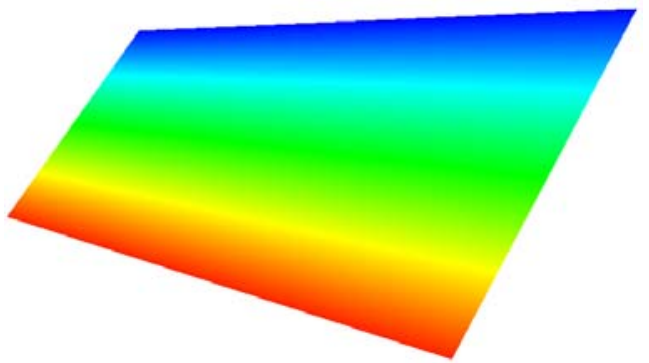

(a)

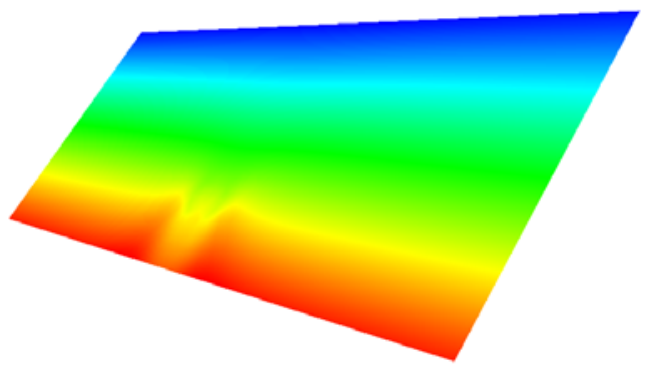

(c)

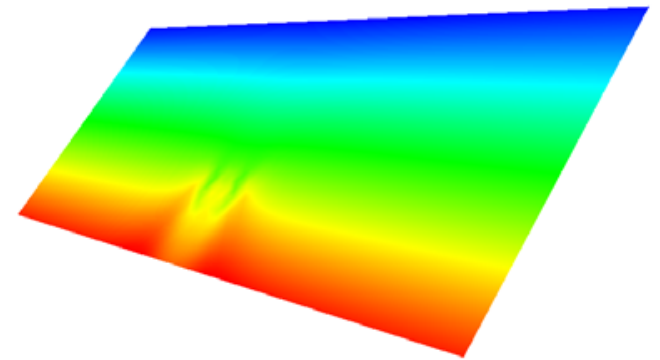

(b)

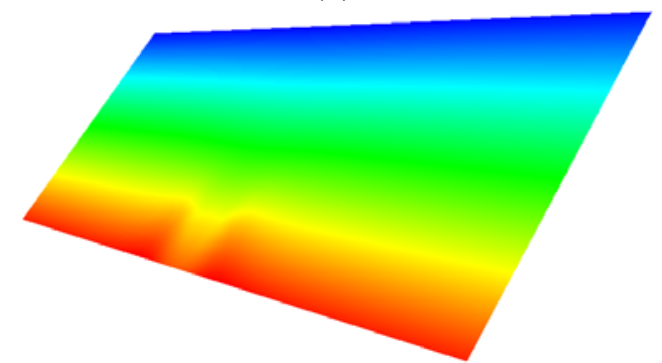

(d)

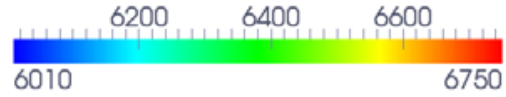

Figure 5.11 Normal stress distribution on the reverse/strike-slip fault plane. (a) initial stress state; (b) after applying hydraulic pressure (50 ft); (c) after applying hydraulic pressure (100 ft); (d) after applying hydraulic pressure $(100 \mathrm{ft})$. The number $(50,100,150)$ indicates the closest distance between the hydraulic fractures and the fault plane. 
The normal stress distribution on the reverse/strike-slip fault plane is shown in Figure 5.11. Before applying hydraulic pressure, the normal stress ranges from 6016 to 6723 psi. It ranges from 6015 to 6756 psi after applying hydraulic pressure. It should be noticed that though the range of stress does not alter a lot, the stress distribution on the fault plane has been changed. The normal stress on the fault plane decreases at the region where the closest distance between hydraulic fracture and the fault plane exists.

The ratio of shear to effective normal stress distributed on the reverse/strike-slip fault plane is presented in Figure 5.12. It ranges from 0.09 to 0.17 before applying hydraulic pressure. After applying hydraulic pressure, the range does not change, however, the ratio at the area A (Figure 5.12) on the fault plane increases, which means it tend to become unstable.

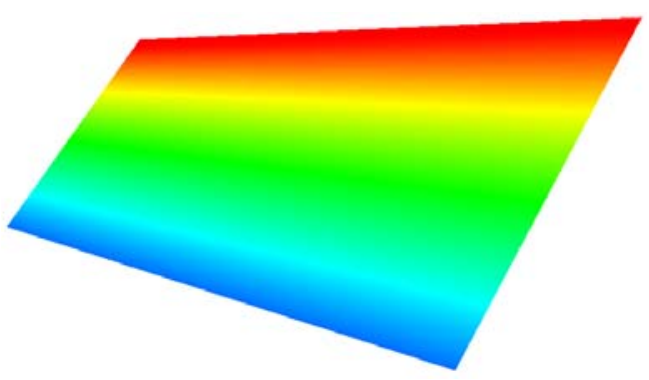

(a)

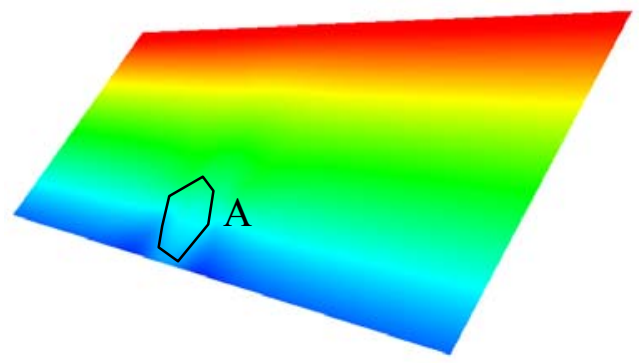

(c)

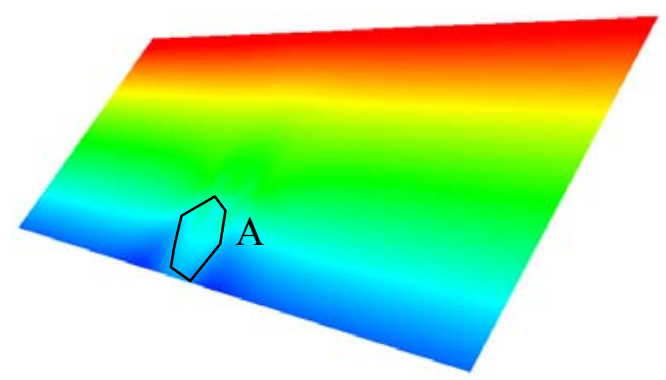

(b)

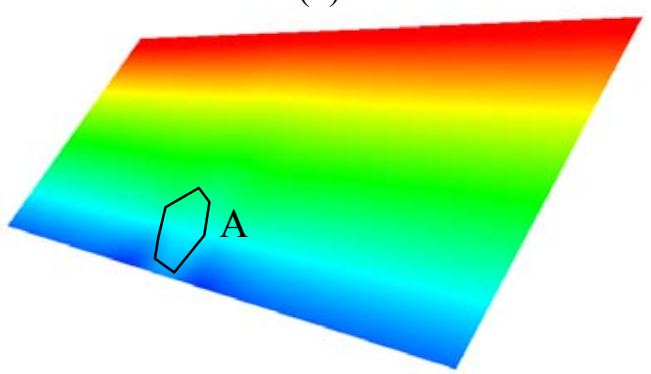

(d)

$$
\begin{array}{lllll} 
& 0.1 & 0.12 & 0.14 & 0.16 \\
\hline 0.08 & & 0.16
\end{array}
$$

Figure 5.12 Ratio of shear to effective normal stress distributed on the reverse/strike-slip fault plane. (a) initial state; (b) after applying hydraulic pressure (50 ft); (c) after applying hydraulic pressure $(100 \mathrm{ft})$; (d) after applying hydraulic pressure $(100 \mathrm{ft})$. The number $(50$, $100,150)$ indicates the closest distance between the hydraulic fractures and the fault plane. 


\subsection{Discussion}

Due to the alteration of stress field caused by hydraulic fracturing, faults nearby the treatment wells have potential to be reactivated. Numerical results indicate that the distance between the fracture and the fault plane has influence on the change of stress magnitude distributed on the fault plane, but it does not change the patterns of stress distribution. Comparing the three types of fault environment, it is indicated that the patterns of stress distribution on the fault planes are different, which depend on the angle between fracture orientation and fault strike.

Table 5.1 summarized the shear and normal stress changes, also the alterations of the ratio of shear to effective normal stress are included. As can be seen, the normal faulting environment has the largest fluctuation in stresses and the ratio of shear to effective normal stress. The reverse/strike-slip fault has the least perturbation when hydraulic pressure is applied.

In-situ stresses control the propagative direction of the created fractures and thus determine the angle between fracture orientation and fault strike. Numerical simulations demonstrate that the angle has a strong influence on the stability of a fault based on the change in the ratio of shear to effective normal stresses. When the created fractures parallel to the normal fault plane (Figure 5.5), the fault plane has the largest extent of stress change range compared to other types of faulting environment. In the reversal/strike-slip faulting environment (Figure 5.9), the hydraulic fracture is perpendicular to the fault plane, the creation of the fracture has the least influence on the fault stability. However, there is a great possibility that the fracture propagating perpendicularly to the fault plane may extent to the fault, which may cause early aborting/failure of fracturing treatment, fluid leakage along the fault.

Table 5.1 Summary of stress and ratio changes for different fault types. (Positive represents increased value, negative represents decreased value.)

\begin{tabular}{c|c|c|c|c|c|c}
\hline \multirow{2}{*}{ Fault Type } & \multicolumn{2}{|c|}{ Shear Stress (psi) } & Normal Stress (psi) & \multicolumn{2}{c}{ Ratio } \\
\cline { 2 - 7 } & $\begin{array}{c}\text { Upper } \\
\text { Bound }\end{array}$ & $\begin{array}{c}\text { Lower } \\
\text { Bound }\end{array}$ & $\begin{array}{c}\text { Upper } \\
\text { Bound }\end{array}$ & $\begin{array}{c}\text { Lower } \\
\text { Bound }\end{array}$ & $\begin{array}{c}\text { Upper } \\
\text { Bound }\end{array}$ & $\begin{array}{c}\text { Lower } \\
\text { Bound }\end{array}$ \\
\hline Strike-slip & +26 & -117 & +240 & -30 & +0.02 & -0.07 \\
\hline Normal & +260 & -195 & +470 & 0 & +0.08 & -0.14 \\
\hline Reverse/strike-slip & 0 & -21 & +33 & -1 & 0 & 0 \\
\hline
\end{tabular}




\section{Conclusions}

This study investigates the stress distribution underground during hydraulic stimulation and the effect of stress change on fault stability is also analyzed. 3D numerical models based on the finite element method are developed and validated. An excellent agreement between analytical and numerical solutions has been obtained, which demonstrates the suitability of using the numerical models to simulate complex situations.

The opening of propped hydraulic fractures generally alters in-situ stresses. Larger additional stresses perpendicular to the fracture wall can be generated compared to the additional stresses parallel to the fracture wall. It is found that the initial in-situ stress contrast has a strong influence on the extent of stress-reversal region and reoriented-stress region. If the generated stress contrast is larger than the initial in-situ stress contrast in horizontal plane, the directions of horizontal principal stresses will be reversed. When the generated stress contrast is less than the initial in-situ stress contrast in horizontal plane, the directions of horizontal principal stresses are oriented as initially except the region around fracture tips, which generally have stress-reoriented region due to stress concentration. Usually the stress-reversal region is in the vicinity of fractures, the reoriented-stress region is beyond the stress reversal region and around fracture tips.

Three typical faulting environments were considered in this study. They are normal, strike-slip, and strike-slip/reverse faults. The orientation and relative magnitudes of insitu stress fields differ under different faulting environments, which in turn control the direction of fracture propagation. Three hydraulic fractures created simultaneously are considered in all case studies.

It was found that the angle between fracture orientation and fault strike has a strong effect on the stability of a fault based on the change in the ratio of shear to effective normal stresses. Along the fault plane, the stability is strengthened in certain regions but weakened in other regions. The stress alteration patterns are different on the three types of fault. The normal faulting environment has the largest fluctuation in stresses and in the ratio of shear to effective normal stress. The reverse/strike-slip fault has the least perturbation when hydraulic pressure is applied. 


\section{References}

Atsushi, Y. (2007). An introduction to tectonophysics. Tokyo: TERRAPUB.

Axelsson, O. (1972). A generalized SSOR method. BIT Numerical Mathematics, 12(4), 443-467.

Barrett, R., Berry, M., Chan, T. F., Demmel, J., Donato, J., Dongarra, J., et al. (1987). Templates for the solution of linear systems: Building blocks for iterative methods Society for Industrial Mathematics.

Bretan, P., Yielding, G., Mathiassen, O. M., \& Thorsnes, T. (2011). Fault-seal analysis for $\mathrm{CO} 2$ storage: An example from the troll area, norwegian continental shelf. Petroleum Geoscience, 17(2), 181.

Byerlee, J. (1978). Friction of rocks. Pure and Applied Geophysics, 116(4), 615-626.

Chen, R. S., \& Yung, E. K. N. (2001). SSOR preconditioned conjugate gradient method for solution of large sparse linear equations from vector FEM. Paper presented at the Antennas and Propagation Society International Symposium, 2001. IEEE, , 3. pp. 188-191 vol.3.

Cheng, Y. (2009). Boundary element analysis of the stress distribution around multiple fractures: Implications for the spacing of perforation clusters of hydraulically fractured horizontal wells. Paper presented at the SPE Eastern Regional Meeting,

Chiaramonte, L., Zoback, M. D., Friedmann, J., \& Stamp, V. (2008). Seal integrity and feasibility of $\mathrm{CO} 2$ sequestration in the teapot dome EOR pilot: Geomechanical site characterization. Environmental Geology, 54(8), 1667-1675.

Dhondt, G. D. C. (2004). The finite element method for three-dimensional thermomechanical applications Wiley Online Library.

Downie, R., Kronenberger, E., \& Maxwell, S. (2010). Using microseismic source parameters to evaluate the influence of faults on fracture treatments: A geophysical approach to interpretation. Paper presented at the SPE Annual Technical Conference and Exhibition,

Economides, M. J., Nolte, K. G., \& Ahmed, U. (1989). Reservoir stimulation Prentice Hall.

Gudehus, G. (1978). Finite elements in geomechanics. Soil Science, 125(6), 394. 
Haimson, B. C. (1972). Earthquake related stresses at rangely, colorado. Paper presented at the The 14th US Symposium on Rock Mechanics (USRMS),

Hinton, E., \& Owen, D. R. J. (1977). Finite element programming Academic Press London.

Hughes, T. J. R. (2000). The finite element method: Linear static and dynamic finite element analysis Dover Publications.

Ikari, M. J., Marone, C., \& Saffer, D. M. (2011). On the relation between fault strength and frictional stability. Geology, 39(1), 83.

Jaeger, J. C., Cook, N. G. W., \& Zimmerman, R. (2007). Fundamentals of rock mechanics (4th ed.) Wiley-Blackwell.

Lewis, R. W., \& Schrefler, B. A. (1987). The finite element method in the deformation and consolidation of porous media.

Majer, E. L., Baria, R., Stark, M., Oates, S., Bommer, J., Smith, B., et al. (2007). Induced seismicity associated with enhanced geothermal systems. Geothermics, 36(3), 185222.

McClure, M. W., \& Horne, R. N. (2011). Investigation of injection-induced seismicity using a coupled fluid flow and rate/state friction model.

Morrow, C., Shi, L., \& Byerlee, J. (1982). Strain hardening and strength of clay-rich fault gouges. Journal of Geophysical Research, 87(B8), 6771-6780.

Olson, J. E. (2008). Multi-fracture propagation modeling: Applications to hydraulic fracturing in shales and tight gas sands. Paper presented at the The 42nd US Rock Mechanics Symposium (USRMS),

Palmer, I. (1993). Induced stresses due to propped hydraulic fracture in coalbed methane wells. Paper presented at the Low Permeability Reservoirs Symposium,

Plumb, R. (1994). Variations of the least horizontal stress magnitude in sedimentary rocks. Rock Mechanics Models and Measurements: Challenges from Industry: Rotterdam, Balkema, , 71-78.

Raleigh, C. B., Healy, J. H., \& Bredehoeft, J. D. (1976). An experiment in earthquake control at rangely, colorado. Science, 191(4233), 1230.

Raleigh, C., Healy, J., \& Bredehoeft, J. (1972). Faulting and crustal stress at rangely, colorado. Flow and Fracture of Rocks, Geophys.Monogr.Ser, 16, 275-284. 
Raleigh, C., Healy, J., \& Bredehoeft, J. (1976). An experiment in earthquake control at rangely, colorado. Work (Fig.I b), 108(52), 30.

Roussel, N., \& Sharma, M. (2010). Optimizing fracture spacing and sequencing in horizontal well fracturing. Paper presented at the SPE International Symposium and Exhibiton on Formation Damage Control,

Rutqvist, J., Birkholzer, J., Cappa, F., \& Tsang, C. F. (2007). Estimating maximum sustainable injection pressure during geological sequestration of $\mathrm{CO}<\operatorname{sub}>2</$ sub $>$ using coupled fluid flow and geomechanical fault-slip analysis. Energy Conversion and Management, 48(6), 1798-1807.

Scholz, C. H. (2002). The mechanics of earthquakes and faulting Cambridge university press.

Segall, P. (1989). Earthquakes triggered by fluid extraction. Geology, 17(10), 942-946.

Segall, P. (1992). Induced stresses due to fluid extraction from axisymmetric reservoirs. Pure and Applied Geophysics, 139(3), 535-560.

Sibson, R. H. (1974a). Frictional constraints on thrust, wrench and normal faults.

Siebrits, E., Elbel, J., Detournay, E., Detournay-Piette, C., Christianson, M., Robinson, B., et al. (1998). Parameters affecting azimuth and length of a secondary fracture during a refracture treatment. Paper presented at the SPE Annual Technical Conference and Exhibition,

Singh, V., Roussel, N., \& Sharma, M. (2008). Stress reorientation around horizontal wells. Paper presented at the Paper SPE 116092 Presented at the 2008 SPE Annual Technical Conference and Exhibition, Denver, Colorado, pp. 21-24.

Smith, I. M., \& Griffiths, D. V. (1998). Programming the finite element method John Wiley \& Sons, Inc.

Sneddon, I., \& Elliot, H. (1946). The opening of a griffith crack under internal pressure. Quart.Appl.Math, 4(3), 262-267.

Soliman, M., East, L., \& Adams, D. (2004). Geomechanics aspects of multiple fracturing of horizontal and vertical wells. Paper presented at the SPE International Thermal Operations and Heavy Oil Symposium and Western Regional Meeting,

Sone, H., \& Zoback, M. (2010). Strength, creep and frictional properties of gas shale reservoir rocks. Paper presented at the 44th US Rock Mechanics Symposium and 5th US-Canada Rock Mechanics Symposium, 
Streit, J. E., \& Hillis, R. R. (2004). Estimating fault stability and sustainable fluid pressures for underground storage of $\mathrm{CO}<\mathrm{sub}>2</ \mathrm{sub}>$ in porous rock. Energy, 29(9), 1445-1456.

Sutton, R., Cox, S., \& Barree, R. (2010). Shale gas plays: A performance perspective. Paper presented at the Tight Gas Completions Conference,

Talwani, P. (1997). On the nature of reservoir-induced seismicity. Pure and Applied Geophysics, 150(3-4), 473-492.

Townend, J., \& Zoback, M. D. (2000). How faulting keeps the crust strong. Geology, 28(5), 399-402.

Van der Pluijm, B. A., \& Marshak, S. (2004). Earth structure: An introduction to structural geology and tectonics New York: WW Norton; 2nd ed.

Warpinski, N., \& Branagan, P. (1989). Altered-stress fracturing. Journal of Petroleum Technology, 41(9), 990-997.

Warpinski, N., Du, J., \& Zimmer, U. (2012). Measurements of hydraulic-fractureinduced seismicity in gas shales. Paper presented at the SPE Hydraulic Fracturing Technology Conference,

Warpinski, N., \& Wright, C. (2001). Analysis and prediction of microseismicity induced by hydraulic fracturing. Paper presented at the SPE Annual Technical Conference and Exhibition,

Yerkes, R. F., \& Castle, R. O. (1976). Seismicity and faulting attributable to fluid extraction. Engineering Geology, 10(2), 151-167.

Zienkiewicz, O. C., Taylor, R. L., \& Zhu, J. Z. (2005). The finite element method: Its basis and fundamentals Butterworth-Heinemann.

Zoback, M. D. (2010). Reservoir geomechanics Cambridge University Press.

Zoback, M. D., \& Healy, J. H. (1984). Friction, faulting and < in situ > stress.2(6), 689698.

Zoback, M. D., \& Zinke, J. C. (2002). Production-induced normal faulting in the valhall and ekofisk oil fields. Pure and Applied Geophysics, 159(1), 403-420.

Zoback, M. L., \& Zoback, M. D. (1980). Faulting patterns in north-central nevada and strength of the crust. 
Zoback, M. D., Kohli, A., Das, I., \& Mcclure, M. (2012). The importance of slow slip on faults during hydraulic fracturing stimulation of shale gas reservoirs. Paper presented at the SPE Americas Unconventional Resources Conference, 